\author{
Universidade de São Paulo \\ Instituto de Psicologia \\ Departamento de Psicologia Experimental
}

RODOLFO SANTOS FLABOREA

AVALIAÇÃO NEUROPSICOLÓGICA DA TOMADA DE DECISÃO NO COMPROMETIMENTO COGNITIVO LEVE

São Paulo

2015 
RODOLFO SANTOS FLABOREA

\section{AVALIAÇÃO NEUROPSICOLÓGICA DA TOMADA DE DECISÃO NO COMPROMETIMENTO COGNITIVO LEVE}

Dissertação apresentada ao Instituto de Psicologia da Universidade de São Paulo, como parte dos requisitos para obtenção do grau de Mestre em Psicologia.

Área de Concentração: Psicologia Experimental Orientador: Prof. Dr. Marcelo Fernandes da Costa

São Paulo

2015 
Autorizo a reprodução e divulgação total e parcial deste trabalho, por qualquer meio convencional ou eletrônico, para fins de estudo e pesquisa, desde que citada a fonte.

\author{
Catalogação na publicação \\ Serviço de Biblioteca e Documentação \\ Instituto de Psicologia da Universidade de São Paulo
}

Flaborea, Rodolfo Santos.

Avaliação neuropsicológica da tomada de decisão no comprometimento cognitivo leve / Rodolfo Santos Flaborea; Orientador: Prof. Dr. Marcelo Fernandes da Costa. São Paulo, 2015.

$109 f$.

Dissertação (Mestrado - Programa de Pós-Graduação em Psicologia. Área de Concentração: Psicologia Experimental) - Instituto de Psicologia da Universidade de São Paulo.

1. Neuropsicologia 2. Comprometimento cognitivo leve 3. Avaliação neuropsicológica 4. Tomada de decisão I. Título. 
Título: Avaliação neuropsicológica da tomada de decisão no comprometimento cognitivo leve

Dissertação apresentada ao Instituto de Psicologia da Universidade de São Paulo para obtenção do título de Mestre em Psicologia Experimental

Aprovado em:

BANCA EXAMINADORA

Prof. Dr. Marcelo Fernandes da Costa

Universidade São Paulo

$\operatorname{Prof}^{\mathrm{a}} \operatorname{Dr}^{\mathrm{a}}$ Mariana Kneese Flaks

Universidade Federal de São Paulo

Prof. Dr. Ivan Aprahamian

Universidade de São Paulo 


\section{Agradecimentos}

Aos meus pais, Rita e Fábio, pelo amor e incentivo e por serem os principais responsáveis por eu ser a pessoa que sou hoje.

À minha noiva, Sarah, pelo amor, dedicação, carinho, paciência e pela presença e ajuda constantes ao longo dessa pesquisa.

Ao meu orientador, Prof. Dr. Marcelo Fernandes da Costa, pelo incentivo, abertura, tranquilidade e confiança, elementos essenciais para a minha formação como pesquisador.

À Elanie, Rosani e Dani, pela amizade, por serem meus guias, da graduação à pós, e por serem minhas terapeutas nas ocasiões necessárias.

Ao Dr. Ivan Aprahamian, pela disponibilidade, profissionalismo e pelo auxílio fundamental para realização dessa pesquisa.

À Marina von Zuben, à Jouce e à toda equipe de neuropsicologia do LIM-27, pela valioso suporte e pela incrível recepção dada a mim.

Aos meus amigos, pelos momentos de descontração e pelas longas e divertidas conversas durante nossos encontros.

Ao Vinícius, pelas valiosas longas discussões estatísticas.

Ao Conselho Nacional de Desenvolvimento Científico e Tecnológico (CNPq), pela concessão da Bolsa de estudos. 

"A little learning is a dangerous thing; Drink deep, or taste not the Pierian spring: There shallow draughts intoxicate the brain, And drinking largely sober us again" Alexander Pope, Essay on Criticism 


\section{RESUMO}

Flaborea, Rodolfo Santos. (2015). Avaliação neuropsicológica da tomada de decisão no comprometimento cognitivo leve. Dissertação de Mestrado, Instituto de Psicologia, Universidade de São Paulo, São Paulo.

Introdução: o aumento da população idosa traz uma demanda significativa sobre as ciências da saúde para lidar com os problemas característicos do envelhecimento. Neste contexto, as demências são as desordens neuropsiquiátricas de maior impacto atualmente. Poucas pesquisas acerca do CCL foram dedicadas a analisar a função neuropsicológica da tomada de decisão. Esta é definida como o processo de escolher uma ação específica, dentro de um rol de alternativas possíveis, que produza o resultado mais vantajoso para o sujeito. Logo, ela possui papel clínico fundamental, pois subsidia importante espectro da funcionalidade. Objetivo: avaliar se idosos com CCL amnéstico de múltiplos domínios ou de único domínio apresentam prejuízos na tomada de decisão sob risco, quando comparados a idosos saudáveis. Métodos: foram analisados os desempenhos de 20 sujeitos (9 CCL e 11 controles) no teste de tomada de decisão Cambridge Gambling Task (CGT). Utilizou-se modelo linear geral acompanhado de análise de covariância para idade, anos de escolaridade e escore do Mini Exame do Estado Mental. Resultados: Foi verificado efeito de grupo e da idade sobre a aversão ao atraso, proporção global de aposta e assunção de risco. Conclusão: pacientes com CCL demonstraram maior impulsividade nas escolhas das apostas, além de terem apostado menos ao longo de todo o CGT. O déficit no controle da impulsividade pode ser um indicador de maior risco para conversão para demência, hipótese esta que necessita ser mais investigada. Apostas menores podem constituir estratégia compensatória em reação à impulsividade ou, ainda, ser resultado da menor confiança do paciente com CCL em suas capacidades para lidar com o teste.

Palavras-chave: neuropsicologia; comprometimento cognitivo leve; avaliação neuropsicológica; tomada de decisão. 


\section{ABSTRACT}

Flaborea, Rodolfo Santos. (2015). Neuropsychological assessment of decisionmaking in the mild cognitive impairment. Dissertação de Mestrado, Instituto de Psicologia, Universidade de São Paulo, São Paulo.

Introduction: The increase in elderly population brings a significant demand upon the health sciences to deal with aging-specific issues. In this context, dementia is currently the group of neuropsychiatric disorders with the greatest impact. Research on cerebral reserve shows the importance of early treatment in these syndromes, highlighting the need for comprehension about Mild Cognitive Impairment ( $\mathrm{MCl}$ ), classically defined by literature as a prodromic stage for dementia. Few existing studies on $\mathrm{MCl}$ aimed at investigating the neuropsychological function of decision-making, which is defined as the process of choosing a specific action among several options in order to achieve the most advantageous outcome. Therefore, this function has a fundamental clinical role, since it grants the basis for the individual functionality. Objective: investigate possible deficits in the decision-making of a sample of elderly patients diagnosed with amnestic $\mathrm{MCl}$ of multiple or single domain by comparing their performance with that of healthy ones. Methods: the performances of a sample 20 subjects (9 $\mathrm{MCl}$ and 11 controls) in the Cambridge Gambling Task (CGT) were analysed. General linear model with covariance analysis for age, years of schooling and the Mini Mental State Examination scores was used for the statistical analyses. Results: it was found that group and age effect on delay aversion, overall proportion bet, and risk taking. Conclusion: $\mathrm{MCl}$ patients showed higher impulsivity on bet choices and made smaller bets throughout the CGT run. The impulsivity control deficit can be an indicator of the conversion risk from $\mathrm{MCl}$ to dementia, hypothesis that needs further investigation. Smaller bets may be a compensatory strategy for the increased impulsivity or the result of $\mathrm{MCl}$ patient's less confidence in their own cognitive ability to deal with the test.

Keywords: neuropsychology; mild cognitive impairment; neuropsychological assessment; decision-making. 


\section{Sumário}

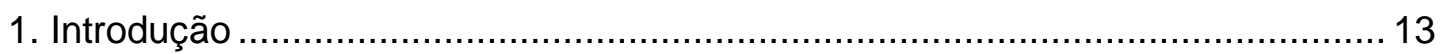

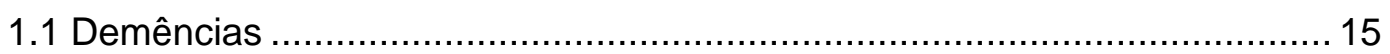

1.2 Fatores de risco para a demência ................................................... 17

1.3 Reserva cerebral .......................................................................... 19

1.4 Comprometimento Cognitivo Leve ......................................................... 25

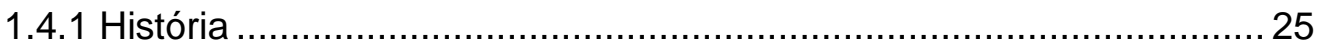

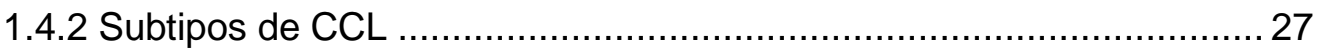

1.4.3 Prevalência e fatores de risco........................................................ 29

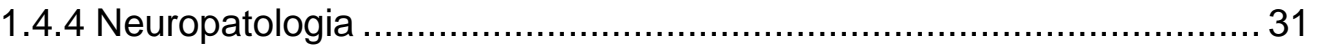

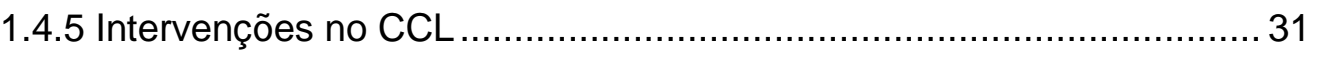

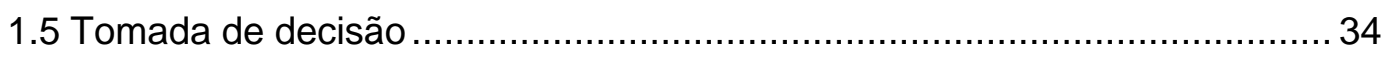

1.5.1 Tomada de decisão sob ambiguidade ......................................... 35

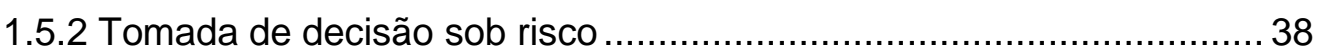

1.5.3 Tomada de decisão e envelhecimento.............................................. 44

1.5.4 Tomada de decisão e CCL ............................................................ 48

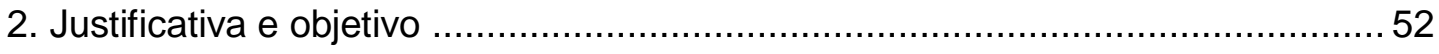

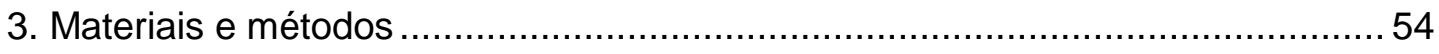

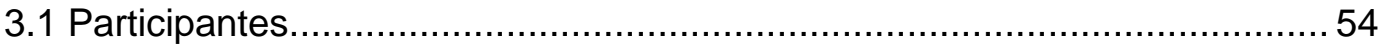

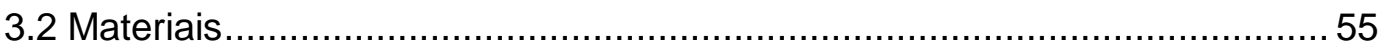

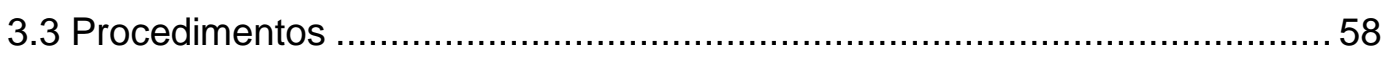

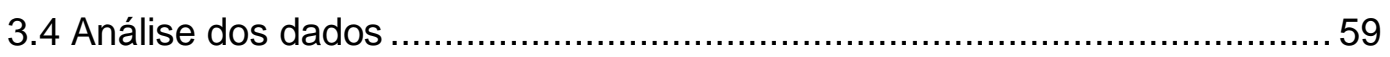

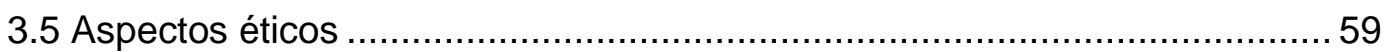

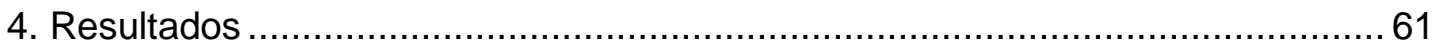

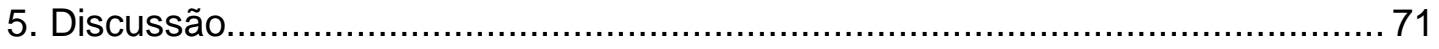

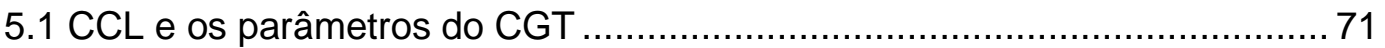

5.2 CCL e síntese da tomada de decisão ....................................................... 75

5.3 Tomada de decisão e idade ................................................................. 76

6. Limitações e recomendações para estudos futuros .......................................... 79

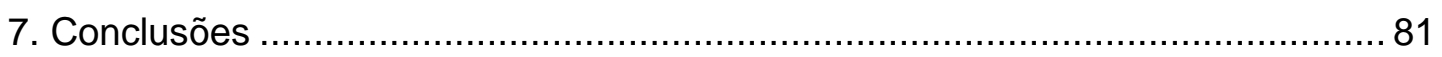

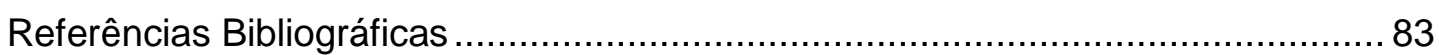

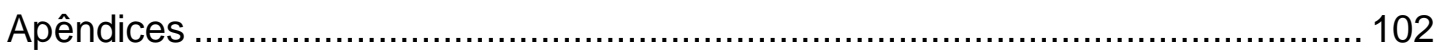




\section{Lista de Figuras}

Figura 1. Crescimento da incidência de demência segundo a renda do país

Figura 2. Variação da reserva cognitiva ao longo da evolução da $D A$

Figura 3. Algoritmo diagnóstico tradicional pra o CCL.........................................28

Figura 4. Esquema cognitivo dos processos de tomada de decisão sob risco..........40

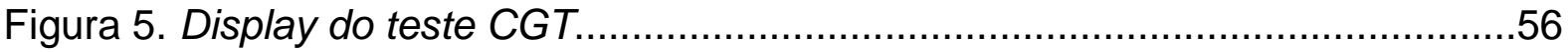

Figura 6. Intervalo de confiança referente à idade em cada grupo.............................61

Figura 7. Intervalo de confiança referente à escolaridade em cada grupo.................62

Figura 8. Boxplot referente à variável aversão ao atraso do CGT...........................67

Figura 9. Boxplot referente à variável proporção global de aposta do CGT..............67

Figura 10. Boxplot referente à variável assunção de risco do CGT............................68

Figura 11. Gráfico de correlação entre idade e aversão ao atraso.............................69

Figura 12. Gráfico de correlação entre idade e proporção global de aposta.............69

Figura 13. Gráfico de correlação entre idade e assunção de risco..............................70 


\section{Lista de Tabelas}

Tabela 1. Características demográficas da amostra 62

Tabela 2. Resultados dos testes de normalidade para as covariáveis e variáveis dependentes. .63

Tabela 3. Resultados dos testes de homocedasticidade. .64

Tabela 4. Análise descritiva dos parâmetros do CGT 64

Tabela 5. Resultados da análise multivariada. .65

Tabela 6. Resultados das análises de variância realizadas. .66

Tabela 7. Resultados dos testes de correlação entre idade e parâmetros do CGT. 68 


\section{Lista de Apêndices}

Apêndice A. Termo de Consentimento Livre e Esclarecido .................................102

Apêndice B. Boxplots referentes à idade e à escolaridade...................................103

Apêndice C. Boxplot referente ao escore do MEEM.........................................104

Apêndice D. Boxplots referentes ao intervalo de deliberação, qualidade de tomada de decisão e ajuste de risco........................................................................ 105

Apêndice E. Intervalo de confiança referente ao escore do MEEM.......................106

Apêndice F. Intervalos de confiança referentes aos parâmetros do CGT..............107 


\section{Introdução}

O aumento da expectativa de vida e o decréscimo da taxa de fertilidade promovem, atualmente, um aumento da população de idosos em todo o mundo e, de maneira mais acelerada, nos países em desenvolvimento, como o Brasil. É o chamado processo de transição demográfica (Aprahamian, Martinelli, \& Yassuda, 2009; Soares, Soares, \& Caixeta, 2012). No ano de 2000, a taxa de crescimento da população idosa brasileira foi oito vezes maior do que aquela apresentada pela população jovem (Inouye, Pedrazzani, \& Pavarini, 2008; Lebrão, 2007; de Melo et al., 2009). Especificamente para a faixa de pessoas com mais de 80 anos de idade, o crescimento foi de $246 \%$ no período entre 1985 e 2005, significativamente maior do que os $55,3 \%$ do aumento da população total (Inouye, Pedrazzani, \& Pavarini, 2008; Lebrão, 2007; de Melo et al., 2009). Até 2025, prevê-se que o Brasil irá ocupar o sexto lugar na classificação mundial de países relativa ao número de idosos, o que se traduz em trinta e quatro milhões de idosos ou $15 \%$ da população brasileira total (Inouye, Pedrazzani, \& Pavarini, 2008; Lebrão, 2007; de Melo et al., 2009).

Este crescimento no número de idosos se deve a vários fatores, que se remontam no começo do século XX, destacando-se dois principais (Alves, 2008). Em primeiro lugar, o desenvolvimento industrial proporcionou um aumento dos recursos de utilidade diária à população (Alves, 2008; Lebrão, 2007; de Melo et al., 2009). Somam-se a isso, os avanços da ciência médica, o aperfeiçoamento das políticas públicas de saúde e o maior acesso ao saneamento básico e a melhores técnicas de higiene pessoal (Alves, 2008; Lebrão, 2007; de Melo et al., 2009).

No entanto, ainda que a população idosa goze de melhores infraestrutura e atendimento médico, muitos desafios se apresentam em diversos campos. No âmbito financeiro, o crescimento da população com mais de 64 anos exerce pressão sobre os gastos em previdência social, ao mesmo tempo em que a população em idade produtiva diminui em porcentagem (Alves, 2008; Paiva \& Wajnman, 2005). 
Junta-se a tais desafios o aumento na incidência de doenças relacionadas ao envelhecimento (Aprahamian et al., 2009; Godinho, Gorczevski, \& Heisler, 2010; Soares et al., 2012; World Health Organization [WHO], 2011). De fato, segundo a OMS (Organização Mundial da Saúde) (WHO, 2011), em todo o mundo ocorre um declínio na incidência de doenças infecto-contagiosas e, simultaneamente, aumenta a frequência de doenças crônicodegenerativas, processo este conhecido como transição epidemiológica. O impacto de doenças crônicas sobre a saúde ${ }^{1}$, dentro de um período de 15 a 25 anos, irá aumentar em praticamente todos os países. Em nações de menor renda, por exemplo, este impacto constituirá mais da metade do efeito das doenças em geral sobre a vida das pessoas, enquanto, em países de renda média, comporá mais de três quartos do total (WHO, 2011).

Sendo assim, a maior longevidade traz uma demanda significativa sobre as ciências da saúde, problema este que não se resume ao tratamento medicamentoso de doenças do envelhecimento (WHO, 2011). Faz-se necessário também prover um melhor manejo clínico e uma qualidade de vida mais adequada aos cada vez mais numerosos pacientes idosos, considerando não só o tratamento, mas também as condutas necessárias à prevenção de doenças associadas à idade (Karsch, 2003; Motta \& Aguiar, 2007; Queiroz \& Ramalho, 2009; WHO, 2011).

Deste modo, uma maior compreensão sobre os aspectos epidemiológicos, patológicos, etiológicos e clínicos dos quadros relacionados à idade é essencial para o desenvolvimento de intervenções mais efetivas na saúde do idoso. As demências são as desordens neuropsiquiátricas relacionadas à idade de maior impacto atualmente $(\mathrm{WHO}$, 2012).

\subsection{Demências}

Define-se demência como uma síndrome causada por doenças que afetam diversas regiões do encéfalo. Dentre as possíveis alterações, observa-se a deterioração generalizada

\footnotetext{
${ }^{1} \mathrm{O}$ conceito de impacto sobre saúde - em inglês, burden of disease - é uma medida que se refere à perda de anos de vida saudável devido a uma causa específica. Ela é elaborada para cada um dos países analisados - divididos em três grupos, a saber, renda alta, renda média e renda baixa - com base em informações epidemiológicas detalhadas (WHO, 2011).
} 
e progressiva de funções neuropsicológicas, tais como a memória, as funções executivas e visuo-espaciais. A capacidade funcional do sujeito, isto é, a habilidade de realizar as atividades de vida diária, também é significativamente prejudicada, comprometendo sua autonomia e gerando dependência de cuidados constantes e paulatinamente mais ubíquos na vida do paciente (Mandell \& Green, 2011; Reitz, Brayne, \& Mayeux, 2011; Sosa-Ortiz, Acosta-Castillo, \& Prince, 2012; VandenBos, 2010; WHO, 2012).

A prevalência global de demência recentemente analisada indica que, no ano de 2010, aproximadamente $4,7 \%$ dos idosos com mais de 60 anos de idade foram afetados por essa condição. A distribuição regional, segundo o estudo, foi de $2,6 \%$ na África, $4,0 \%$ na Ásia, 6,2\% na Europa e, por fim, para o continente americano, a prevalência correspondeu a 6,5\% (Prince \& Jackson, 2009; Prince et al., 2013; Sosa-Ortiz et al., 2012; WHO, 2012). Especificamente na América Latina, foi constatada uma taxa ao redor de $8,5 \%$ (Prince \& Jackson, 2009; Prince et al., 2013; Sosa-Ortiz et al., 2012; WHO, 2012).

A partir de tais análises, prevê-se um crescimento significativo no número de casos para as próximas décadas. Estimou-se que, a cada período de 20 anos, a quantidade de pacientes tende a quase dobrar. Por exemplo, para o ano de 2030, aferiu-se, aproximadamente, 65,7 milhões de casos ao redor do mundo. Em 2050, estima-se que este número aumente para 115,4 milhões (Sosa-Ortiz et al., 2012; WHO, 2012). As taxas de crescimento, no entanto, tenderão a variar expressivamente de acordo com a região (Figura 1), com as maiores taxas ocorrendo em países em desenvolvimento: na América Latina, a taxa será de 146\% em um período de 20 anos, enquanto, na Europa, observar-se-á um aumento de 40\% (Prince \& Jackson, 2009; Prince et al., 2013; Sosa-Ortiz et al., 2012; WHO, 2012). 


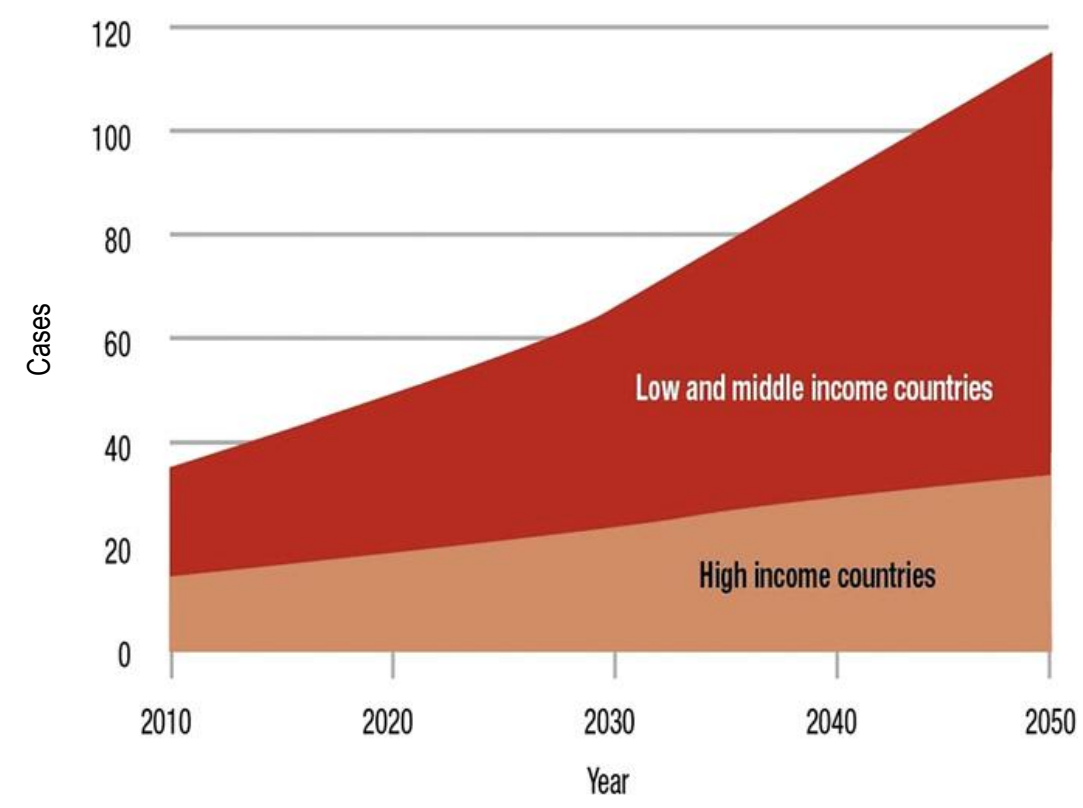

Figura 1: crescimento no número de casos de demência (em milhões) de acordo com a renda dos países. Países de renda baixa e média estão incluídos em low and middle income countries, enquanto os dados referentes a países ricos se localizam em high income countries. No eixo da abscissa está indicado o ano, enquanto que no da ordenada, o número de casos. Adaptado de SosaOrtiz, A. L., Acosta-Castillo, I., \& Prince, M. J. (2012). Epidemiology of dementias and Alzheimer's disease. Archives of medical research, 43(8), 600-608.

Os subtipos mais comuns de demência são, em ordem de frequência, a doença de Alzheimer (DA), a demência vascular (DV), a demência por corpos de Lewuy (DCL) e a demência fronto-temporal (DFT) (Knapp \& Prince, 2007; Ratnavalli, Brayne, Dawson, \& Hodges, 2002; Suh \& Shah, 2001; Sosa-Ortiz et al., 2012; WHO, 2012; Ziegler-Graham, Brookmeyer, Johson, \& Arrighi, 2008). É importante destacar que os dados epidemiológicos referentes a tais subgrupos, segundo Sosa-Ortizs et al. (2012) e WHO (2012), devem ser interpretados com cautela. Isto porque não apenas o diagnóstico diferencial é baseado fortemente na evolução clínica esperada para cada subgrupo, mas também porque ele depende da obtenção de muitos parâmetros, tais como história clínica, avaliação neuropsicológica contínua e exames laboratoriais, o que dificulta sobremaneira a realização da coleta de dados necessária para os estudos epidemiológicos. Sendo assim, estimativas sobre a proporção de casos para cada uma das diferentes patologias representaria, de acordo com WHO (2012), apenas um índice aproximado das diferentes patologias. 


\subsection{Fatores de risco para a demência}

Diversos são os fatores de risco associados à demência, especialmente no que se refere à DA e à DV. Entre os aspectos mais estudados estão os genes, idade, sexo, atividade física, fumo, álcool e outras drogas, nível educacional, comorbidades com outras doenças, nutrição e exposição a metais (Chen, Lin, \& Chen, 2009; WHO, 2012).

Desde o começo da década de 90, diversos estudos apontaram a importância do gene ApoE\&4 para o aumento do risco de DA (Chen et al., 2009; WHO, 2012). Farrer et al. (1997), realizando uma metanálise sobre a influência do genótipo ApoE $\varepsilon 4$, verificaram que este gene representa um significativo fator de risco para DA (OR=14,9, 95\% IC=10,8-20,6 para o genótipo $\varepsilon 4 / \varepsilon 4)$. Pesquisas mais recentes, utilizando a abordagem genômica, também vão ao encontro do risco representado pelo gene ApoEع4 (Abraham et al., 2008; Bertram et al., 2008; Carrasquillo et al., 2009).

A idade também se mostra um fator de risco significativo para a demência (Chen et al., 2009; WHO, 2012). Diversos estudos de coorte com a população norte-americana e européia apontaram que a probabilidade para a ocorrência de DA aumenta sensivelmente conforme a idade (Ganguli, Dodge, Chen, Belle, \& DeKosky, 2000; Kukull et al., 2002; Launer et al., 1998; López-Pousa, Vilalta-Franch, Llinás-Regla, Garre-Olmo, \& Román, 2004). López-Pousa et al. (2004) verificaram esta associação também nos demais tipos de demência. Liu, Guo, Zhou e Xia (2003), por sua vez, demonstraram a idade como um fator de risco para a DA e para a DV.

Foram observadas também diferenças entre homens e mulheres no que se refere ao risco para a demência (Chen et al., 2009). De maneira geral, observa-se uma maior incidência de DA em mulheres do que em homens com mais de 60 anos de idade, diferença esta que aumenta quanto maior a faixa etária (Andersen et al., 1999). Para a DV, inversamente, foi constatada uma maior incidência no sexo masculino, o que pode ser atribuído ao fator protetor do estrógeno na fase de pré-menopausa e uma maior frequência 
de doenças cardiovasculares em homens (Andersen et al., 1999; Azad, Al Bugami, \& LoyEnglish, 2007; Ruitenberg, Ott, van Swieten, Hofman \& Breteler, 2001). Chen et al. (2009) destacam que diversos aspectos, que refletem diferenças entre os sexos, podem interferir na verificação da associação entre gênero e demência, tais como estilo de vida, hormônios e herança ligada ao sexo.

O sedentarismo, de acordo com a literatura, consiste em outro fator de risco para a demência (Chen et al., 2009; WHO, 2012). Por outro lado, a realização frequente de atividade aeróbica se mostra como um fator de proteção contra a doença, assim como um atenuante do declínio cognitivo característico do envelhecimento saudável (Chen et al., 2009; WHO, 2012). Metanálises recentes mostraram evidências de que o costume de praticar exercícios melhora, ainda que modestamente, o desempenho cognitivo em diversas funções, tais como atenção, funções executivas, memória e velocidade de processamento (Ahlskog, Geda, Graff-Radford, \& Petersen, 2011; Angevaren, Aufdemkampe, Verhaar, Aleman, \& Vanhees, 2008). Correspondentemente, em ressonância magnética funcional, observou-se, em idosos que adotaram um programa de exercícios durante seis meses, uma maior ativação dos circuitos neurais que subsidiam aquelas funções. Por fim, constatou-se um significativo aumento do volume hipocampal em idosos após um ano de treinamentos aeróbicos constantes (Ahlskog et al., 2011; Angevaren et al., 2008).

Barnes e Yaffe (2011), por sua vez, procuraram analisar o possível efeito que a retirada de fatores de risco teria sobre a incidência de casos de DA. Os pesquisadores elaboraram uma medida denominada "risco atribuível à população" (RAP), que corresponde à proporção dos casos de DA na população que podem ser prevenidos se o fator de risco correspondente pudesse ser totalmente removido. Dentro desta medida, o RAP relacionado ao sedentarismo foi um dos mais altos, correspondendo a $12,7 \%$ dos casos passíveis de prevenção.

A comorbidade com outras doenças é outro fator de risco fundamental (Chen et al., 2009; Who, 2012). Distúrbios cardiovasculares, como hipertensão e doenças cardíacas, 
predispõem tanto ao surgimento de DA quanto de DV (Casserly \& Topol, 2004; Daviglus et al., 2011; Yip, Brayne, \& Matthews, 2006; Whitmer, Sidney, Selby, Claiborne Johnston, \& Yaffe, 2005). Anomalias endocrinológicas, como diabetes e hipercolesterolemia, aumentam a probabilidade de DA (Whitmer et al., 2005). A combinação de fatores vasculares e endocrinológicos foi associada a um risco maior para a DA, em comparação com os fatores isolados (Luchsinger et al., 2005).

Outro fator de risco com papel preponderante é o grau de educação formal do idoso (Chen et al., 2009; WHO, 2012). Valenzuela e Sachdev (2006), utilizando metanálise, verificaram que, em países de alta renda, uma maior escolaridade foi fortemente associada a uma menor incidência de demência. Evidências referentes a países de renda média e baixa são mais limitadas: em populações de Pequim, na China, e em Catanduva, no Brasil, houve tendências, ainda que sem resultados estatisticamente significativos, apontando para esse papel protetor da escolaridade (Li et al., 1991; Nitrini et al., 2004).

\subsection{Reserva cerebral}

A partir das tentativas de se compreender como determinados fatores influenciam o risco para a demência, tem-se colocado o questionamento inverso, isto é, por que alguns indivíduos não sofrem os efeitos nefastos de uma síndrome demencial (Caixeta \& Pinto, 2014; Stern, 2012; WHO, 2012).

Katzman et al. (1988), no final da década de 80, realizaram análises post-mortem em 137 residentes de um asilo. Do total da amostra, 78\% desenvolveram síndrome característica com DA, com concomitante neuropatologia. No entanto, 10 sujeitos, apesar de apresentarem placas neuríticas características de uma neuropatologia moderada de DA, além de não exibirem DA, também apresentaram desempenho cognitivo superior aos seus colegas de instituição. Especificamente, eles exibiam quase o dobro do número de grandes neurônios piramidais. 
Estudos subsequentes acabaram por demandar um conceito que pudesse descrever e explicar os motivos da resistência dessas pessoas à neuropatologia (Caixeta \& Pinto, 2014; Stern, 2012). Surge, assim, o conceito de reserva cerebral ${ }^{2}(R C)$, que seria estimada pelo número de neurônios que um indivíduo tem. Um maior número de células neurais implicaria uma resistência cerebral maior às lesões, o que resultaria na ausência de prejuízo clinicamente relevante (Caixeta \& Pinto, 2014; Katzman et al., 1988; Stern, 2012).

Essa conceituação inicial, no entanto, possuía suas limitações. Na base de sua elaboração, estava o pressuposto de que esta RC seria eminentemente genética, não sendo passível de alteração ao longo da vida. O que a produção científica subsequente demonstrou, todavia, é que o risco para demência pode ser modificado pela experiência, mesmo que de maneira tardia na vida (Stern, 2009; Valenzuela \& Sachdev, 2006; Valenzuela, 2008). Além disso, sua definição implicava problemas operacionais significativos, tal como a contagem do número de neurônios no paciente vivo, necessária para a estimação de sua RC (Caixeta \& Pinto, 2014; Stern, 2012).

Em reação a essas questões, diversas noções alternativas sobre $R C$ foram sugeridas (Caixeta \& Pinto, 2014; Stern, 2012). Uma delas propôs a substituição do número de neurônios por medidas de inteligência. Pressupõe-se, neste constructo, que pessoas com melhores desempenhos em testes cognitivos necessitariam de uma patologia mais grave para que seus escores alcançassem o limiar diagnóstico (Figura 2). Outro modelo proposto é o neurocomputacional. Nele, considera-se que, quanto mais o indivíduo desenvolve estratégias cognitivas para lidar com as exigências diárias, concomitantemente gera uma maior disponibilidade de circuitos neurais. Em face de uma lesão cerebral, este sujeito seria mais flexível, isto é, seria capaz de recrutar mais estratégias alternativas - e

\footnotetext{
${ }^{2}$ Caixeta e Pinto (2014) colocaram que o conceito de RC ainda sofre de falta de uma definição mais rigorosa. Segundo tais autores, uma parte da literatura fala da existência de uma reserva global, sendo dividida em reserva cerebral e reserva cognitiva. O primeiro subconceito se referiria aos aspectos anatomofisiológicos da resistência do indivíduo. Já o segundo diz respeito ao grau de prejuízo clínico do paciente em uma atividade pré-aprendida. No entanto, Caixeta e Pinto (2014) ressaltaram que este conceito não é compartilhado em toda a literatura. Desse modo, tais autores decidiram adotar apenas o termo "reserva cerebral", para efeitos de simplificação. Para o presente texto optou-se por adotar postura semelhante.
} 
circuitos neurais, consequentemente - para lidar com limitações cognitivas que acompanham a neuropatologia (Stern, 2002; Stern, 2009; Stern, 2012).

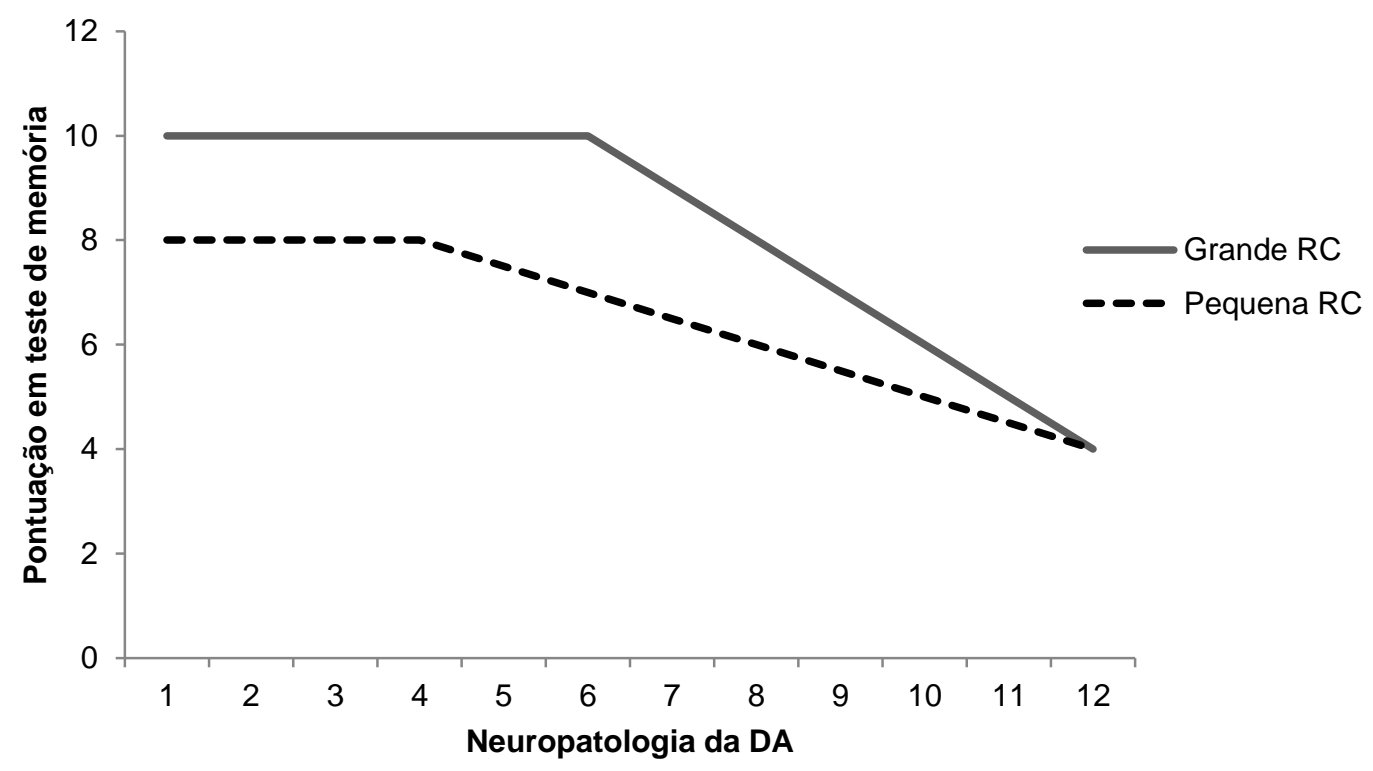

Figura 2: exemplo ilustrado teórico sobre como seria a variação da reserva cognitiva na evolução do paciente até a expressão clínica da DA. O eixo y se refere ao escore em um teste hipotético de memória. $O$ eixo $x$, por sua vez, retrata o grau de aumento da patologia da DA no encéfalo. A DA demorará mais para surgir em indivíduos com ponto de inflexão mais tardio. Correspondentemente, o critério diagnóstico para DA poderá ser atingido mais tardiamente (com uma patologia subjacente mais grave, consequentemente). Por fim, a progressão clínica em pacientes com grande RC será mais rápida. Adaptado de Caixeta, L. \& Pinto, P. H. (2014). Reserva cerebral, plasticidade e o cérebro do idoso. In: L. Caixeta \& A. L. Teixeira, Neuropsicologia Geriátrica: neuropsiquiatria cognitiva em idosos. Porto Alegre: Artmed.

Para Caixeta e Pinto (2014), estas duas alternativas, a psicométrica e a neurocomputacional, teriam problemas teóricos e operacionais. Os pressupostos da primeira não consideram, por exemplo, que diferentes funções neuropsicológicas são processadas de maneira diversa entre si. Além disso, o modelo psicométrico não abarca o fato de que diferentes configurações lesionais afetam de maneira idiossincrática a cognição e a funcionalidade do paciente. A proposta neurocomputacional, por sua vez, não circunscreveria, a priori, se a pouca flexibilidade do sujeito seria um preditor ou uma consequência do distúrbio clínico e de sua neuropatologia concomitante (Caixeta \& Pinto, 2014). 
No que diz respeito à aplicabilidade prática, o chamado modelo comportamental seria o mais promissor (Caixeta \& Pinto, 2014). Esse constructo estabelece que, para uma definição mais confiável do que seria reserva, é necessário associá-la a aspectos da história do sujeito que, de alguma forma, demandam o uso de mecanismos neuropsicológicos complexos, como o grau de atividade intelectual desta pessoa e seu engajamento em atividades sociais e de lazer (Caixeta \& Pinto, 2014). De fato, há evidências de que níveis elevados de atividade mental podem proporcionar uma melhor resistência e resiliência a traumas e neuropatologias (Valenzuela, Breakspear, \& Sachdev, 2007).

Correspondentemente, observa-se um aumento de fatores neuroprotetores em resposta à estimulação ambiental e ao engajamento em atividades mentais complexas (Valenzuela et al., 2007). A curto prazo, foi constatado, tanto em seres humanos como em não-humanos, o aumento no número e na ativação de moléculas essenciais para os processos de plasticidade sináptica (PLP e DLP ${ }^{3}$ ), tais como os receptores sinápticos AMPA e NMDA (Artola et al., 2006; Tang, Wang, Feng, Kyin, \& Tsien, 2001). Ainda a curto prazo, também se observa um incremento nos níveis de fatores neurotróficos - substâncias responsáveis por estimular a neurogênese - como o FNDC e FCN ${ }^{4}$ (Adlard, Perreau, Pop, \& Cotman, 2005; Mohammed et al., 2002; Sofroniew, Howe, \& Mobley, 2001).

$\mathrm{Na}$ literatura também foram relatadas mudanças a médio prazo. Concomitantemente a uma interação mais rica com o ambiente, ocorre um aumento na sinaptogênese, tal como relatado em modelos animais (Valenzuela et al., 2007). Em humanos, de forma correspondente, foram observadas correlações entre a complexidade das árvores dendríticas, o nível educacional e a sofisticação cognitiva das ocupações dos sujeitos (Valenzuela et al., 2012). Simultaneamente ao aumento da demanda metabólica em

\footnotetext{
${ }^{3}$ Siglas correspondents a potenciação de longo prazo (PLP) e depressão de longo prazo (DLP). Na PLP, observa-se um fortalecimento da ligação sináptica, traduzido por uma transmissão mais eficiente do impulso nervoso entre os neurônios. A DLP, por sua vez, é o processo no qual a sinapse pouco utilizada é enfraquecida e, em última instância, eliminada. Atuando em conjunto, PLP e DLP estão na base do fenômeno de modelagem sináptica necessária para o aprendizado do indivíduo (Kandel, Schwartz \& Jessell, 2012).

${ }^{4}$ Respectivamentefator neurotrófico derivado do cérebro e fator de crescimento de nervos.
} 
decorrência do incremento da sinaptogênese, foi constatada uma maior produção de vasos sanguíneos cerebrais, fator neuroprotetor importante tanto para a DV como para a DA (Prakash, Voss, Erickson, \& Kramer, 2014).

Por fim, a longo prazo, associações foram encontradas entre estimulação ambiental e maior eficiência do processamento neural, traduzida em um menor consumo de glicose após treinamento cognitivo intensivo (Haier et al., 1992).

Segundo Sporns (2011), robustez traduz a capacidade de uma rede neural em transmitir a informação adequadamente, mesmo quando diversas de suas vias de ligação estão interrompidas devido, por exemplo, a um processo neurodegenerativo. Em última instância, robustez confere flexibilidade para a rede neural, pois ela pode ter uma mesma performance com configurações estruturais diferentes (Sporns, 2011). Quanto mais robustas as redes neurais de um indivíduo, mais resistente ele será àquele processo, isto é, será necessária uma carga neuropatológica maior para que algum prejuízo clínico seja observado (Sporns, 2011; Valenzuela et al., 2007). Isto vai ao encontro dos achados anteriormente citados no que se refere à plasticidade sináptica, à sinaptogênese e aos fatores neurotróficos, visto que estes são fenômenos que promovem a construção e proliferação da conectividade de redes neurais (Valenzuela et al., 2007).

No nível comportamental, são diversos os fatores associados a uma maior RC e, portanto, a um menor risco para demência. Entre eles estão escolaridade, complexidade ocupacional, interação social frequente e positiva e, por último, atividades de lazer (Caixeta \& Pinto, 2014).

Barnes e Yaffe (2011) procuraram analisar o possível efeito que a retirada de fatores de risco teria sobre a incidência de casos de DA. O RAP associado a baixo nível educacional foi o de maior magnitude $(19,1 \%)$, superando o de sedentarismo $(12,7 \%)$. Boa parte da literatura aponta para o mesmo caminho, demonstrando menor incidência de demência quanto maior for a escolaridade (Nitrini et al., 2004). 
A complexidade inerente a determinadas atividades ocupacionais, principalmente em trabalhos intelectuais, também foi associada a um menor impacto dos prejuízos cognitivos característicos do envelhecimento. Inversamente, indivíduos que realizam atividades profissionais de baixa exigência intelectual exibiram maior probabilidade para declínio cognitivo. Profissões mais técnicas e de gerenciamento são consideradas de alta demanda intelectual, enquanto tarefas artesanais e braçais exigiriam cognitivamente menos do sujeito (Baldivia, Andrade, \& Bueno, 2008).

Fratiglioni, Wang, Ericsson, Maytan e Winblad (2000), por sua vez, mostraram, em estudo longitudinal com 1203 idosos, que sujeitos socialmente isolados ou com relacionamentos interpessoais negativos ou insatisfatórios possuem alto risco para demência, além de maior probabilidade para depressão. Caixeta e Pinto (2014) sugerem que um ambiente social complexo e constantemente mutável oferece ao idoso a oportunidade para o desenvolvimento e a manutenção de diversas funções cognitivas.

Na literatura também é discutido o papel de atividades de lazer na formação de $R C$ e seu efeito protetor para a ocorrência de demência (Wang, Xu, \& Pei, 2012). Caixeta e Pinto (2014) propuseram, teoricamente, que o lazer - como visitas a museus, idas a restaurantes, jogos, leitura, televisão e música - confere estimulação cognitiva ao idoso, o que reforçaria sua reserva cogntiva. Fabrigoule et al. (1995), em um estudo longitudinal, verificaram uma menor incidência de demência em idosos que frequentemente se engajavam em atividades de lazer. Por outro lado, Wang et al. (2012), em sua revisão sistemática, verificaram que este efeito é frequentemente constatado em estudos observacionais, mas inconsistentes em pesquisas clínicas mais sistematizadas. Estes autores sugerem que, para uma melhor análise, estudos subsequentes padronizem a avaliação das atividades, como frequência, intensidade e duração dos diversos tipos de lazer.

Um aspecto importante evidenciado pelos estudos sobre $\mathrm{RC}$ diz respeito a quais fatores ontogenéticos interferem no risco do sujeito desenvolver uma síndrome demencial na velhice (Caixeta \& Pinto, 2014). Desta forma, intervenções objetivando mudanças de 
hábito, mesmo em idades mais avançadas e em fases anteriores à demência, possuem efeito protetor, reduzindo o impacto do declino cognitivo e a probabilidade para a demência (Caixeta \& Pinto, 2014; Stern, 2012). Para que estas intervenções sejam mais bem direcionadas, faz-se necessário compreender mais aprofundadamente um quadro clínico central para o estudo das demências: o Comprometimento Cognitivo Leve (CCL) (Li et al., 2011; Petersen et al., 2014).

\subsection{Comprometimento Cognitivo Leve}

\subsubsection{História}

O conceito de CCL foi trazido à tona pela primeira vez no final da década de 80 por Reisberg et al. (1988). A intenção destes autores era identificar mais precisamente o estágio de prejuízo neuropsicológico intermediário entre perda cognitiva normal do envelhecimento e a demência.

Petersen et al. (1999), em trabalho posterior na Mayo Clinic, propuseram critérios mais sistematizados e aprofundados a partir da observação clínica longitudinal dos sinais clínicos e do desempenho cognitivo de idosos. Os critérios diagnósticos utilizados pelos autores incluíram (1) presença de queixas de memória, (2) déficit mnéstico confirmado por avaliação da memória episódica, (3) preservação do funcionamento cognitivo geral, (4) preservação da capacidade funcional independente e (5) ausência de síndrome demencial.

Tais critérios estavam obviamente focados em prejuízos na memória, os quais eram considerados como sinais de pródromo para a DA. Perdas em outras funções foram incluídas no estudo, mas déficits isolados não foram considerados na investigação (Petersen et al., 2014). Análises ulteriores verificaram que nem todos os pacientes afetados pelo CCL convertiam especificamente para DA, fato este que demandava critérios diagnósticos mais amplos (Petersen et al., 2014).

Nesse sentido, no First Key Symposium, foi realizado esforço para que um consenso sobre os critérios adequados para CCL pudesse ser alcançado (Winblad et al., 2004). 
Expandindo os critérios do grupo da Mayo Clinic, retirou-se o foco sobre prejuízos mnésticos, abarcando também aqueles perfis cognitivos que apresentavam danos em outras funções neuropsicológicas. Foram mantidas as exigências para ausência de demência e preservação da funcionalidade, ainda que déficits mínimos em atividades instrumentais mais complexas fossem aceitos ${ }^{5}$.

De acordo com Stella (2012), ainda há um debate na literatura sobre como a avaliação neuropsicológica deve ser utilizada no diagnósico. Basicamente, discute-se se o melhor seria levar em conta uma avaliação transversal, considerando-se a presença de declínio cognitivo a partir de escores abaixo de 1,5 de desvio-padrão, ou uma avaliação longitudinal, que evidencie declínio a partir da comparação dos resultados ao longo de um dado período de tempo, normalmente um ano. No geral, Stella (2012) aponta que há uma tendência para maior aceitação de avaliações longitudinais para confirmação da hipótese diagnóstica.

Mais recentemente, esforços têm sido dedicados para se caracterizar o CCL especificamente dentro do espectro da DA (Albert et al., 2011). A rediscussão proposta pretende circunscrever etiologicamente parte dos casos de CCL, definindo-os como CCL devido à DA, a partir dos biomarcadores associados a este subtipo de demência (Albert et al., 2011; Petersen et al., 2014).

A Associação Psiquiátrica Americana (APA), por sua vez, elaborou critérios próprios para caracterizar a fase pré-demencial, publicados na quinta edição do Diagnostic and Statiscal Manual of Mental Disorders (DSM-5) (American Psychiatric Association [APA], 2013). A classificação, conhecida por mild neurocognitive disorder (NCD), possui muitas das características do CCL, como o reconhecimento de certas alterações cognitivas que não se

\footnotetext{
${ }^{5}$ A capacidade funcional de um indivídiuo pode ser dividida em (1) atividades básicas de vida diária e (2) atividades instrumentais de vida diária. A primeira se refere aos comportamentos de autocuidado, como higiene, alimentação e habilidade de se vestir. Atividades instrumentais, por sua vez, dizem respeito a tarefas mais complexas, frequentemente relacionadas com sua participação e funcionamento na comunidade em que vive. Entre elas, estão incluídas uso do transporte para se locomover, realizar compras no supermercado, manejar medicamentos e administrar adequadamente as finanças (Del Duca, Silva \& Hallal, 2009).
} 
configuram nem como típicas do envelhecimento normal nem como integrantes de uma síndrome demencial. Ademais, também considera, para o diagnóstico de NCD, critérios como ausência de demência e preservação da capacidade funcional (APA, 2013). O DSM-5 ainda propõe que o processo diagnóstico inclua também a busca por fatores etiológicos, como as síndromes neurodegenerativas associadas à velhice (DA, DV, DFT e DCL, por exemplo) e outros distúrbios, como AIDS, traumas crânio-encefálicos e abuso de substâncias (APA, 2013). Todavia, indo ao encontro de Winblad et al. (2004) e Albert et al. (2011), essa mesma publicação recomenda que esses biomarcadores não sejam considerados na confirmação do diagnóstico, apenas servindo para o uso de pesquisas acerca da etiologia do quadro. O CCL, desse modo, permanece como um diagnóstico de caráter eminentemente clínico (Petersen et al., 2014). Abaixo são expostos os critérios que guiam o diagnóstico de CCL.

\subsubsection{Subtipos de CCL}

De acordo com os critérios de Winblad et al. (2004), o CCL pode ser dividido primariamente em dois subtipos. Caso haja déficit em tarefas de memória episódica, tem-se a categoria amnéstica (CCL-a). Quando não se observam prejuízos na memória episódica, mas sim em outros domínios neuropsicológicos, como funções executivas, linguagem e funções visuoconstrutivas, define-se o subtipo como CCL não-amnéstico (CCL-na). Pressupõe-se que, na avaliação médica inicial, tenham sido preenchidos os critérios iniciais referentes à ausência de demência e preservação funcional. Além dessa divisão, as diretrizes diagnósticas especificam que o CCL seja subdivido de acordo com a extensão do prejuízo cognitivo, isto é, se se trata de CCL de único domínio ou de CCL de múltiplos domínios (Winblad et al., 2004).

Como resultado, o paciente em avaliação pode ser classificado em um dentre quatro domínios: CCL-a de único domínio, CCL-a de múltiplos domínios, CCL-na de único domínio e CCL-na de múltiplos domínios (Figura 3) (Winblad et al., 2004). Além das informações 
obtidas por meio de anamnese e de avaliação neuropsicológica, outros dados, como os fornecidos por neuroimagem e neuropatologia, podem auxiliar o racicínio clínico, apontando para possíveis evoluções do quadro (Petersen et al., 2014; Winblad et al., 2004).

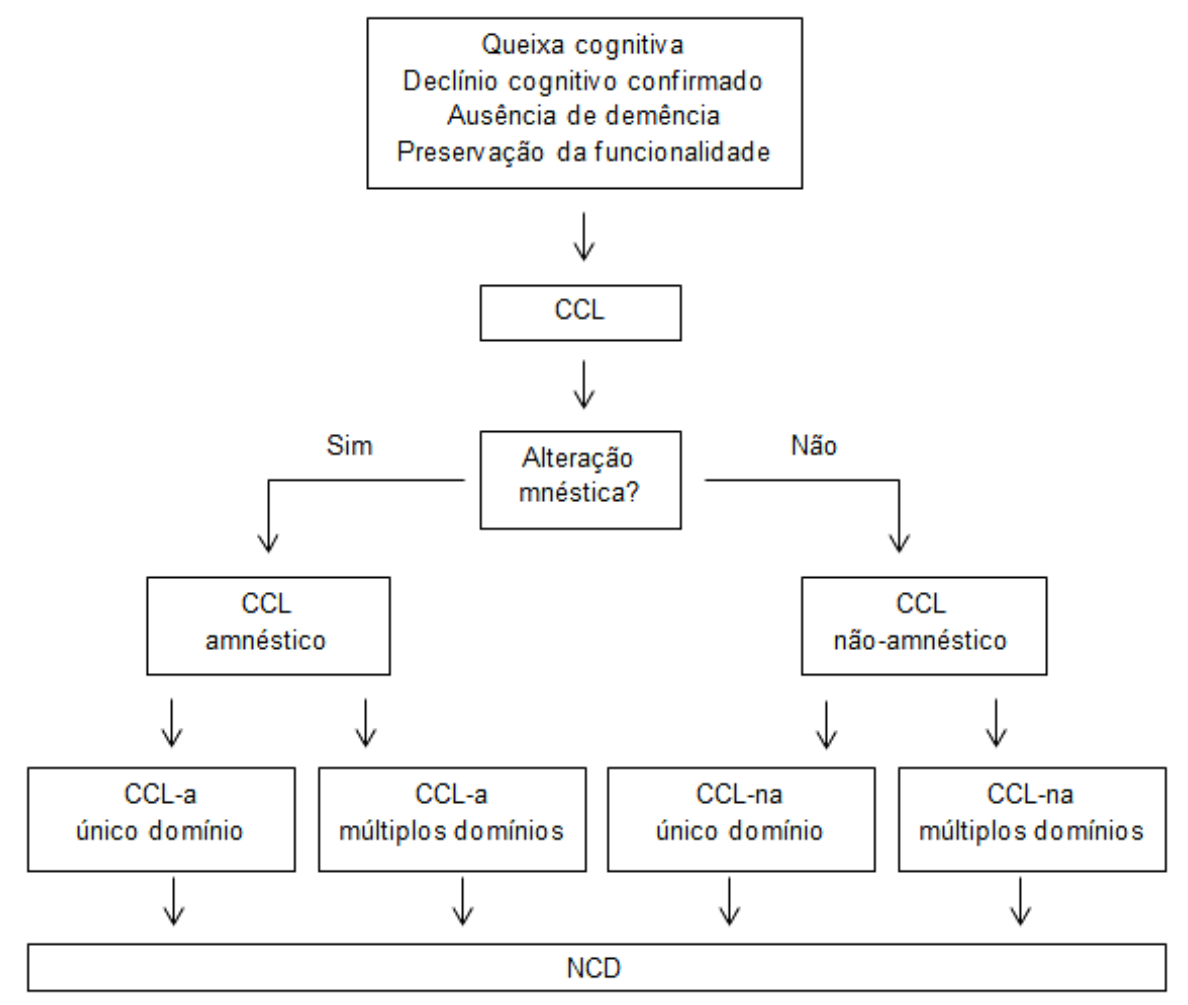

Figura 3: algoritmo diagnóstico tradicional para o CCL. A categoria de mild neurocognitive disorder, do DSM-5, foi adicionada ao modelo. Adaptado de Petersen, R. C., Caracciolo, B., Brayne, C., Gauthier, S., Jelic, V., \& Fratiglioni, L. (2014). Mild cognitive impairment: a concept in evolution. Journal of internal medicine, 275(3), 214-228.

Ainda que inicialmente para fins de pesquisa, estudos focados no CCL devido à DA determinaram certos biomarcadores potencialmente úteis para identificar a etiologia do caso em análise, especificamente relacionada à DA (Albert et al., 2011). São considerados dois grupos principais: biomarcadores para depósito de proteína beta amiloide e para danos neuronais. Indicadores confiáveis referentes ao primeiro grupo são (A) concentrações de resíduo $A \beta 42$ no líquido cefalorraquidiano (LCR) e (B) tomografia por emissão de pósitrons para amilóide (PET amilóide). Biomarcadores para lesões neuronais são (A) presença de proteína tau-fosforilada no LCR, (B) atrofia hipocampal ou têmporo-medial constatada a partir de medidas volumétricas ou conferência visual, (C) taxa de atrofia cerebral, (D) PET 
por fluorodeoxiglicose e (E) imageamento de perfusão por tomografia computadorizada por emissão de fóton único (SPECT) (Albert et al., 2011).

Além dos déficits cognitivos, é digna de nota a presença de sintomas neuropsiquiátricos no CCL (Apostolova \& Cummings, 2007; Monastero, Mangialasche, Camarda, Ercolani, \& Camarda, 2009; Petersen et al., 2014). Em uma revisão sistemática da literatura, Apostolova e Cummings (2007) relataram que sintomas comportamentais são observados entre 35 e $75 \%$ dos pacientes, sendo os mais comuns depressão, apatia, ansiedade e irritabilidade. Achados semelhantes foram relatados em revisão mais recente (Monastero et al., 2009).

\subsubsection{Prevalência e fatores de risco}

Ao longo dos anos 2000, estudos epidemiológicos cada vez mais numerosos procuraram estimar a prevalência do CCL na população. As frequências observadas acompanharam a evolução dos critérios clínicos. Prevalências menores foram inicialmente constatadas em estudos que utilizaram as diretrizes diagnósticas do grupo da Mayo Clinic, pois estas abarcavam apenas prejuízos na memória episódica (Petersen et al., 2014). Pesquisas mais recentes, nas quais foram aplicados os critérios expandidos do Key Symposium, apontaram para porcentagens significativamente maiores (Petersen et al., 2014).

A maioria das análises epidemiológicas foi realizada nos Estados Unidos e na Europa, com exceção de três estudos, feitos no Japão, na Coréia do Sul e na Índia (Petersen et al., 2014). Em média, a prevalência de CCL na população idosa foi de 18,9\%, quase três vezes maior do que os $7 \%$ médios referentes somente aos casos de CCL-a. A prevalência média observada foi de 47,9 casos a cada 1000 pessoas/ano, número maior que o triplo da prevalência média para casos puramente amnésticos (15,2 casos para cada 1000 pessoas/ano) (Petersen et al., 2014). 
As pesquisas dedicadas aos fatores de risco ainda são relativamente recentes, com a maioria dos dados tendo sido obtida na última década. Luck, Luppa, Briel e Riedel-Heller (2010), em revisão sistemática, revelaram, como seria esperado, que a maioria dos fatores de risco para as diversas síndromes demenciais - idade avançada, nível acadêmico, sedentarismo e isolamento social - também são aplicáveis aos casos de CCL. No entanto, Petersen et al. (2014) ressaltam que ainda não há consenso sobre a extensão de tais associações.

No que se refere à genética, foi amplamente estudada a relação entre CCL e os alelos $\varepsilon 4$ do gene APoE, mais conhecido em pesquisas com DA (Boyle, Buchman, Wilson, Leurgans. \& Bennet, 2010; Lopez et al., 2003; Tervo et al., 2004). Tervo et al. (2004), por exemplo, constataram que indivíduos portadores dos alelos $\varepsilon 4$ apresentaram maior risco de converter para o CCL (OR 2.04, 95\% Cl 1.15-3.64). Resultado semelhante foi encontrado por Lopez et al. (2003). A importância de uma base genética, no entanto, não foi confirmada em estudos com gêmeos, não havendo diferenças significativas entre gêmeos mono e dizigóticos (Caracciolo, Gatz, Xu, Pedersen, \& Fratiglioli, 2012).

A comorbidade com outras doenças também foi largamente analisada nos últimos anos (Caracciolo et al., 2013; Stephan, Brayne, Savva, \& Matthews, 2011). Os estudos sobre o efeito de distúrbios cardiovasculares apresentam resultados inconsistentes: abordagens transversais observaram uma maior probabilidade para CCL frente à presença de acidente vascular encefálico (AVE) e infartos, enquanto metodologias longitudinais prospectivas não confirmaram tais associações. Discrepâncias semelhantes ocorrem também no que se refere à diabetes (Artero et al., 2008; Atti et al., 2010; Luck et al., 2010; Roberts et al., 2008; Solfrizzi et al., 2004; Xu et al., 2010).

Sintomas neuropsiquiátricos também podem se constituir como fatores de risco para o CCL (Petersen et al., 2014). A presença de síndromes depressivas, mais extensamente estudadas, está relacionada a uma maior razão de probabiblidades para o desenvolvimento ulterior de CCL (Barnes, Alexopoulos, Lopez, Williamson, \& Yaffe, 2006; Geda et al., 2006; 
Lopez et al., 2003; Stepaniuk, Ritchie, \& Tuokko, 2008). Apatia, labilidade emocional e rigidez comportamental também foram associadas a maior risco para CCL (Stepaniuk et al., 2008).

\subsubsection{Neuropatologia}

A neuropatologia por trás do CCL é significativamente variada. Em uma revisão sistemática da literatura abrangendo 162 estudos, Stephan et al. (2011) verificaram diversas patologias possíveis em casos de CCL: placas neuríticas, emaranhados neurofibrilares, patologia vascular, déficits neuroquímicos, dano celular, inflamações, estresse oxidativo, alterações mitocondriais, anomalias na atividade genômica, disfunção sináptica e mudanças no metabolismo protéico e na homeostase. Neste grupo de pesquisas, estão incluídas as pesquisas sobre biomarcadores em CCL devido à DA.

Petersen et al. (2014) ressaltam que, pelo fato da categoria clínica do CCL poder abarcar diversas etiologias - como anteriormente apontado -, um único substrato neuropatológico já não seria esperado. Além disso, a constatação de patologias neurodegenerativas, inclusive em idosos saudáves, contribui para a dificuldade em se determinar com precisão uma neuropatologia característica para o CCL (Petersen et al., 2014). Ademais, questões metodológicas, como variações na operacioalização dos critérios diagnósticos - por exemplo, diferentes instrumentos para se detectar declínio cognitivo -, provavelmente interferem nos esforços de padronização da neuropatologia (Petersen et al., 2014).

\subsubsection{Intervenções no CCL}

Segundo as evidências sobre intervenções farmacológicas no CCL, não há no momento medicamentos indicados para o quadro (Petersen et al., 2014). De fato, na última década, diversas pesquisas procuraram identificar substâncias capazes de reduzir a taxa de declínio cognitivo, mas nenhum composto se mostrou clinicamente efetivo (Farina, Isaac, 
Clark, Rusted, \& Tabet, 2012; Lloret, Badía, Mora Pallardó, Alonso, \& Viña, 2009; Petersen et al., 2005; Russ \& Morling, 2012).

Russ e Morling (2012) procuraram verificar possíveis efeitos de inibidores da acetilcolinesterase (donepezil, galantamina e rivastigmina) sobre a cognição em CCL. Foram avaliados nove estudos, com um total de 5149 sujeitos em ensaios clínicos randomizados. Não foram observados efeitos significativos desta classe de medicamentos sobre o desempenho cognitivo dos pacientes. Também não foram constatados efeitos benéficos sobre o processo de conversão do CCL para demência (Russ \& Morling, 2012). Especificamente para o donepezil, Petersen et al. (2005) verificaram resultados semelhantes, não havendo discrepâncias significativas na taxa de conversão do CCL para DA.

Em outra revisão sistemática da literatura, procurou-se investigar possíveis efeitos da vitamina E sobre a progressão de CCL para DA (Farina et al., 2012). Os resultados observados são semelhantes às pesquisas com inibidores de acetil-colinesterase: nos ensaios clínicos randomizados analisados, não foram observadas diferenças nas probabilidades para conversão entre o grupo placebo e o grupo experimental (Farina et al., 2012).

Por outro lado, a literatura aponta para possíveis benefícios que tratamentos não farmacológicos podem ter sobre a cognição de pacientes com CCL (Petersen et al., 2014). Dois grupos de intervenções analisadas envolvem exercícios físicos e treinamento cognitivo (Lautenschlager, Cox, \& Kurz, 2010; Miller, Taler, Davidson, \& Messier, 2012).

Lautenschlager et al. (2010) realizaram revisão não-sistemática da literatura procurando verificar o efeito de programas de exercícios físicos sobre a cognição em pacientes com CCL. Apenas dois ensaios clínicos randomizados foram encontrados, sendo que eles apontaram leve efeito da atividade física ${ }^{6}$ sobre o desempenho cognitivo de

\footnotetext{
${ }^{6}$ No primeiro estudo, a atividade física consistiu de, aproximadamente, 150 minutos de caminhada de moderada intensidade. Na segunda pesquisa, foram realizados treinos aeróbicos de academia, como esteira, bicicleta ergométrica e elíptico (Baker et al., 2010; Lautenschlager et al., 2008).
} 
pacientes com CCL (Lautenschlager et al., 2010). Os autores de tal revisão ressaltaram a preliminaridade desses resultados e a necessidade de mais estudos que possam confirmar a relação de causa e efeito.

Em outras revisões recentes da literatura, foram constatados potenciais benefícios de técnicas de treino cognitivo sobre as funções neuropsicológicas de pacientes com CCL, especificamente em medidas de funcionamento cognitivo global, memória e meta-memória (Gates, Sachdev, Singhl \& Valenzuela, 2008; Simon, Yokomizo, \& Bottino, 2012).

Gates et al. (2011) analisaram 10 estudos, dos quais apenas cinco eram ensaios clínicos randomizados. A maioria dos participantes eram pacientes diagnosticados com CCL-a. As técnicas aplicadas variaram entre treinos computadorizados multimodais e multifunção ${ }^{7}$ e treinos de estratégias de memorização envolvendo escrita e fala, como associação, categorização e visualização. Foram observados tamanhos de efeito de moderados $(0,3$ a 0,5$)$ a grandes $(>0,5)$ em oito pesquisas, relativamente a medidas de memória e cognição geral, com destaque para recordação de histórias escritas. Todavia, foi destacada, no artigo, a relativa escassez de ensaios clínicos randomizados, propondo-se a realização destes como uma prioridade.

Na revisão de Simon et al. (2012), todos os programas de treinamento analisados tiveram como foco pacientes com CCL-a. Desse modo, uma parte sensivelmente grande dos treinos era dedicada à memória episódica, com estratégias compensatórias ou restaurativas: além de categorização e visualização, foram aplicadas técnicas de mapeamento, organização hierárquica e aprendizagem com ou sem erro. Alguns dos estudos, entretanto, focaram também em atenção, linguagem, velocidade de processamento e funções executivas. Segundo os autores, foi possível constatar que pacientes com CCL-a são capazes de aprender satisfatoriamente novas informações e técnicas mnemônicas. Resultados em medidas não padronizadas, relacionadas diretamente com a tarefa ensinada - por exemplo, tempo de reação ou número de palavras lembradas -, mostraram mudanças

\footnotetext{
${ }^{7}$ Buscou-se o treino de habilidades matemáticas, atencionais e de funções executivas, tal como planejamento. No entanto, a memória episódica foi a mais frequentemente exercitada.
} 
signficativas. Já em testes neuropsicológicos padronizados, a melhora foi mais limitada. Ademais, alguns estudos incluíram medidas de ressonância magnética funcional, que revelaram mudanças nos padrões de ativação cerebral e aumento da conectividade entre regiões corticais (Simon et al., 2012).

As revisões bibliográficas sobre treino cognitivo revelam um foco da literatura em funções e habilidades voltadas para a memória episódica. No entanto, como já apontado acima, o CCL é uma categoria diagnóstica heterogênea, tanto na sua etiologia como em seus aspectos clínicos. Nesse sentido, é razoável considerar que uma conceituação mais compreensiva sobre a neuropsicologia deste grupo clínico, estabelecido de maneira relativamente recente na literatura, demanda uma exploração mais ampla, que procure investigar outras funções pouco abordadas, mas de significância clínica tão importante quanto a memória. Deste modo, a presente pesquisa procurou analisar uma função ainda pouco explorada dentro do campo de estudo sobre o CCL. Esta função é a tomada de decisão, cuja literatura é explorada abaixo.

\subsection{Tomada de decisão}

Todos os indivíduos são constantemente demandandos a fazer escolhas. Diversos são os cenários cotidianos que demandam decisões, desde sobre qual seria a melhor rota para o trabalho, passando pelo manejo das finanças pessoais, até a interação do indivíduo com as pessoas ao seu redor. Subsidiando todo este importante espectro da funcionalidade do indivíduo está a função neuropsicológica da tomada de decisão (Gupta, Koscik, Bechara, \& Tranel, 2011; Kim \& Lee, 2011).

Tomada de decisão é defininda na literatura como o processo de escolher uma ação específica, dentro de um rol de alternativas possíveis, que produza o resultado mais benéfico ao sujeito (Gupta, Koscik, Bechara, \& Tranel, 2011; Kim \& Lee, 2011; VandenBos, 2010). Essa função é considerada um processo complexo, no qual convergem diversos 
mecanismos, tanto cognitivos como emocionais, e que pode ser influenciado por aspectos da tarefa em si e do ambiente no qual a tarefa é executada (Finucane \& Lees, 2005).

É largamente aceito na literatura que situações de tomada de decisão podem ser classificadas em dois grupos principais, a saber, decisões sob certeza e decisões sob incerteza (Yates \& Stone, 1992). No primeiro caso, o indivíduo possui conhecimento sobre as consequências que irão advir das opções disponíveis a ele em um dado momento, havendo certeza de que tais consequências irão ocorrer. Já no segundo caso, as potenciais consequências não estão claras, isto é, de uma dada opção podem advir diferentes resultados. Baseando-se em quão explicitamente o sujeito é informado sobre as regras que governam a ocorrência das consequências, este segundo grupo de situações de tomada de decisão é dividido em dois subgrupos: decisões sob ambiguidade e decisões sob risco (Bechara, Damasio, Damasio, \& Anderson, 1994; Brand, Labudda, \& Markowitsch, 2006; Damasio, 1994; Edwards, 1954; Knight, 1921).

\subsubsection{Tomada de decisão sob ambiguidade}

Em situações de tomada de decisão sob ambiguidade, o indivíduo não é informado explicitamente sobre as regras de perdas e ganhos. Deste modo, ele não pode predizer com exatidão qual consequência irá ocorrer nem a probabilidade associada a tal evento, obrigando este sujeito a basear suas escolhas em palpites ou adivinhações e aprender a tomar as decisões da maneira mais vantajosa possível por meio do feedback das contingências, que o informa sobre as consequências negativas e positivas associadas às opções disponíveis no momento (Bechara, 2011; Damasio, 1994).

A hipótese do marcador somático propõe um modelo explicativo para situações de ambiguidade (Bechara \& Damasio, 2005; Damasio, Tranel, \& Damasio, 1991; Damasio, 1994). Seus autores sugerem que, nestes contextos de decisão, o sujeito automaticamente adquire preferências para as situações vantajosas. Este aprendizado dependeria de 
mecanismos neurais complexos que integram reações emocionais somáticas ao feedback esperado para uma determinada opção.

Basicamente, em uma situação de tomada de decisão sob ambiguidade, as primeiras escolhas são realizadas aleatoriamente. Após cada uma dessas escolhas, segue-se um dado feedback (reforço ou punição), que, por sua vez, elicia uma reação somática emocional (por exemplo, mudanças na frequência cardíaca, alterações na condutância da pele e contrações musculares diminutas). Esta reação será, então, associada implicitamente com a alternativa escolhida, dando origem ao marcador somático. Futuramente, quando o sujeito tiver que novamente selecionar entre as opções disponíveis, este marcador atuará enviesando seu comportamento, como uma reação antecipatória, aumentando a probabilidade de manter uma dada escolha - caso o marcador seja positivo - ou dirigir-se a outra opção - caso seja negativo.

Diversas estruturas cerebrais subsidiariam este processo de aprendizado. Segundo Bechara e Damasio (2005), a amígdala é responsável por eliciar a reação somática. Após passarem para o corpo através do tronco cerebral, os córtices sensoriais processam a resposta somática e as informações ambientais concernentes aos ganhos ou perdas. Esses diferentes processamentos então convergem para uma região fundamental para o processo de tomada de decisão sob ambiguidade: o córtex ventromedial (CPFvm). É nele que o marcador somático seria criado e ligado à escolha realizada. Sua elaboração se daria pela combinação da reação emocional eliciada pela consequência da opção escolhida com a informação perceptual sobre tal escolha. O córtex pré-frontal dorsolateral (CPFDL) seria responsável por armazenar as representações dos comportamentos emitidos, ao passo que outras regiões seriam essenciais para o processamento das respostas somáticas antecipatórias, como o córtex insular, a área tegmental ventral e o corpo estriado (Bechara \& Damasio, 2005; Carter \& Pasqualini, 2004; Clark et al., 2008; Gupta et al., 2011; Shiv, Loewenstein, \& Bechara, 2005; Verdejo-García, Pérez-García, \& Bechara, 2006). 
O teste mais utilizado na literatura para investigar os processos de tomada de decisão sob ambiguidade é o lowa Gambling Task (IGT) (Bechara, 2007; Bechara et al, 1994; Bechara, Tranel, \& Damasio, 2000). O IGT consiste em uma situação na qual o participante não é informado sobre as regras de ganhos e perdas, suas quantidades e as probabilidades de ocorrência a elas associadas. O sujeito deve escolher, em 100 tentativas, retirar uma carta de quatro baralhos disponíveis. Após cada escolha, dá-se um feedback sobre o resultado obtido. Aparentemente, ganhos e perdas ocorrem de maneira randômica, o que impossibilita a detecção das probabilidades agregadas a cada um dos quatro baralhos. No entanto, dois baralhos são denominados "vantajosos" (ou "seguros") e os outros dois, "desvantajosos" (ou "arriscados"). Os primeiros fornecem mais frequentemente ganhos pequenos e perdas levemente menores. Os desvantajosos, por outro lado, proveem ganhos expressivos, mas, algumas vezes, perdas significativas que podem ser, inclusive, maiores que os ganhos acumulados. Logo, optar continuamente pelos baralhos vantajosos acarreta, no fim da tarefa, lucro para o sujeito, enquanto concentrar-se nos baralhos desvantajosos resulta em prejuízo (Bechara, 2007; Bechara et al, 1994; Bechara et al., 2000).

Diversos estudos que utilizaram o IGT mostraram que pacientes com lesões na amígdala ou nas porções ventromediais do lobo pré-frontal, ainda que tenham as demais funções cognitivas intactas, falham na tarefa de construir uma estratégia vantajosa de tomada de decisão. Comparações com controles mostraram que, além de déficits em tomada de decisão, estes pacientes apresentam respostas somáticas reduzidas (medidas por meio da resposta de condutância da pele) (Bechara, Damasio, Tranel, \& Damasio,1997; Carter \& Pasqualini, 2004; Crone, Somsen, Van Beek, \& Van der Molen, 2004; Suzuki, Hirota, Takasawa, \& Shigemasu, 2003). Estudos subsequentes com diferentes condições psiquiátricas (por exemplo, depressão, esquizofrenia e transtorno do déficit de atenção e hiperatividade) também revelaram déficits em tomada de decisão, provavelmente decorrentes das alterações emocionais características desses quadros clínicos (Haalland, 
Landrø, Kano, Ito, \& Fukudo, 2007; Must et al., 2006; Smoski Lynch, Rosenthal, Cheavens, Chapman, \& Krishnan, 2008).

Em demência, apenas duas pesquisas sobre tomada de decisão sob ambiguidade foram realizadas, utilizando o IGT com um grupo de pacientes com DA (Márquez \& Bailén, 2012; Sinz, Zamarian, Benke, Wenning, \& Delazer, 2008). Na primeira delas, foi comparado o desempenho de idosos saudáveis ao de idosos com DA moderada. Os participantes com DA tomaram decisões mais desvantajosas do que os participantes saudáveis, além de oscilarem mais frequentemente entre os dois tipos de baralhos ("arriscados" e "seguros"). Esses resultados evidenciam, segundo o estudo, falta de desenvolvimento de estratégias mais seguras ao longo da aplicação do teste (Sinz et al., 2008). De maneira semelhante, Màrquez e Bailén (2012) compararam as respostas de idosos saudáveis e idosos diagnosticados com DA no IGT. Foram obtidos resultados parecidos com aqueles do estudo anterior: idosos com DA demonstraram um padrão randômico de tomada de decisão, sem a criação de estratégias específicas para a obtenção de ganhos (Màrquez \& Bailén, 2012).

\subsubsection{Tomada de decisão sob risco}

Em situações de tomada de decisão sob risco, o contexto provê informação explícita sobre as contingências em ação. Este conhecimento explícito se refere tanto às possíveis consequências associadas a diferentes opções como à probabilidade de que estas consequências aconteçam de fato (Brand et al., 2006; Epstein \& Wang, 1994).

Brand et al. (2006) postularam um modelo explicativo sobre os processos subjacentes a este tipo de tomada de decisão (Figura 4). Segundo tal modelo, há uma dependência copiosa entre tomada de decisão sob risco e funções executivas. Isto porque o sujeito, para responder de maneira vantajosa, deve (1) perceber, organizar e integrar as diversas informações fornecidas pela tarefa, (2) compará-las a memórias de longo prazo referentes a situações de decisão semelhantes e a alguma noção sobre probabilidades e (3) escolher uma conduta. Todas estas etapas dependem de funções executivas como 
abstração, categorização e flexibilidade cognitiva. A memória operacional também possui papel preponderante, sendo responsável por (A) manter representações, em tempo real, sobre a situação de tomada de decisão, tais como estratégias utilizadas, escolhas anteriores e seus respectivos resultados, e por (B) resgatar informações sobre situações semelhantes no passsado. À opção escolhida, segue-se um reforço ou punição, o que elicia uma resposta somática emocional, criando, de maneira semelhante ao modelo anterior, um marcador somático (Brand et al., 2006).

Além da resposta emocional, Brand et al. (2006) sugeriram que o feedback é também aplicado ao plano cognitivo, integrando-se à memória de longo prazo. Esta informação adicionada poderá auxiliar na melhor compreensão das regras, na checagem dos resultados de uma dada estratégia de decisão e, se necessário, na correção desta tática.

Percebe-se que existem duas rotas possíveis para que uma dada decisão seja realizada, a saber, uma cognitiva e outra emocional. O modelo propõe que a melhor maneira de se levar decisões vantajosas a cabo seria a partir da integração das duas rotas, ainda que seja possível tomar decisões de maneira puramente cognitiva (Brand, Recknor, Grabenhorst, \& Bechara, 2007; Brand, 2008; Brand, Laier, Pawlikowski, \& Markowitsch, 2009; Brand et al., 2009). Vale lembrar que, apesar de compreensivo, o modelo de Brand et al. (2006) ainda não conseguiu apontar sistematicamente o papel que cada uma das funções executivas, isoladamente, teria nos diferentes domínios de uma situação de tomada de decisão sob risco, tais como apreciação do contexto ou desenvolvimento e aplicação das estratégias desenvolvidas. 


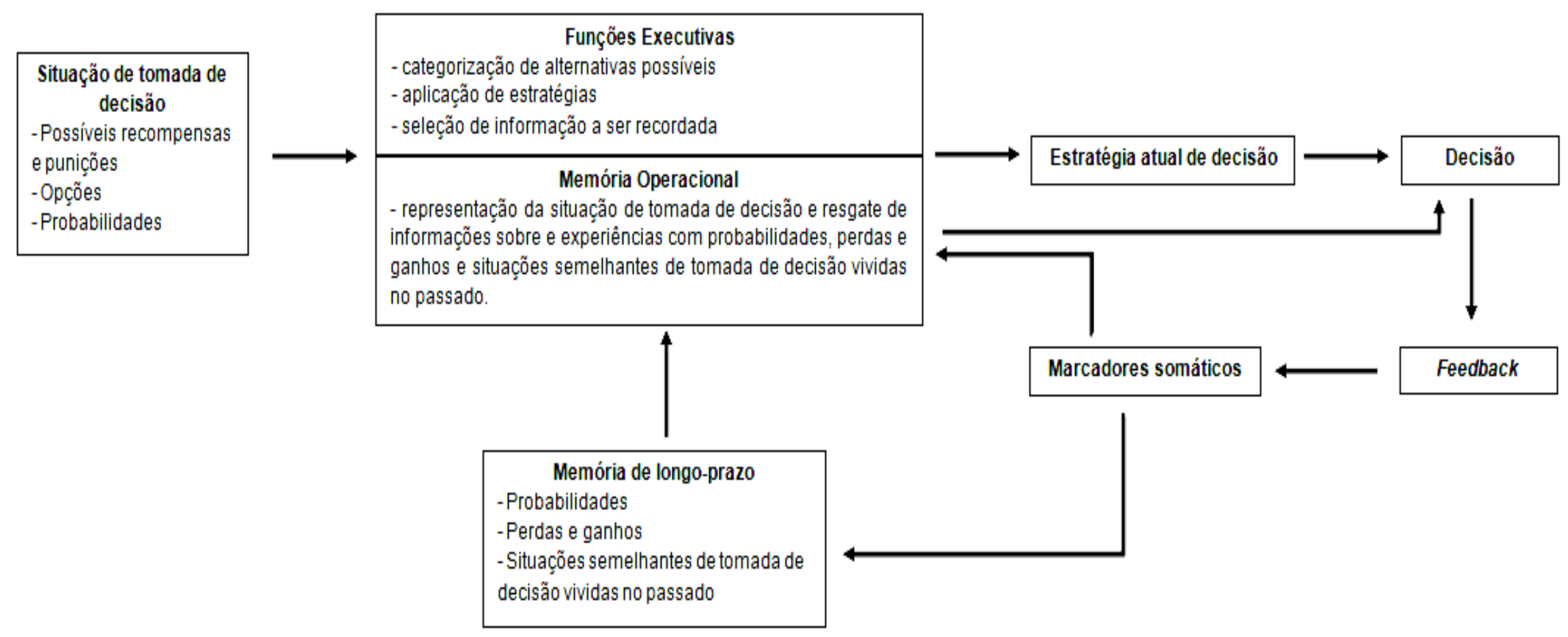

Figura 4: esquematização dos processos que subsidiam a tomada de decisão sob risco, como exposto por Brand et al. (2006). As funções executivas e a memória operacional são responsáveis pela manipulação da informação ao longo de todo o processo de tomada de decisão, tanto aquelas referentes ao contexto no momento como as que dizem respeito à experiência do indivíduo com situações semelhantes no passado. Após as consequências das escolhas terem sido percebidas, por meio do feebback, marcadores somáticos são formados, não só se integrando à memória de longo prazo mas também enviesando os processos executivos e de memória operacional que irão subsidiar novas escolhas. Adaptado de Brand, M., Labudda, K., \& Markowitsch, H. J. (2006). Neuropsychological correlates of decision-making in ambiguous and risky situations. Neural Networks, 19, $1266-1276$. doi:10.1016/j.neunet.2006.03.001. 
A partir do modelo teórico acima proposto, pode-se inferir que diversas regiões cerebrais estariam envolvidas na tomada de decisão sob risco. O CPFDL e a porção anterior do giro cingulado são estruturas normalmente associadas a funções executivas, como planejamento, categorização e flexibilidade cognitiva (Bear, Connors, \& Paradiso, 2008; Kandel, Schwartz, \& Jessell, 2012; Leber, Turk-Browne, \& Chun, 2008). Pela presença de marcadores somáticos, também é razoável assumir que o CPFvm participaria do processamento, da mesma forma que outras estruturas relacionadas ao processamento emocional, como a amígdala (Gupta et al., 2011; LeDoux, 2007; Salzman \& Fusi, 2010).

A literatura aponta três testes como sendo os instrumentos mais utilizados para se estudar a tomada de decisão sob risco: o Cambridge Gambling Task (CGT), o Game of Dice Task (GDT) e o Probability-Associated Gambling task (PAG) (Brand, Fujiwara, Borsutzky, Kalbe, Kessler \& Markowitsch, 2005; Cambridge Cognition, 2005; Sinz, et al., 2008; Zamarian, Sinz, Bonatti, Gamboz \& Delazer, 2008).

No CGT, são apresentadas caixas vermelhas e azuis cuja proporção varia entre as tentativas. Os participantes devem adivinhar em qual caixa, vermelha ou azul, estará uma recompensa. Após esta escolha, o sujeito decide qual proporção de seus pontos deve apostar nesta sua suposição. Para tanto, uma caixa é apresentada com uma quantia que aumenta a cada cinco segundos. Desse modo, o participante pode escolher a quantia presente ou esperar por uma quantia maior. Um outro conjunto de rodadas apresenta as quantias de modo inverso, isto é, com um valor que diminui com o passar do tempo (Cambridge Cognition, 2005).

O GDT, por sua vez, consiste em um jogo no qual o participante aposta em números que aparecem em um dado virtual (Brand et al, 2005). O sujeito deve adivinhar, ao longo de 18 tentativas, qual número irá aparecer no lançamento do dado, apostando, nesta suposição, uma determinada proporção de pontos a ele fornecidos no começo do jogo. Neste contexto, o participante pode apostar em apenas um número ou em combinações numéricas, que variam de dois até quatro números. A proporção apostada é menor em combinações maiores, e máxima quando se aposta em apenas um número. Se o indivíduo 
perde, a quantia apostada é subtraída do montante total; se ele ganha, ela é somada. Todas essas regras são explicadas ao sujeito antes do teste começar. O que não é colocado explicitamente são os riscos inerentes a cada modo de aposta: apostar em um número ou em uma combinação binária tem alto risco (possibilidade de $34 \%$ de ganho) enquanto apostas em combinações de três ou quatro números são bem seguras (probabilidade de ganho igual ou superior a 50\%) (Brand et al. 2005).

Por último, no PAG, instrui-se o participante a imaginar que ele está em um jogo cujo objetivo é ganhar o máximo de dinheiro que conseguir. Em todas as tentativas, o indivíduo deve escolher entre uma opção fixa, com ganho ou perda de 20 ou 40 pontos (denominada "soma fixa"), e uma opção de aposta, na qual, se houver ganho, ele será maior que a opção anterior (100 pontos). Na aposta, a chance de vitória é sinalizada pela relação numérica entre quadrados vermelhos e azuis. Se, no sorteio, um quadrado vermelho é selecionado, o participante ganha a aposta; ao contrário, se um quadrado azul é selecionado, perde-se a quantia apostada. Desse modo, uma aposta é arriscada se há uma proporção maior de quadrados azuis. Se a proporção é inversa, a aposta é vantajosa. Rodadas com uma baixa probabilidade de ganho nas apostas e, inversamente, com uma alta probabilidade, são apresentadas de forma pseudorrandômica, sendo combinadas tanto com "somas fixas" negativas (-20 pontos ou -40 pontos) como positivas ( +20 pontos ou +40 pontos). Rodadas que combinam uma baixa probabilidade de ganho na aposta com uma "soma fixa" de -40 pontos são denominadas "incongruentes", pois é vantajoso apostar, ainda que a probabilidade de ganhar seja pequena. Por sua vez, rodadas na quais há uma alta chance de ganho na aposta e uma "soma fixa" de +40 pontos também são "incongruentes", já que é proveitoso optar pela "soma fixa", conquanto a aposta tenha possibilidades altas de ganho. As demais combinações são chamadas de "congruentes". O participante é instruído a responder o mais rápido possível, sendo dado um limite de tempo de 10 segundos (Sinz et al., 2008; Zamarian, Weiss, \& Delazer, 2010).

Todos os três testes, CGT, GDT e PAG, foram extensamente aplicados em diversas pesquisas, e auxiliaram na formulação e fortalecimento do modelo de Brand et al. (2006). 
Em estudos clínicos, revelou-se que pacientes com déficits executivos também apresentaram dificuldades em estabelecer estratégias vantajosas em tarefas de tomada de decisão sob risco (Brand et al., 2005; Brand et al., 2004; Brand et al., 2004). Outras pesquisas procuraram testar possíveis preditores do desempenho nesses testes, tais como fatores de personalidade e capacidade para estabelecer pensamento lógico (Bayard, Raffard, \& Gely-Nargeot, 2011; Brand \& Altstötter-Gleich, 2008; Brand, Laier, Pawlikowski, \& Markowitsch, 2009; Kim \& Lee, 2011; Schiebener, Zamarian, Delazer, \& Brand, 2011).

Estudos clínicos em pacientes com demência - DA e DFT - foram mais numerosos no campo da tomada de decisão sob risco do que no da tomada de decisão sob ambiguidade (Delazer, Sinz, Zamarian, \& Benke, 2007; Rahman et al., 2005; Rahman, Sahakian, Hodges, Rogers, \& Robbins, 1999; Sinz et al., 2008). Delazer et al. (2007), por exemplo, aplicaram o GDT a controles e a idosos diagnosticados com DA. Em comparação com os controles, os idosos com DA oscilaram mais frequentemente entre as opções mais seguras e as mais arriscadas, demonstrando um padrão de respostas menos consistente. Segundo os autores, esse padrão sinaliza que as decisões no grupo de DA foram tomadas de maneira aleatória, sem o desenvolvimento de uma estratégia vantajosa (Delazer et al., 2007). Em pesquisa descrita anteriormente (Sinz et al., 2008), além do IGT, pacientes com DA realizaram também o PAG. Tais indivíduos desenvolveram estratégias mais inseguras no PAG, apostando mais frequentemente nas ocasiões mais arriscadas, e menos naquelas em que havia uma maior probabilidade de ganho (Sinz, et al., 2008).

No campo da tomada de decisão sob risco em DFT, foram realizadas duas pesquisas. Na primeira delas (Rahman et al., 1999), aplicou-se o CGT em oito pacientes com DFT, comparando-se seus desempenhos aos de controles pareados por nível intelectual. Os idosos com DFT demonstraram comportamento arriscado, com maiores impulsividade e tempo de deliberação. Ao mesmo tempo, estes mesmos indivíduos não exibiram déficits executivos nos outros testes aplicados. O outro estudo (Rahaman et al., 2005), mais recente, investigou se a ritalina poderia melhorar o desempenho de pacientes com DFT na mesma tarefa anteriormente aplicada. De fato, o medicamento teve efeito 
positivo sobre os escores do CGT nos sujeitos experimentais, com decisões comparativamente menos arriscadas. No entanto, a droga não foi capaz de melhorar os resultados em outras funções, como memória operacional, aprendizagem reversa e flexibilidade cognitiva.

\subsubsection{Tomada de decisão e envelhecimento}

Dentro do campo sobre tomada de decisão, o tema do envelhecimento vem sendo explorado com frequência, ainda que de maneira relativamente incipiente ao se comparar com as análises sobre as demais funções neuropsicológicas. Os estudos descritos abaixo foram divididos de acordo com o tipo de tomada de decisão avaliada, isto é, tomada de decisão sob ambiguidade e tomada de decisão sob risco.

MacPherson, Phillips e Della Sala (2002) procuraram investigar possíveis diferenças na tomada de decisão sob ambiguidade em três faixas etárias nas quais se inseriram os participantes: 20 a 38 anos (jovens), 40 a 59 anos (meia-idade) e 61 a 80 anos (idosos). Não foi observada nenhuma diferença significativa entre os três grupos nos escores do IGT. Por outro lado, foram encontradas diferenças relacionadas à idade em tarefas subsidiadas principalmente pelo CPFDL, como no Teste Wisconsin de Classificação de Cartas (erros totais, erros perseverativos, respostas perseverativas, com escores crescentes conforme a idade e respostas de nível conceitual, que foram menores em faixas etárias mais velhas) (McPherson et. al, 2002). Tais achados, segundo os autores, sugerem que não há um declínio geral no lobo frontal, mas sim específico para o CPFDL, ao passo que o CPFvm permanece relativamente preservado.

Lamar e Resnick (2004), em estudo semelhante, também verificaram diferenças entre CPFDL e CPFvm, mas em apenas duas faixas etárias. Análises inferenciais detectaram diferenças significativas entre idosos e sujeitos mais jovens nas tarefas envolvendo as regiões CPFDL e CPFvm, com tamanhos de efeito maiores no segundo grupo de sujeitos. Vale notar, todavia, que, das três tarefas envolvendo o CPFvm, foi observado efeito de grupo em duas delas: delayed match to sample e delayed nonmatch to 
sample. Enquanto isso, não houve discrepâncias significativas referentes ao desempenho no IGT (Lamar \& Resnick, 2004). Conforme sugerido no artigo, tais resultados se devem a diferenças nas demandas. Em comparação ao IGT, os outros dois testes demandam respostas mais restritas, o que levaria a mais erros por parte dos idosos. Além disso, o IGT apresenta feedback imediatamente após cada resposta, o que pode ter auxiliado no desempenho dos participantes (Lamar \& Resnick, 2004).

Em uma análise mais complexa, Wood, Busemeyer, Koling, Cox e Davis (2005) investigaram não apenas diferenças na concentração de apostas em baralhos seguros e arriscados, mas também entre os perfis de tomada de decisão. Ambos os grupos realizaram o IGT de maneira igualmente adequada. Usando o modelo de expectativa-valência de Busemeyer e Stout (2002), os autores mostraram que o desempenho de indivíduos idosos foi caracterizado por valoração igualitária de perdas e ganhos ao longo do teste. Segundo os autores, tal postura proporcionou uma maximização dos ganhos, quando comparados aos sujeitos mais jovens. No entanto, o benefício dessa postura se manteve apenas a curto prazo, isto é, a maximização dos ganhos estava condicionada a ganhos recentes. Os jovens, por outro lado, ainda que com vieses negativos para perdas, puderam adaptar sua postura ao longo do teste, beneficiando-se de memória e aprendizado mais preservados (Wood et al., 2005).

Na pesquisa de Denburg et al. (2007), foi investigado o desempenho de 80 sujeitos no IGT. Esta amostra total foi dividida em duas faixas etárias, a saber, de 26 a 55 anos (“Jovens") e de 56 a 85 anos (“Idosos"). O desempenho dos "Idosos" apresentou prejuízo em comparação com a performance dos "Jovens". Todavia, os autores verificaram a existência de dois subgrupos em "Idosos", compostos por sujeitos com desempenhos semelhantes aos dos mais jovens e indivíduos com déficits em tomada de decisão. Estes últimos, além de apresentarem prejuízos no IGT, também foram mais propensos a serem iludidos por propagandas enganosas, quando comparados com seus pares de faixa etária semelhante (Denburg et al., 2007). 
Por último, Zamarian et al. (2008), de maneira semelhante às demais pesquisas, investigaram diferenças entre os denominados pelos autores como "jovens" (18 a 54 anos) e como "idosos" (55 a 88 anos) no IGT. Apesar dos sujeitos no segundo grupo terem conseguido desenvolver estratégias de ganhos vantajosas ao longo do teste, eles concentraram, no geral, mais respostas em baralhos desvantajosos quando sua performance foi comparada com a do grupo dos jovens. Além disso, houve maior oscilação entre alternativas vantajosas e desvantajosas. Tal diferença, de acordo com os pesquisadores, provavelmente se deveu a um leve déficit executivo e de memória operacional por parte dos idosos, constatado por testes normatizados (Zamarian et al., 2008).

Ainda que não explicitado pela teoria do marcador somático, a proposta de Zamarian et al. (2008) denota que as demais funções executivas possuem certo impacto em condições de tomada de decisão sob ambiguidade. Brand et al. (2009) verificaram correlações significativas entre os escores do Wisconsin e os blocos finais do IGT, em oposição à ausência de correlações entre aqueles escores e os blocos iniciais. À luz desses achados, os autores propuseram que os blocos iniciais do IGT seriam responsáveis por mensurar a tomada de decisão sob ambiguidade, já que o avaliando não tem conhecimento das regras que estão em ação. No entanto, após diversas tentativas, as regras são aprendidas e tornadas explícitas pelo sujeito, o que tornaria a parte final do IGT uma medida da tomada de decisão sob risco. Esta proposta vai ao encontro do que foi colocado por Zamarian et al. (2008).

No que se refere à tomada de decisão sob risco em idosos, quatro estudos foram realizados até o momento, com testes distintos cada um (Brand \& Schiebener, 2013; Deaking, Aitken, Robbins, \& Sahakian, 2004; Dror, Katona, \& Mungur, 1998; Zamarian et al., 2008). Diferentes paradigmas, covariáveis e técnicas estatísticas foram considerados, com diversos resultados obtidos, como apresentado a seguir.

Dror et al. (1998) investigaram possíveis diferenças entre jovens e idosos em uma tarefa semelhante ao jogo blackjack ("vinte-e-um"). Nesse teste, diversas combinações de 
cartas eram apresentadas, uma de cada vez, com diferentes níveis de risco. Pedia-se ao sujeito que escolhesse entre adicionar uma carta à combinação apresentada ou não adicionar. Ambos os grupos tiveram desempenhos semelhantes, ajustando adequadamente suas estratégias conforme o risco de cada combinação.

Ulteriormente, Deakin et al. (2004) avaliaram o desempenho de idosos no CGT. Quando comparados com indivíduos mais jovens, idosos apresentaram maior tempo de deliberação, menor porcentagem média de apostas e menor ajuste de risco, isto é, apostaram quantias semelhantes em situações com diferentes probabilidades de ganho. Além disso, a maior idade foi também associada à menor probabilidade do sujeito escolher a opção mais otimizada, ou seja, a mais provável de ganho (na cor mais numerosa em uma dada tentativa) (Deakin et al., 2004).

Zamarian et al. (2008) aplicaram também o PAG, adicionalmente ao IGT. Inversamente aos resultados no IGT, a performance dos sujeitos no grupo "idosos" foi semelhante àquela do grupo "jovens", demonstrando habilidade por parte dos "idosos" em tomar decisões quando informações sobre as probabilidades de perdas e ganhos está explícita, o que não ocorre no IGT (Zamarian et al., 2008).

Em pesquisa mais recente, Brand e Schiebner (2013) utilizaram o GDT em sua investigação. Foi composta uma amostra de 538 sujeitos com idades entre 18 e 80 anos. Foram aplicados também testes de função executiva (Modified Card Sorting Test) e de pensamento lógico (subteste de raciocínio lógico da bateria alemã Leistungsprüfsystem). A análise de regressão hierárquica implementanda demonstrou interação significativa entre idade e funções executivas e entre idade e pensamento lógico. A partir do modelo resultante, os autores puderam constatar que idosos com boa capacidade executiva e lógica conseguiram realizar o GDT adequadamente, enquanto idosos com déficit nos testes de execução e de lógica demonstraram estratégias mais arriscadas (Brand \& Schiebener, 2013).

Os diferentes estudos acima apontados permitem considerar a possibilidade de haver efeitos do envelhecimento em tomada decisão, tanto em situações ambíguas quanto 
em contextos sob risco. No entanto, é prudente considerar em análises futuras que as diferenças entre as faixas etárias podem ser significativamente influenciadas pelo estado de preservação das funções executivas dos idosos, como sugerido por Zamarian et al. (2008) para o IGT e demonstrado por Brand e Schiebener (2013) em relação ao GDT. Especificamente para contextos de tomada de decisão sob risco, possíveis diferenças entre as demandas das diversas tarefas aplicadas também devem ser levadas em conta.

\subsubsection{Tomada de decisão e CCL}

Visando à localização de estudos sobre o tema da tomada de decisão em CCL, foi realizada uma revisão bibliográfica buscando-se artigos nas bases de dados Scielo, BVSPsi, Psyclnfo, Web of Science e Google Scholar. Os termos utilizados foram "comprometimento cognitivo leve", "CCL", "mild cognitive impairment", "MCl", "Tomada de decisão", "decision-making", "lowa Gambling Task", "Cambridge Gambling Task", "Probability-Associated Gambling task" e "Game of dice task".

A partir da revisão, concluiu-se que o tema sobre tomada de decisão em CCL é pouco abordado dentro da literatura, tendo sido encontrados apenas três artigos dedicados a esse assunto, sendo que dois utilizaram os testes tradicionais acima descritos (Brandt, Aretouli et al., 2009; Zamarian et al., 2010) e o terceiro abordou a tomada de decisão de uma maneira mais próxima a decisões reais, pelo uso de um instrumento formado por situações médicas hipotéticas nas quais o participante deveria tomar decisões sobre sua própria saúde (Griffith et al., 2010).

Brandt et al. (2009) procuraram analisar o perfil executivo dos subtipos de CCL a partir da aplicação de 18 testes de funções executivas (entre elas, a tomada de decisão, representada pelo IGT) em pacientes de todos os subgrupos. Por meio do método de análise de componentes principais, agruparam-se os resultados de todos os testes aplicados. Tal procedimento resultou em três componentes (ou fatores), denominados pelos autores de "planejamento/resolução de problemas", "memória operacional" e "julgamento" 
(componente este do qual fez parte o IGT, juntamente com medidas experimentais de julgamento).

Os resultados apresentados por Brandt et al. (2009) mostraram que não houve diferenças estatisticamente significativas entre o grupo de pacientes com CCL e o grupo controle. Os autores, no entanto, apontaram uma limitação de seu estudo, que interfere na interpretação desses resultados: o alfa de Cronbach - aplicado pelos autores para medir a confiabilidade dos escores de cada um dos componentes - dos dois primeiros fatores foi substancial. No entanto, o de "julgamento" se apresentou baixo, o que limita a interpretabilidade dos resultados a partir desse componente (Brandt et al., 2009).

Zamarian et al. (2010), por sua vez, compararam o desempenho de pacientes com CCL e controles em dois testes de tomada de decisão: o IGT e o PAG. O intuito do estudo ao aplicar os dois testes foi verificar como os pacientes com CCL lidam com duas situações de tomada de decisão, uma envolvendo ambiguidade, representada pelo IGT, e outra envolvendo riscos, composta pelo PAG.

No IGT, os controles desenvolveram uma estratégia de ganhos vantajosa ao longo da sessão de testagem. Os pacientes com CCL, no entanto, apresentaram um padrão aleatório de respostas, mostrando dificuldade de aprendizagem a partir do feedback do teste. Os autores, no entanto, destacam que tal padrão de respostas difere dos pacientes com danos ventro-mediais, já que estes concentram suas respostas consistentemente em opções mais arriscadas. No PAG, por sua vez, os controles conseguiram decidir favoravelmente tanto em situações incongruentes como em situações congruentes, adaptando suas respostas para os diversos cenários de acordo com as informações disponíveis, isto é, probabilidade de ganho na aposta juntamente com a característica da "soma fixa". Já os pacientes com CCL mostraram modelos de tomada de decisão mais desvantajosos, em comparação com os controles. Tais modelos sugerem que suas decisões foram baseadas apenas nas probabilidades de ganho nas apostas, ignorando as mudanças nas condições de "soma fixa" (Zamarian et al., 2010). 
Por último, Griffith et al. (2010) abordaram o tema da tomada de decisão em CCL por um viés mais estrito. Os autores tiveram como objetivo avaliar possíveis correlações entre alterações do metabolismo cerebral - obtidas por meio de espectroscopia por ressonância magnética - e o desempenho em um instrumento utilizado para avaliar a capacidade de decisão sobre participar de tratamentos médicos. Tal instrumento, denominado Instrumento de Capacidade para Consentir a Tratamento (CCTI, na sigla em inglês), avalia decisões por meio do relato de dois cenários hipotéticos: (1) decisões sobre o tratamento para uma neoplasia cerebral recentemente descoberta e (2) decisões sobre o tratamento para um bloqueio de artéria coronária, também recentemente diagnosticado. As respostas do paciente para cada uma das situações são, então, classificadas de acordo com cinco parâmetros de consentimento: expressar uma escolha de tratamento, realizar uma escolha razoável de tratamento, compreender as consequências dessa escolha, fornecer razões racionais para essa escolha e entender as opções de tratamento. Cada parâmetro recebe uma pontuação de acordo com a qualidade da resposta (Griffith et al., 2010).

Em comparação com o grupo controle, os pacientes com CCL tiveram desempenhos prejudicados no parâmetro "entender as opções de tratamento" e "realizar uma escolha razoável de tratamento", enquanto, nos aspectos "compreender as consequências" e "expressar uma escolha", não foram observados déficits (Griffith et al., 2010). As correlações entre os escores do CCTI e os resultados de neuroimagem, realizadas apenas com o grupo com CCL, mostraram-se positivas com relação ao parâmetro "realizar escolha razoável de tratamento". A área cerebral analisada pelo estudo foi a região posterior do giro cingulado, área normalmente associada a atividades de vida diária mais complexas (Griffith et al., 2010).

É válido ter cautela ao considerar este último estudo. Isso porque o instrumento utilizado para se mensurar a tomada de decisão estabelece como contexto decisões sobre a própria saúde. Este tema específico possui fortes implicações emocionais, principalmente para sujeitos idosos, cuja saúde é constantemente questionada. Este fator emocional associado a preocupações com a saúde possivelmente ocasiona um significativo viés na 
tomada de decisão, quando comparados com os testes mais experimentais utilizados nos outros dois artigos.

O reduzido número de estudos dedicados a analisar a tomada de decisão no CCL não permite derivar conclusões mais sólidas sobre como tal função neuropsicológica se apresenta nessa condição. Além disso, Brandt et al. (2009) e Zamarian et al. (2010) utilizam instrumentos neuropsicológicos experimentais, enquanto Griffth et al. (2010) aplicaram um questionário, diferença esta que dificulta a comparação dos resultados, visto que os parâmetros analisados são divergentes entre si. Isso representa um déficit importante da literatura em abranger um tópico clínico significativo. 


\section{Justificativa e objetivo}

\subsection{Justificativa}

A partir do exposto, compreende-se que a população idosa mantém uma tendência de aumento significativo para os próximos anos, havendo, concomitantemente, um incremento na incidência de doenças relacionadas ao envelhecimento. Dentre elas, destacam-se os quadros demenciais. Estudos sobre a interação entre RC e demência ressaltam que intervenções anteriores ao diagnóstico podem ter efeito clínico significativo, de modo que tratamentos mais bem direcionados podem ser proporcionados por um conhecimento mais compreensivo sobre quadros possivelmente prodrômicos aos diversos tipos de demência, tal como o CCL.

$\mathrm{Na}$ literatura sobre o CCL, há um foco predominante na análise de funções mnésticas, sendo baixo o número absoluto de pesquisas voltadas ao tema da tomada de decisão. Tendo em vista sua grande importância no subsídio a um amplo espectro da funcionalidade do ser humano, entende-se a necessidade da realização de mais estudos sobre a função da tomada de decisão em pacientes diagnosticados com CCL. Um maior conhecimento sobre a neuropsicologia deste quadro pode contribuir para a literatura sobre demência e envelhecimento, possibilitando um melhor direcionamento de intervenções precoces e, em última instância, uma base mais sólida para a atenção à saúde da crescente população idosa.

\subsection{Objetivo}

O presente estudo tem por objetivo geral avaliar a tomada de decisão sob risco em idosos com CCL quando comparados a idosos saudáveis.

Com base nos dados da literatura referentes à tomada de decisão e ao quadro do CCL, levanta-se a hipótese de que haja possíveis déficits em uma ou mais facetas da tomada de decisão sob risco em pacientes diagnosticados com a condição. Isso porque tal 
função pode sofrer influência de diversas outros domínios neuropsicológicos, domínios estes que podem estar prejudicados no quadro de CCL. Destaca-se, nesse sentido, especial influência das funções executivas, grupo do qual a tomada de decisão é componente. 


\section{Materiais e métodos}

\subsection{Participantes}

A presente pesquisa constitui-se como um estudo observacional transversal. Incluiuse um grupo experimental de idosos diagnosticados com Comprometimento Cognitivo Leve e um grupo controle composto por idosos sem indícios de CCL. As diretrizes diagnósticas utilizadas correspondem às de Albert, DeKosky, Dickson, Dubois, Feldman, Fox e colaboradores (2011).

Os pacientes foram provenientes do Laboratório de Neurociências LIM-27 do Instituto de Psiquiatria do Hospital das Clínicas da Faculdade de Medicina da Universidade de São Paulo (IPqHC-FMUSP). Para o estabelecimento do diagnóstico, cada paciente passa por cinco estágios de atendimento, compreendidos por (1) consulta clínica com queixa cognitiva corroborada por familiar, (2) exame clínico e testagem cognitiva com os instrumentos MiniExame do Estado Mental, Fluência Verbal Animais e Teste do Desenho do Relógio, (3) avaliação neuropsicológica e funcional, (4) exames laboratorias e de ressonância e, por fim, (5) reunião de consenso multiprofissional para fechamento do diagnóstico. A fim de homogeinezar a amostra, foram considerados apenas pacientes com CCL amnéstico, seja de único ou de múltiplos domínos.

Os critérios de inclusão para os dois grupos foram:

- Diagnóstico de CCL amnéstico de múltiplos domínios ou de CCL amnéstico de único domínio;

- Idade maior ou igual a 60 anos;

- Escore mínimo de 20 (para idosos não escolarizados) a 24 (para idosos não escolarizados) no Mini-Exame do Estado Mental (MEEM), para a exclusão de possíveis casos de demência.

Os critérios de exclusão, por sua vez, consistiram de:

- Presença de déficits sensoriais que pudessem prejudicar a execução dos testes; 
- Presença de comorbidades psiquiátricas e neurológicas, que pudessem enviesar os resultados;

- Analfabetismo.

\subsection{Materiais}

Foram utilizados, na presente pesquisa, os seguintes instrumentos:

a) Mini-Exame do Estado Mental (MEEM) (Brucki, Nitrini, Caramelli, Bertolucci \& Okamoto, 2003; Folstein, Folstein \& McHugh, 1975): exame, adaptado e padronizado para o Brasil, que serve de rastreio para a presença de demência. Constitui-se de questões e testes agrupados em sete categorias: orientação no tempo; orientação espacial; registro de três palavras; atenção e cálculo; recordação das três palavras; linguagem; e capacidade construtiva visual. Dá-se um ponto para cada resposta correta em cada item. O escore final é dado pela somatória dos pontos, podendo-se chegar ao máximo de 30 pontos. De acordo com Brucki et al. (2003), adotou-se um ponto de corte de 20 para idosos não escolarizados e de 24 para idosos escolarizados.

b) Cambridge Gambling Task: teste que faz parte da bateria neuropsicológica computadorizada Cambridge Neuropsychological Test Automated Battery (CANTABeclipse versão 3.0) (Cambridge Cognition, 2005), que consiste de um software composto por 22 testes utilizados para avaliação neuropsicológica, incluindo medidas de atenção, funções executivas, memória e tomada de decisão. Nenhum dos testes da bateria foi normatizado para a população brasileira. Para registro das respostas, a bateria inclui uma tela sensível ao toque e uma caixa de respostas com dois botões. Vários parâmetros da resposta (item escolhido, tempo de reação, número de erros etc.) são armazenados pelo software.

Como colocado acima, o CGT avalia a tomada de decisão e assunção de riscos. Em cada tentativa, são apresentadas na tela uma fila de dez caixas, das quais algumas são vermelhas e as restantes, azuis (Figura 5). O participante deve adivinhar se uma caixa 
amarela estará dentro de uma caixa vermelha ou azul, apostando em uma dessas duas cores, pressionando um dos dois retângulos localizados na parte inferior da tela, nos quais estão escritos "vermelho" ou "azul". Em seguida, o participante deve apostar uma determinada porção de seus pontos nessa escolha. Para tanto, uma caixa de apostas aparece na região medial direita da tela, apresentando quantias que, a cada cinco segundos, aumentam ou diminuem (dependendo do modo do teste em ação no momento ascendente ou descendente). Estas quantias compreendem $5 \%, 25 \%, 50 \%, 75 \%$ e $95 \%$ dos pontos do participante. A quantia escolhida é selecionada mediante toque do participante sobre a caixa de apostas. Se este não a pressionar, a última quantia apresentada é automaticamente selecionada para a aposta. Para o presente estudo, todos os sujeitos realizaram o teste no modo ascendente, seguido do modo descendente.

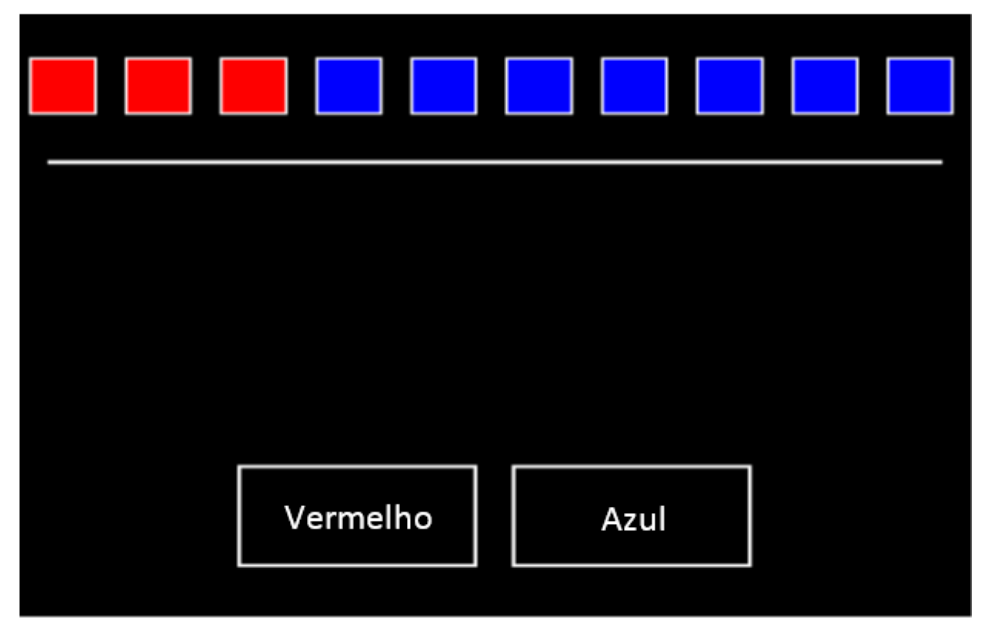

Figura 5: Display do teste CGT, da bateria neuropsicológica CANTAB.

O teste é composto de cinco estágios, com instruções dadas no início de cada um deles:

1. O primeiro estágio consiste apenas por escolhas das cores, sem apostas.

2. No segundo estágio, o sujeito deve treinar apostas, de modo a compreender como elas são realizadas.

3. Em seguida, no terceiro estágio, ocorre a avaliação das escolhas e apostas do sujeito. 
4. O quarto estágio compreende um novo treino de apostas, agora com as quantias da caixa de apostas indo na direção oposta àquela presente no segundo e terceiro estágios.

5. Por fim, no quinto estágio, ocorre novamente a avaliação das escolhas e apostas, com as quantias movendo-se na mesma direção do quarto estágio.

O primeiro, segundo e quarto estágios são formados por quatro tentativas cada. $\mathrm{O}$ terceiro e quinto estágios são compostos de quatro blocos de nove tentativas cada, totalizando 36 tentativas para cada estágio.

O CGT gera seis parâmetros passíveis de análise quantitativa. As descrições de cada um desses escores foram elaboradas a partir da tradução de suas definições no manual do CANTAB (Cambridge Cognition, 2005), descritas a seguir.

- Qualidade da tomada de decisão: na maioria das situações de aposta, há mais caixas de uma cor do que de outra. Nestas tentativas, o indivíduo pode apostar na cor com maior possibilidade de acerto ou na cor com menor probabilidade. A presente medida é a proporção das tentativas nas quais o avaliando decidiu apostar na cor com maior probabilidade de acerto;

- Tempo de deliberação: refere-se à latência média, medida em milissegundos, entre a apresentação das caixas coloridas e a escolha, por parte do indivíduo, da cor na qual irá apostar.

- Assunção de risco: é a média da proporção do total de pontos (a percentagem dos pontos, entre $5 \%$ e $95 \%$, que é usada como referência para calcular o valor da aposta apresentado na caixa de apostas) que o indivíduo decide apostar nas situações em que ele escolheu a opção com maior probabilidade de ganho do que de perda.

- Ajuste de risco: o avaliando tipicamente irá apostar uma quantidade maior dos seus pontos quando as probabilidades estão fortemente a seu favor. Esta medida reflete a tendência em apostar quantias maiores de pontos em tentativas nas quais a grande maioria das caixas é da cor escolhida pelo indivíduo, em comparação com tentativas em que uma quantidade menor de caixas é da cor em que o examinando decidiu apostar. 
- Aversão ao atraso: indivíduos que são incapazes ou que não querem esperar o valor da caixa de apostas mudar vão apostar quantias maiores quando estas são apresentadas no estágio descendente do teste e quantias menores quando são apresentadas no estágio ascendente. Esta medida reflete tal tendência. Ela é calculada subtraindo-se a Assunção de risco da fase ascendente da Assunção de risco da fase descendente.

- Proporção global de aposta: esta medida reflete a proporção média dos pontos disponíveis que o avaliando decide apostar em cada uma das tentativas de aposta, incluindo as tentativas em que este indivíduo apostou na alternativa com menor probabilidade de ganho e nas tentativas em que ambas as cores tinham $50 \%$ de chance de ganho.

\subsection{Procedimentos}

Cada participante, após leitura e assinatura do Termo de Consentimento Livre e Esclarecido (Apêndice A), foi submetido a uma sessão de avaliação neuropsicológica, com duração aproximada de 45 minutos, realizada no piso térreo do IPq HCFMUSP e aplicada pelo pesquisador. A testagem foi feita individualmente, em ambiente neutro e silencioso. As sessões foram realizadas durante o horário de atendimento ambulatorial dos pacientes, que ocorre todas as quintas-feiras, no período da manhã. Antes de cada sessão, os pacientes passavam por consultas médicas em uma sala ao lado da sala de avaliação neuropsicológica.

Concomitantemente à aplicação das instruções dos testes, o examinador buscou observar os aspectos qualitativos dos comportamentos dos sujeitos que realizavam testes, incluindo comentários e reações não verbais.

Os escores do MEEM, bem como os dados demográficos - idade, sexo e anos de escolaridade - foram retirados do banco de dados pertencente ao LIM-27. Os escores do MEEM correspondiam ao resultado da última aplicação realizada, de maneira que fosse o mais próximo possível temporalmente do dia da avaliação. A presença de déficits sensoriais e de distúrbios psiquiátricos e neurológicos também foi verificada por meio do banco de dados. 


\subsection{Análise dos dados}

Os escores obtidos nos testes neuropsicológicos do CANTAB foram considerados como variáveis dependentes. Idade e anos de escolaridade constituem variáveis de confusão, tendo sido considerados em análise de covariância. Os resultados quantitativos obtidos foram submetidos, primeiramente, a testes para verificação de normalidade Kolmogorov-Smirnov (KS) e Shapiro-Wilk (SW) - e homocedasticidade - $\quad$ Levene.

Após este procedimento, os grupos foram comparados a partir do modelo linear geral (Lambda de Wilks), do programa SPSS 20 para Windows. Testes ANOVA foram realizados para verificação de efeitos particulares em cada uma das variáveis dependentes. Também realizou-se ANOVA para a comparação da idade. Por terem distribuição não paramétrica, as comparações da escolaridade e dos escores do MEEM foram realizadas por meio do teste não-paramétrico Kruskal-Wallis. Todas as análises inferenciais, com exceção dos testes não-paramétricos, foram acompanhadas por estimativas de poder estatístico e de tamanho de efeito. Considerou-se a utilização de análises de correlação para verificação mais detalhada de possíveis relações entre covariáveis e variáveis dependentes. Os dados foram analisados ajustando-se o nível de significância em $p<0,05$. O tamanho de efeito foi interpretado tomando-se como referência a tabela de magnitude de Cohen (1988).

\subsection{Aspectos éticos}

A presente pesquisa foi aprovada pelo Comitê de Ética em Pesquisa com Seres Humanosdo Instituto de Psicologia da Universidade de São Paulo (CAAE: 10894113.2.0000.5561). Somente mediante a assinatura do Termo de Consentimento Livre e Esclarecido (APÊNDICE A) - conforme a Resolução Normativa 196, de 10 de outubro de 1996, do Ministério da Saúde -, os envolvidos puderam participar da pesquisa. Além disso, o voluntário pôde se recusar a participar do estudo ou retirar seu consentimento a qualquer momento, sem penalização ou prejuízo. O pesquisador se disponibilizou para esclarecer qualquer dúvida a respeito dos procedimentos do estudo. Todos os pacientes, tanto 
controles como aqueles diagnosticados com CCL, continuaram o acompanhamento clínico no ambulatório do LIM-27. 


\section{Resultados}

O grupo com CCL foi formado por 9 pacientes ( 7 mulheres e 2 homens), e o grupo controle, por 11 participantes (10 mulheres e 1 homem). Analisando-se graficamente os intervalos de confiança referentes à idade e à escolaridade, observa-se que há pouca sobreposição entre os grupos, fato este que aponta para uma potencial diferença estatisticamente significativa entre os grupos (Figuras 6 e 7).

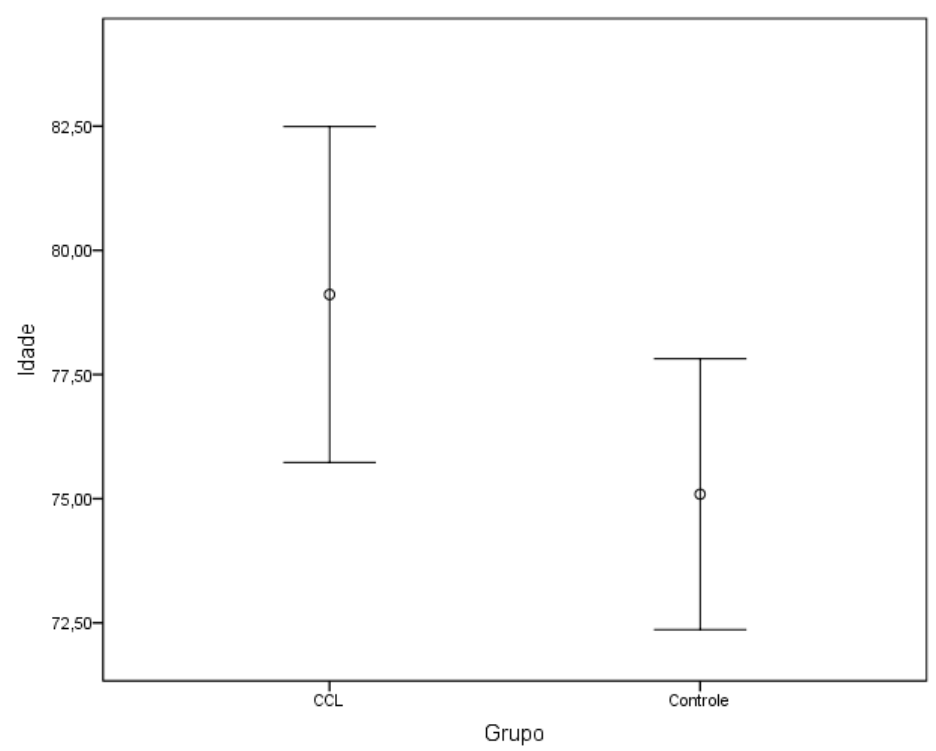

Figura 6: intervalo de confiança referente à idade dos participantes em cada grupo. 


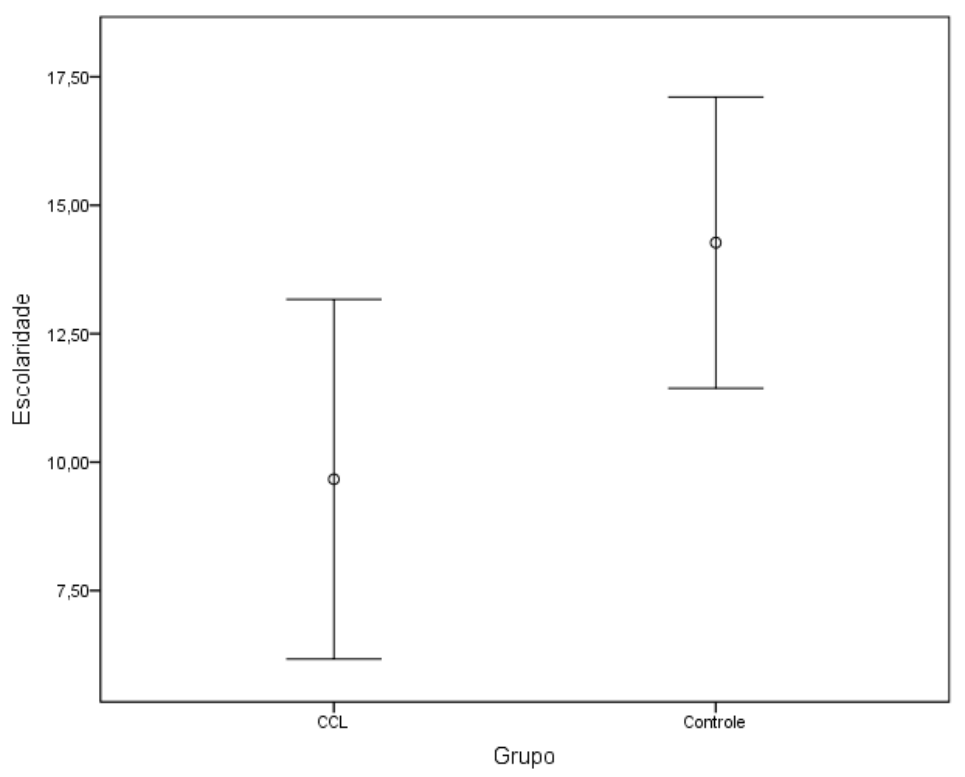

Figura 7: intervalo de confiança referente aos anos de escolaridade dos participantes em cada grupo.

Conforme apresentado na Tabela 1, as diferenças nas idades e escolaridades foram confirmadas pela análise inferencial.

Tabela 1:

Características demográficas da amostra

\begin{tabular}{|c|c|c|c|c|c|c|c|c|}
\hline & & $\mathrm{CCL}$ m(DP) & Controle m(DP) & Total m(DP) & $\mathrm{F}$ & $\mathrm{p}$ & TE $\left(\eta^{2}\right.$ parcial $)$ & Poder $(1-\beta)$ \\
\hline \multirow{2}{*}{ Sexo } & Masculino & 2 & 1 & 3 & - & - & - & - \\
\hline & Feminino & 7 & 10 & 17 & - & - & - & - \\
\hline Idade & & $79,1(4,4)$ & $75,1(4,1)$ & $76,9(4,57)$ & 4,5 & 0,048 & 0,2 & 0,52 \\
\hline $\begin{array}{l}\text { Escolaridad } \\
\mathrm{e}\end{array}$ & & $9,7(4,5)$ & $14,3(4,2)$ & $12,2(4,86)$ & - & 0,036 & - & - \\
\hline MEEM & & $28,2(2,2)$ & $29,6(0,7)$ & $29(1,65)$ & - & 0,102 & - & - \\
\hline \multirow{2}{*}{ Subtipos } & CCL-a m.d. & 7 & - & - & - & - & - & - \\
\hline & CCL-a u.d. & 2 & - & - & - & - & - & - \\
\hline
\end{tabular}

Nota: Os desvios-padrões estão entre parênteses.p $\leq 0,05 . \mathrm{F}=$ estatística teste; $p=$ significância estatística; $\mathrm{TE}=$ tamanho de efeito; CCL-a m.d. = CCL amnéstico de múltiplos domínios; CCL-a u.d. = CCL amnéstico de único domínio.

Conforme apontado na Tabela 2, ambos os testes, KS e SW, acusaram violação da normalidade no grupo controle para os anos de escolaridade, para escores do MEEM e para a variável "ajuste de risco" do CGT. O teste KS também revelou violação para a variável "aversão ao atraso" para o grupo controle. 
Tabela 2:

Resultados dos testes de normalidade aplicados à idade, à escolaridade e às variáveis dos testes MEEM e CGT

\begin{tabular}{llcccccc}
\hline & & \multicolumn{2}{c}{ Kolmogorov-Smirnov } & \multicolumn{3}{c}{ Shapiro-Wilk } \\
\cline { 3 - 7 } & & Estatística & gl & $p$ & Estatística & gl & P \\
\hline \multirow{2}{*}{ Idade } & CCL & 0,198 & 9 & 0,200 & 0,911 & 9 & 0,323 \\
& Controle & 0,146 & 11 & 0,200 & 0,957 & 11 & 0,736 \\
Escolaridade & CCL & 0,123 & 9 & 0,200 & 0,962 & 9 & 0,815 \\
MEEM & Controle & 0,296 & 11 & $0,008^{*}$ & 0,848 & 11 & $0,040^{*}$ \\
& CCL & 0,238 & 9 & 0,148 & 0,839 & 9 & 0,057 \\
Aversão ao atraso & Controle & 0,432 & 11 & $<0,001^{*}$ & 0,619 & 11 & $<0,001^{*}$ \\
& CCL & 0,186 & 9 & 0,200 & 0,947 & 9 & 0,659 \\
Intervalo de deliberação & Controle & 0,253 & 11 & $0,047^{*}$ & 0,866 & 11 & 0,069 \\
Proporção global de & CCL & 0,231 & 9 & 0,181 & 0,903 & 9 & 0,267 \\
aposta & Controle & 0,164 & 11 & 0,200 & 0,932 & 11 & 0,436 \\
Qualidade de tomada de & CCL & 0,228 & 9 & 0,198 & 0,949 & 9 & 0,683 \\
decisão & Controle & 0,173 & 11 & 0,200 & 0,931 & 11 & 0,425 \\
Ajuste de risco & Controle & 0,180 & 11 & 0,200 & 0,939 & 11 & 0,509 \\
Assunção de risco & CCL & 0,192 & 9 & 0,200 & 0,948 & 9 & 0,667 \\
\hline & Controle & 0,260 & 11 & $0,037^{*}$ & 0,754 & 11 & $0,002^{*}$ \\
& CCL & 0,254 & 9 & 0,099 & 0,927 & 9 & 0,456 \\
& Controle & 0,176 & 11 & 0,200 & 0,925 & 11 & 0,363 \\
\hline
\end{tabular}

Nota: $\mathrm{gl}=$ graus de liberdade; $\mathrm{p}=$ significância estatística .

O teste de Levene, realizado em conjunto com o modelo linear geral, não revelou violações à homocedasticidade univariada em nenhuma das variáveis analisadas, tal como demonstrado na Tabela 3. O teste $\mathrm{M}$ de Box para homogeneidade das matrizes de covariância, também executado em conjunto com o procedimento de modelo linear geral, não revelou violações às condições de homocedasticidade multivariada ( $F=0,876 ; p=0,623)$. 


\section{Tabela 3:}

Resultados do teste de homocedasticidade

\begin{tabular}{lcc}
\hline & $\mathrm{F}$ & $\mathrm{p}$ \\
\hline Aversão ao atraso & 3,867 & 0,065 \\
Intervalo de deliberação & 0,302 & 0,589 \\
Proporção global de aposta & 0,304 & 0,588 \\
Qualidade de tomada de decisão & 0,022 & 0,884 \\
Ajuste de risco & 0,479 & 0,498 \\
Assunção de risco & 0,015 & 0,905 \\
\hline
\end{tabular}

Nota: Foi utilizado o teste de homocedasticidade de Levene. $\mathrm{F}=$ estatística teste; $\mathrm{p}=$ significância estatística.

A análise descritiva ${ }^{8}$ dos parâmetros do CGT é apresentada na Tabela 4.

Tabela 4:

Análise descritiva das variáveis do CGT

\begin{tabular}{llcc}
\hline & & Média & Desvio-Padrão \\
\hline \multirow{4}{*}{ CCL } & Aversão ao atraso & 0,524 & 0,28 \\
& Intervalo de deliberação & 3583,48 & 1355,52 \\
& Proporção global de aposta & 0,48 & 0,14 \\
& Qualidade de tomada de decisão & 0,77 & 0,21 \\
& Ajuste de risco & 0,04 & 1 \\
& Assunção de risco & 0,49 & 0,12 \\
\hline \multirow{4}{*}{ Controle } & Aversão ao atraso & 0,33 & 0,34 \\
& Intervalo de deliberação & 3416,2 & 1091,59 \\
& Proporção global de aposta & 0,58 & 0,14 \\
& Qualidade de tomada de decisão & 0,75 & 0,19 \\
& Ajuste de risco & 0,46 & 0,73 \\
& Assunção de risco & 0,59 & 0,13 \\
\hline
\end{tabular}

A análise com o modelo linear geral não revelou efeito dos fatores sobre a combinação linear dos parâmetros do CGT (Tabela 5). No entanto, foi observado efeito multivariado significativo da covariável idade com tamanho de efeito de grande proporção.

\footnotetext{
${ }^{8}$ Os boxplots referente à idade, escolaridade encontram-se no APÊNDICE B; os boxplots referentes aos escores dos testes MEEM e do CGT estão nos APÊNDICES C e D, respectivamente, com exceção dos boxplots das variáveis aversão ao atraso, proporção global apostada e assunção de risco, os quais estão presentes mais adiante nessa seção. Os intervalos de confiança do MEEM e das variáveis do CGT estão nos APÊNDICES E e F, respectivamente. Os intervalos de confiança referentes à idade e à escolaridade estão expostos nesta seção.
} 
Por sua vez, a ANOVA realizada post hoc revelou efeitos do grupo sobre a aversão ao atraso, a proporção global de aposta e a assunção de risco, todos os três acompanhados de pequenos tamanhos de efeito (Tabela 6). Por fim, constatou-se também significância estatística entre a idade e a aversão ao atraso, a proporção global de aposta e a assunção de risco, com tamanhos de efeito moderados para as duas primeiras e um pequeno associado à última variável.

\section{Tabela 5:}

Resultados da análise multivariada

\begin{tabular}{lcccc}
\hline Fator/Covariáveis & $\mathrm{F}$ & $\mathrm{p}$ & $\mathrm{TE}\left(\mathrm{\eta}^{2}\right.$ parcial $)$ & Poder $(1-\beta)$ \\
\hline Idade & 5,885 & $0,007^{*}$ & 0,779 & 0,933 \\
Escolaridade & 0,262 & 0,943 & 0,136 & 0,091 \\
MEEM & 0,642 & 0,696 & 0,278 & 0,162 \\
Grupo & 2,017 & 0,156 & 0,548 & 0,465 \\
\hline
\end{tabular}

Nota: Foi utilizado o modelo linear geral juntamente com análise de covariância ANCOVA. Os resultados significativos estão destacados com asterisco. A significância estatística de referência utilizada foi de $0,05 . F=$ estatística teste; $p=$ significância estatística; $T E=$ tamanho de efeito. 
Tabela 6:

Resultados das análises de variância

\begin{tabular}{|c|c|c|c|c|c|}
\hline Covariáveis e Fator & Variável Dependente & $\mathrm{F}$ & $p$ & $\mathrm{TE}\left(\eta^{2}\right.$ parcial $)$ & Poder $(1-\beta)$ \\
\hline \multirow{6}{*}{ Idade } & Aversão ao atraso & 10,649 & $0,005^{*}$ & 0,415 & 0,862 \\
\hline & Intervalo de deliberação & 0,05 & 0,944 & $<0,001$ & 0,051 \\
\hline & Proporção global de aposta & 12,219 & $0,003^{*}$ & 0,449 & 0,904 \\
\hline & Qualidade de tomada de decisão & 0,012 & 0,913 & 0,001 & 0,051 \\
\hline & Ajuste de risco & 1,413 & 0,253 & 0,086 & 0,2000 \\
\hline & Assunção de risco & 6,332 & $0,024^{*}$ & 0,297 & 0,653 \\
\hline \multirow{6}{*}{ Escolaridade } & Aversão ao atraso & 0,061 & 0,808 & 0,004 & 0,056 \\
\hline & Intervalo de deliberação & 0,293 & 0,596 & 0,019 & 0,080 \\
\hline & Proporção global de aposta & 0,680 & 0,423 & 0,043 & 0,121 \\
\hline & Qualidade de tomada de decisão & 0,479 & 0,499 & 0,031 & 0,099 \\
\hline & Ajuste de risco & 0,097 & 0,760 & 0,006 & 0,060 \\
\hline & Assunção de risco & 0,483 & 0,498 & 0,031 & 0,100 \\
\hline \multirow{6}{*}{ MEEM } & Aversão ao atraso & 0,107 & 0,748 & 0,007 & 0,061 \\
\hline & Intervalo de deliberação & 0,955 & 0,344 & 0,060 & 0,150 \\
\hline & Proporção global de aposta & 0,070 & 0,795 & 0,005 & 0,057 \\
\hline & Qualidade de tomada de decisão & 0,036 & 0,852 & 0,002 & 0,054 \\
\hline & Ajuste de risco & 1,910 & 0,187 & 0,113 & 0,253 \\
\hline & Assunção de risco & 0,051 & 0,825 & 0,003 & 0,055 \\
\hline \multirow{6}{*}{ Grupo } & Aversão ao atraso & 6,028 & $0,027^{*}$ & 0,287 & 0,632 \\
\hline & Intervalo de deliberação & 0,013 & 0,911 & 0,001 & 0,051 \\
\hline & Proporção global de aposta & 6,288 & $0,024^{*}$ & 0,295 & 0,650 \\
\hline & Qualidade de tomada de decisão & 0,259 & 0,618 & 0,017 & 0,076 \\
\hline & Ajuste de risco & $<0,001$ & 0,990 & $<0,001$ & 0,050 \\
\hline & Assunção de risco & 4,753 & $0,043^{*}$ & 0,241 & 0,532 \\
\hline
\end{tabular}

Nota: Foi utilizado o teste ANOVA juntamente com análise de covariância ANCOVA. Os resultados significativos estão destacados com asterisco. A significância estatística de referência utilizada foi de 0,05. $\mathrm{F}=$ estatística teste; $\mathrm{p}=$ significância estatística; $\mathrm{TE}=$ tamanho de efeito.

Como se pode constatar por meio dos boxplots (Figuras 8, 9 e 10), a maioria dos idosos com CCL apresentaram uma maior aversão ao atraso quando comparados com controles. Ao mesmo tempo, a maior parte desses sujeitos apostaram quantias menores tanto de maneira geral (proporção global de aposta) como nas situações em que optavam pela cor mais predominante (assunção de risco). 


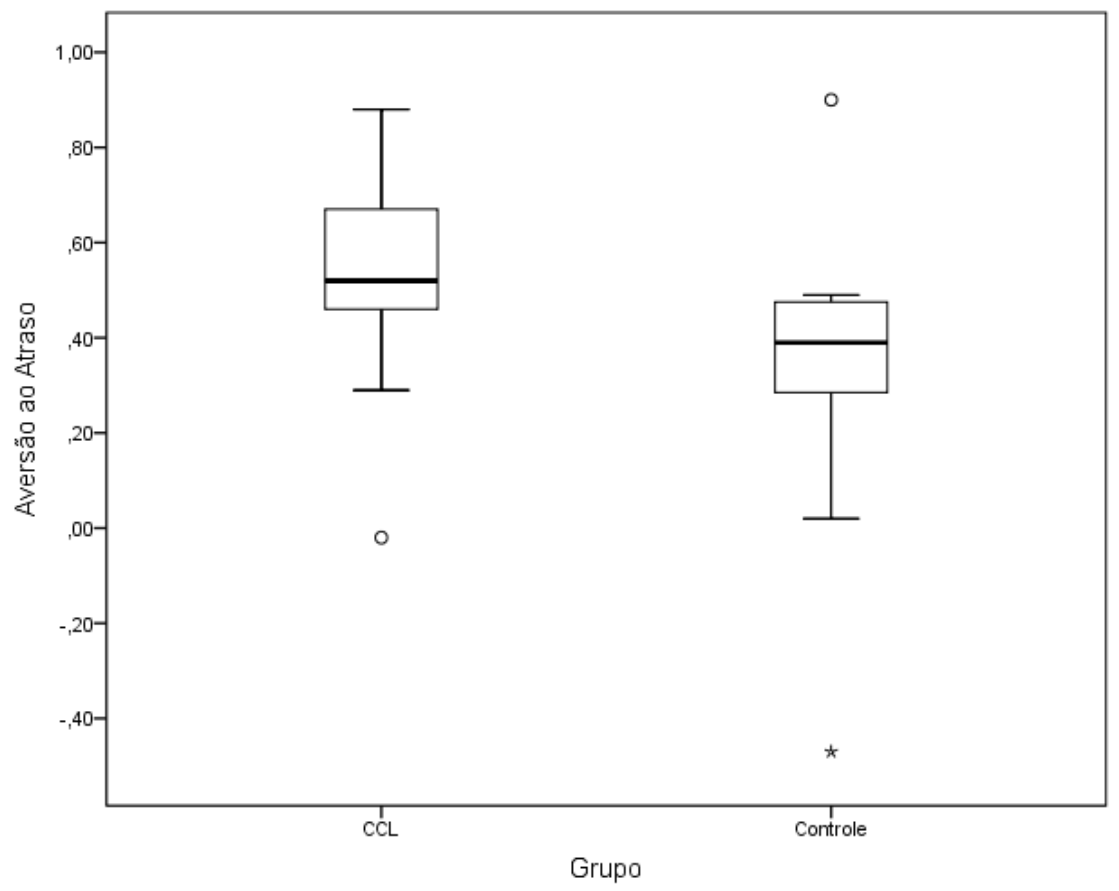

Figura 8: Boxplot referente à variável "aversão ao atraso" do CGT.

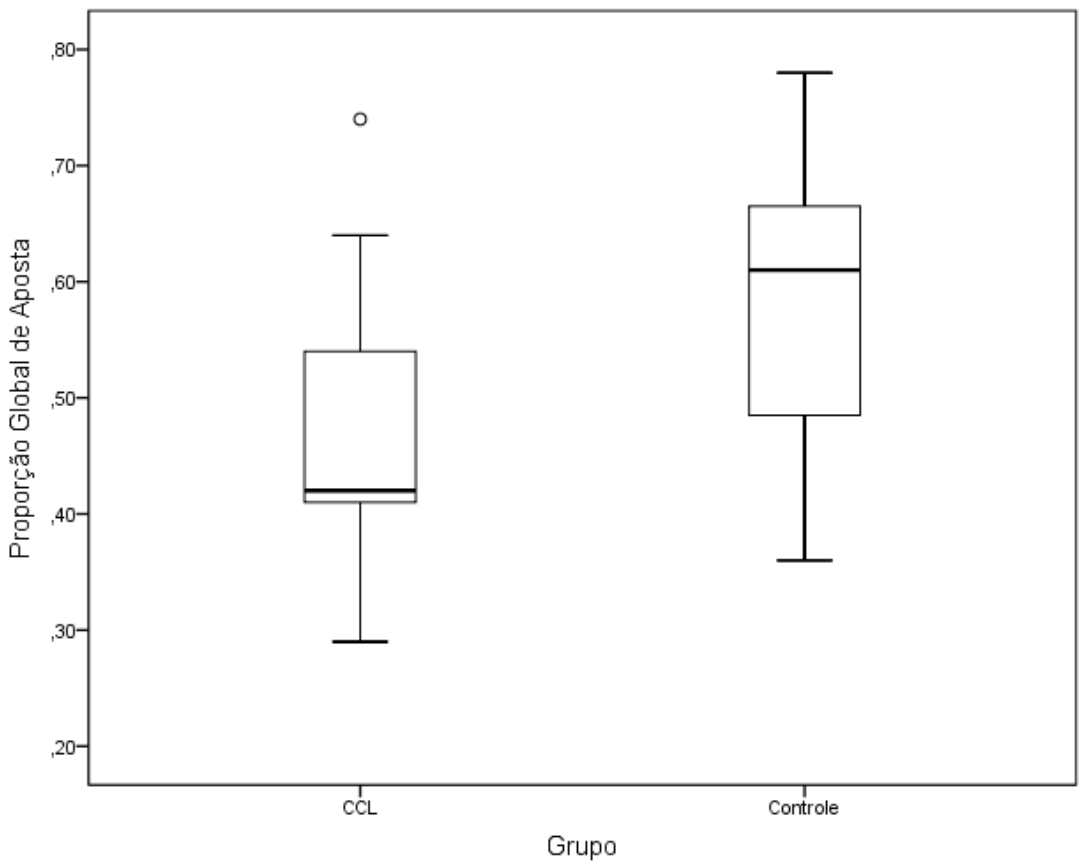

Figura 9: Boxplot referente à variável "proporção global de aposta" do CGT. 


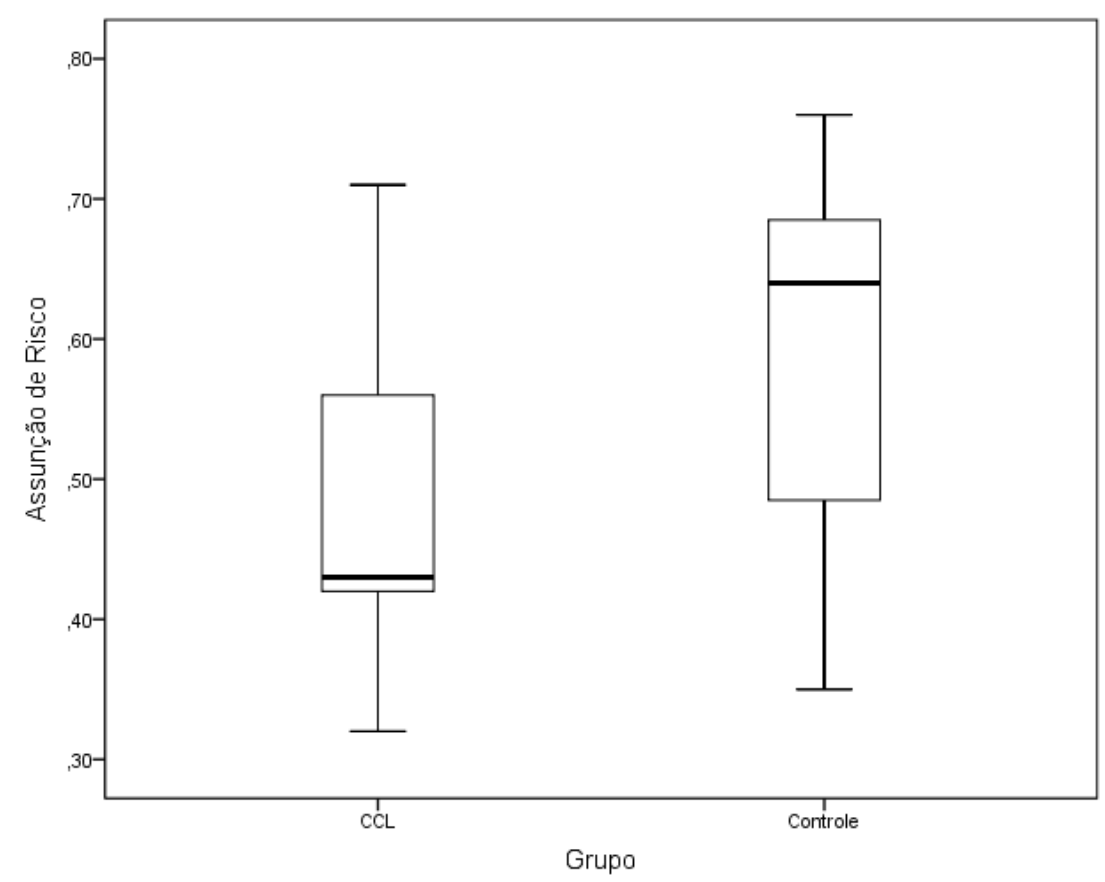

Figura 10: Boxplot referente à variável "assunção de risco" do CGT.

A partir do coeficiente de correlação de Pearson e por meio de inspeção dos gráficos de correlação, foi realizada uma verificação mais detalhada das relações estatisticamente significativas entre a idade e os três parâmetros do CGT (Tabela 7 e Figuras 11, 12 e 13). Foram observadas correlações positivas para as relações envolvendo proporção global de aposta e assunção de risco, sendo cada uma, respectivamente, moderada e baixa. Além disso, constatou-se um coeficiente de correlação negativo entre idade e aversão ao atraso. Todavia, nenhum coeficiente foi estatisticamente significativo.

\section{Tabela 7:}

Correlação entre a idade e os parâmetros do CGT

\begin{tabular}{lccc}
\hline & Aversão ao atraso & Proporção global de aposta & Assunção de risco \\
\hline Idade $r(p)$ & $-0,412(0,071)$ & $0,412(0,071)$ & $0,283(0,226)$ \\
\hline
\end{tabular}

Nota: foi utilizado o teste de correlação de Pearson. A significância estatística de referência utilizada foi de 0,05 . Os níveis de significância estão entre parênteses. 


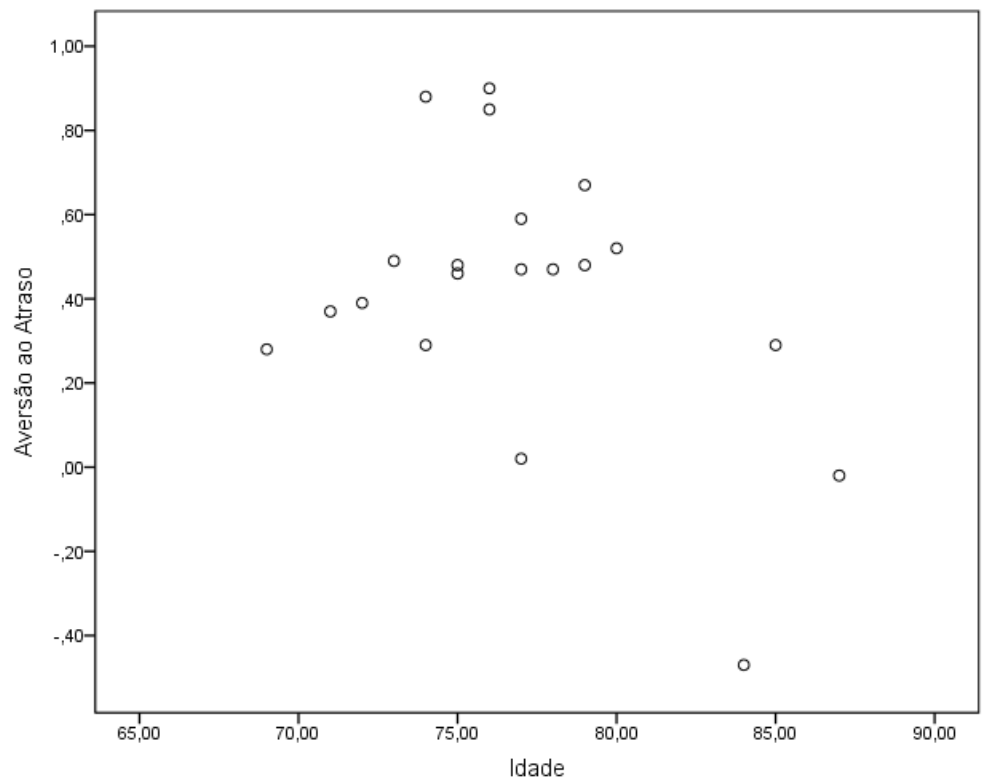

Figura 11: correlação entre idade e o parâmetro "aversão ao atraso" do CGT.

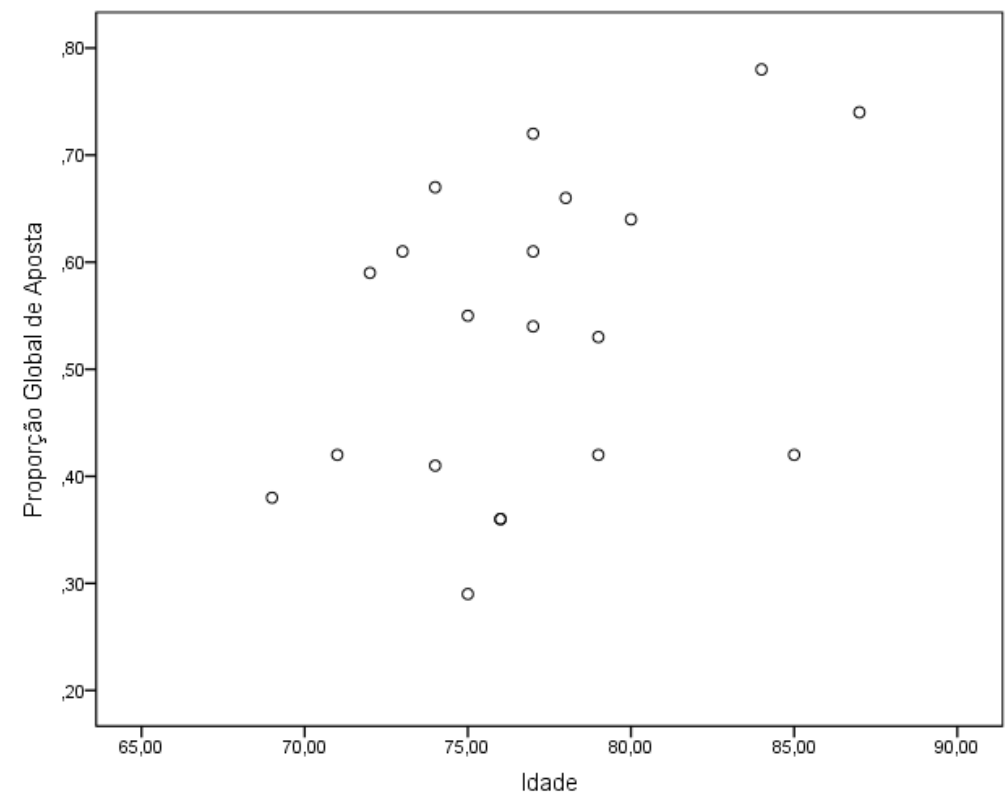

Figura 12: correlação entre idade e o parâmetro "proporção global de aposta" do CGT. 


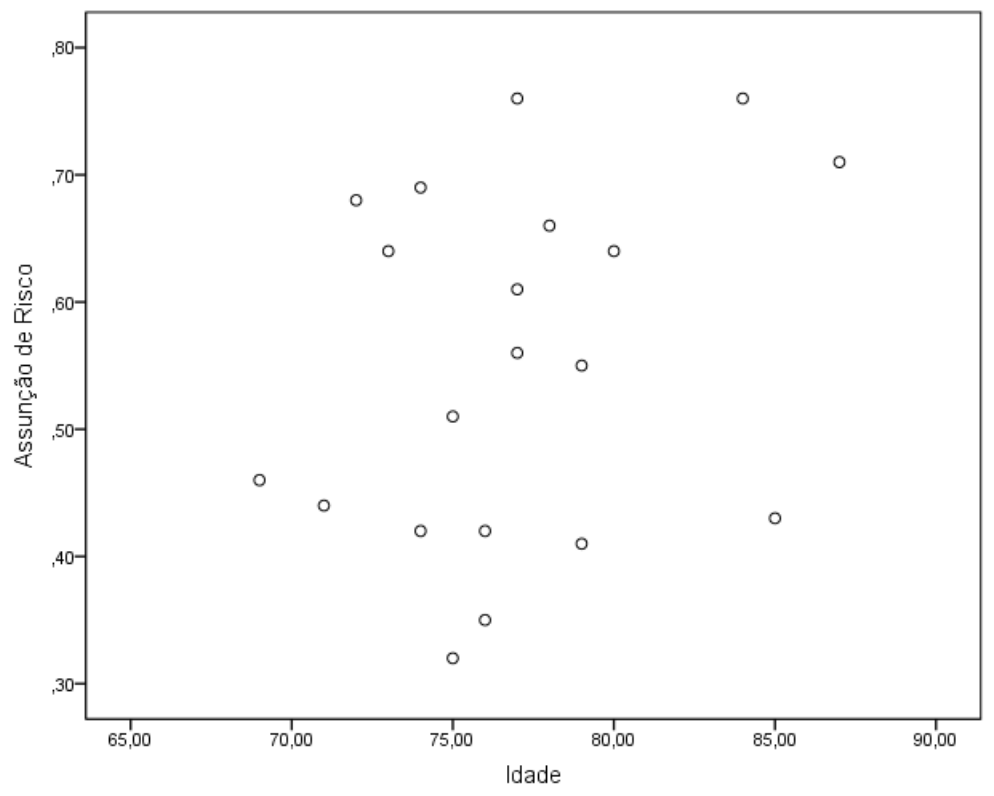

Figura 13: correlação entre a idade e o parâmetro "assunção de risco" do CGT. 


\section{Discussão}

\subsection{CCL e os parâmetros do CGT}

A tomada de decisão é uma função multifacetada, tal como evidenciado pelos diversos parâmetros gerados pelo CGT. Desse modo, tais variáveis serão primeiramente discutidas abaixo em separado para, depois, serem todas consideradas em conjunto, fornecendo um quadro geral sobre a neuropsicologia da tomada de decisão na comparação entre CCL e controles.

Segundo o manual do CANTAB, intervalo de deliberação e aversão ao atraso são variáveis que envolvem, de maneira fundamental, o controle da impulsividade (Cambridge Cognition, 2005). Decisões tomadas de modo relativamente rápido, tanto no que se refere à escolha da cor como à determinação do valor apostado, sugerem um controle mais frouxo de respostas inadequadas.

Ainda que as análises inferenciais não tenham revelado diferenças entre os intervalos de deliberação dos idosos com CCL e dos controles, o mesmo não ocorreu com a aversão ao atraso: foi possível observar que os idosos com CCL tiveram menos tolerância para esperar a disponibilidade de valores maiores, na fase ascendente, e menores, na fase descendente. Essa postura sugere que idosos com CCL apresentaram mais impulsividade na seleção de suas respostas.

De fato, a literatura aponta que pacientes com CCL podem apresentar déficits nas funções executivas, incluindo a presença de impulsividade. Brandt et al. (2009), além de terem investigado a tomada de decisão no CCL, também se dedicaram ao estudo de diversas funções executivas, incluindo medidas de inibição de respostas inadequadas. Em relação a estas, os autores detectaram diferenças significativas entre sujeitos saudáveis e controles. Achados semelhantes foram constatados em estudos mais recentes, como os de Aretouli, Tsilidis e Brandt (2013), Johns et al. (2012) e de Zheng et al. (2014). 
Este resultado da presente pesquisa possui implicações significativas para os estudos sobre risco de conversão para a demência. Um dos principais indicadores desse risco é justamente o declínio em tarefas de função executiva, inclusive as que envolvem o controle da inibição (Aretouli, Okonkwo, Samek \& Brandt, 2011; Aretouli et al., 2013; Clark et al., 2012; Summers \& Saunders, 2012; Tabert et al., 2006). Desse modo, o parâmetro de aversão ao atraso do CGT é um potencial marcador para conversão do CCL-a de múltiplos domínios para DA, papel este que necessita ser investigado mais aprofundadamente.

Quanto aos parâmetros de qualidade de tomada de decisão e de ajuste de risco, eles evidenciam alguns aspectos importantes do perfil de tomada de decisão dos sujeitos aqui analisados. Conforme revelado pela qualidade de tomada de decisão, os sujeitos de ambos os grupos optaram pela cor de ganho mais provável em proporções de tentativas semelhantes. Além disso, nessas tentativas, os participantes regularam a quantia de suas apostas de maneira semelhante, de acordo com as diferentes proporções entre a cor mais numerosa e a menos numerosa, como é colocado pelo parâmentro de ajuste de risco.

Segundo Brand et al. (2006), o modelo cognitivo de tomada de decisão sob risco inclui a participação dos vieses provenientes dos marcadores somáticos. Nesse sentido, Zamarian et al. (2010), utilizando o IGT, verificaram que os pacientes com CCL demonstraram um padrão aleatório de respostas, não tendo preferências por opções vantajosas ou por aquelas desvantajosas. No entanto, tais autores colocam que este tipo de estratégia difere daquelas características de pacientes com danos ventro-mediais, em que há clara concentração nas opções mais arriscadas.

Diante disso, é possível levantar a hipótese de que a ausência de uma postura de tomada de decisão mais arriscada na presente amostra se deve ao fato de que, assim como os sujeitos com CCL no estudo de Zamarian et al. (2010), os idosos do grupo experimental da presente pesquisa não possuem danos ventro-mediais. Alternativamente, é possível que danos ventro-mediais estejam presentes, mas de forma e intensidade tal que não tenham acarretado prejuízos cognitivos detectáveis. 
Por outro lado, indo de encontro com esses dados indicados na presente pesquisa, ainda no estudo de Zamarian et al. (2010), os pacientes com CCL apresentaram no PAG um perfil de tomada de decisão mais arriscado do que aqueles observados nos controles. Isso porque suas decisões se baseavam apenas nas probabilidades de ganho nas apostas, desconsiderando o papel da "soma fixa". Isso significa que, mesmo frente a uma situação em que há uma maior proporção de quadrados azuis - que significam perda - os idosos com CCL preferiram manter sua escolha pela aposta em detrimento de uma perda através da opção "soma fixa" mais baixa (-20 pontos para "soma fixa", ao invés de -100 pontos para a aposta). Esta postura mais arriscada, entretanto, provavelmente não se deveu a um déficit primário na tomada de decisão, mas sim a prejuízos em outras funções, com destaque às funções executivas. Tal hipótese se sustenta, primeiramente, pelo fato de que, se houvesse danos ventro-mediais, estes se expressariam no IGT, o que não ocorreu. Em segundo lugar, os sujeitos com CCL na pesquisa de Zamarian et al. (2010), em comparação com controles, expressaram déficits executivos, apresentando maiores dificuldades em coordenar todas as informações fornecidas pelo teste, o que provavelmente levou à negligência mais frequente de um fator relevante para a tomada de decisão na situação de testagem.

Para se explicar essa discrepância entre a presente pesquisa e o estudo de Zamarian et al. (2010), é razoável se considerar os diferentes níveis de dificuldade entre o PAG e o CGT. Estes testes possuem diferentes graus de demanda executiva: a tomada de decisão no primeiro exige uma integração, em tempo real, de um número maior de informações (quantia de pontos em caixa, quantia de aposta, "soma fixa" presente no momento e proporção de quadrados) do que no segundo (quantia de pontos em caixa, proporção de cores e quantia a ser apostada). A maior exigência do PAG impõe uma grande carga de trabalho sobre o sistema neural dos pacientes com CCL, propiciando a negligência de algumas de suas informações e, portanto, ocasionando o surgimento de déficits na tomada de decisão.

No que se refere à proporção global apostada e a assunção de risco, por sua vez, tratam-se de parâmetros que oferecem uma perspectiva diferente sobre o perfil de tomada 
de decisão dos pacientes aqui analisados. Foi observado que os pacientes com CCL, em média, apostaram quantias menores, tanto ao longo de todas as tentativas do CGT, como especificamente naquelas em que eles optaram pela cor mais provável.

Pode-se levantar a hipótese de que apostar menos pontos se constitui como uma estratégia em resposta às dificuldades no controle da inibição percebidos pelo sujeito como fator impeditivo para uma melhor performance no teste. Tal impulsividade pode ter prejudicado a escolha de quantias julgadas pelo sujeito como mais adequadas para o estabelecimento da estratégia de tomada de decisão vantajosa. Tal hipótese é reforçada pelos sinais verbais (por exemplo, "ai, doutor, não tô indo bem" (sic)) e não-verbais (por exemplo, suspiros e sinais de negativo com a cabeça) percebidos pelo pesquisador como mais frequentes no grupo de pacientes com CCL. Sendo assim, os idosos com CCL tenderam a apostar menos pontos, de modo a conter as perdas, ao invés de se arriscar mais para aumentar o seu montante.

Ainda é possível cogitar que, além de ser uma resposta à impulsividade presente no contexto de testagem, a estratégia característica de apostar sistematicamente menos pontos - o que implica, em última instância, se arriscar menos - pode ter origem no autoconceito do paciente diagnosticado com CCL. Segundo Giacomin, Moraes e Teixeira (2014), o diagnóstico médico tem influência significativa sobre a concepção própria do idoso acerca de suas capacidades como indivíduo. Na perspectiva do paciente, a confirmação do diagnóstico de CCL, proveniente do saber médico largamente respeitado, vem confirmar seus temores e queixas sobre suas capacidades funcionais e cognitivas. Tal influência é reforçada pela associação deste diagnóstico com a demência e com todas as limitações pessoais e familiares que a acompanha.

Um paciente idoso que possui autoconceito influenciado negativamente pelo diagnóstico, como acima colocado, pode ser mais impactado pelas perdas no CGT do que pelos ganhos. Desta forma, ele desenvolve uma estratégia de tomada de decisão voltada não a obter mais pontos ao longo das tentativas no teste, mas sim de evitar a perda dos pontos que possui num dado momento. 


\subsection{CCL e síntese da tomada de decisão}

A qualidade de tomada de decisão e o ajuste de risco dos pacientes com CCL evidenciam capacidade para compreender as regras e contingências do teste e, a partir disso, construir uma estratégia de tomada de decisão tão vantajosa quanto aquela dos controles. Tal capacidade, como exposto anteriormente, se deve possivelmente à ausência de prejuízo funcional dos circuitos centrais do córtex ventro-mediais, responsáveis pelo estabelecimento de comportamentos seguros.

Ao mesmo tempo, entretanto, a maior aversão ao atraso demonstrou problemas de impulsividade: quando comparados com os idosos saudáveis, os pacientes com CCL mostram maiores dificuldades em aguardar o aparecimento de mais opções de apostas. Tal déficit provavelmente limitou o rol de possibilidades de aposta para aqueles sujeitos, havendo, consequentemente, uma restrição no número de alternativas para a formação dos perfis de tomada de decisão. Em resposta a tal restrição, os participantes com CCL podem ter desenvolvido uma estratégia compensatória. Como evidenciado pela proporção global de aposta média e pela assunção de risco, os idosos desse grupo tenderam a apostar menos e, logo, a arriscar menos do seu montante, provavelmente de modo a reduzir a chance de perdas potenciais.

Ainda que de maneira secundária à situação de testagem, este padrão de resposta mais segura também pode ter sido determinado pelo autoconceito dos pacientes. Ao ser colocado no contexto de paciente com um distúrbio neuropsiquiátrico, a confiança do idoso com CCL em suas próprias capacidades pode ser diminuída, pois suas queixas são confirmadas pelo diagnóstico. Por conseguinte, as perdas ao longo do teste recebem especial atenção por parte desse paciente, estabelecendo um padrão de respostas de contenção de perdas, evitando o caráter aversivo das ocasiões em que perde pontos. Concomitantemente, perde oportunidades em que, mesmo se arriscando mais, poderia obter muito mais pontos. 


\subsection{Tomada de decisão e idade}

A ANOVA, controlando para o efeito dos fatores e das outras covariáveis, foi também capaz de verificar relação estatisticamente significativa entre a covariável idade e três variáveis do CGT, a saber, (1) a aversão ao atraso, (2) a proporção global apostada ao longo do teste e (3) a assunção de risco. Para uma discussão mais clara, (1) foi analisado separadamente, enquanto (2) e (3) foram tomados em conjunto, de modo semelhante às análises sobre os efeitos do CCL.

Pôde-se observar, na presente amostra, que idosos mais velhos demonstraram maior tolerância na espera pelo surgimento de mais valores de aposta. Esta relação não foi somente estatisticamente significativa, mas também acompanhada de um tamanho de efeito moderado. Este resultado difere da pesquisa de Deakin et al. (2004), que, utilizando o mesmo instrumento, não mostrou alterações na aversão ao atraso de acordo com a idade. No entanto, conforme mostrado a seguir, outros estudos indicam a existência de diferenças etárias na tolerância ao atraso, alguns deles apontando para uma maior tolerância com o aumento da idade, e outros, uma menor tolerância conforme a idade avança (Drobetz, Maecker \& Forstmeier, 2011; Green, Fry \& Myerson, 1994; Löckenhoff, O’Donoghue \& Dunning, 2011; Read \& Read, 2004).

Por exemplo, Green et al. (1994), investigaram 36 sujeitos divididos em três faixas etárias: 12 crianças (idade média de 12,1 anos), 12 adultos jovens (idade média de 20,3 anos) e 12 adultos mais velhos (idade média de 67,9 anos). A tarefa utilizada envolvia escolher recompensas fixas associadas a um atraso (por exemplo, 1000 pontos) ou recompensas variáveis, porém imediatas (entre 1 ponto até 1000 pontos). Todas as três faixas etárias demonstraram graus de evitação do atraso. Entretanto, adultos mais velhos foram os que demonstraram maior tolerância ao atraso da recompensa.

Read e Read (2004), por sua vez, em teste semelhante ao de Green et al. (1994), analisaram o desempenho de 123 sujeitos, divididos também em três faixas etárias, mas com idades médias maiores do que as do estudo anterior (25, 44 e 75 anos, respectivamente). Os autores encontraram um cenário oposto ao da pesquisa anterior, com 
idosos demonstrando maior aversão ao atraso da recompensa do que os jovens e os adultos de meia-idade.

Ressalta-se que a discussão sobre os resultados do presente estudo referentes ao efeito da idade sobre a aversão ao atraso, realizadas a partir da literatura apresentada acima, deve ser tomada com cautela. A pesquisa aqui desenvolvida possui uma amostra composta de idosos, com uma variação de idade pequena $(M=76,9 ; \mathrm{DP}=4,57)$. Por outro lado, ao investigar os efeitos da idade sobre tolerância ao atraso, todas as pesquisas citadas nesta seção analisaram amostras incluindo diversas faixas etárias, desde crianças até idosos. Logo, para uma discussão metodologicamente mais adequada, seriam necessários estudos voltados às diferenças entre idosos mais novos e mais velhos, verificando as possíveis variações na tolerância ao atraso nas diversas fases do envelhecimento.

A análise acerca do efeito da idade sobre a proporção global de aposta e a assunção de risco, juntamente com os coeficientes de correlação, revela que idosos mais jovens tenderam a apostar uma maior quantia de seu montante disponível, tanto de maneira geral como dentro das situações em que selecionavam a cor mais predominante. Apostas médias maiores apontam para estratégias de tomada de decisão mais arriscadas, pois, independentemente das chances de perdas e ganhos, arrisca-se uma proporção maior dos pontos disponíveis no momento.

Em relação a estes resultados, Deakin et al. (2004) demonstraram, no CGT, uma tendência oposta, com um decréscimo das apostas conforme o avançar da idade. No entanto, Brand e Schiebner (2013) ressaltaram em seu estudo que idosos com maior déficit executivo tendem a desenvolver estratégias mais arriscadas. Ainda que as conclusões destes últimos autores tenham sido derivadas do GDT, a literatura sobre tomada de decisão sob risco destaca a importância das funções executivas para o suporte às escolhas no contexto de risco (Brand et al., 2006; Brand et al., 2007; Brand, 2008; Brand et al., 2009). Considerando que a amostra analisada no presente estudo possui idosos Com CCL-a de múltiplos domínios, pode-se levantar a hipótese de que este efeito seja resultado da 
presença de leves déficits executivos presentes neste quadro clínico, e não da diferença de idade. 


\section{Limitações e recomendações para estudos futuros}

A presente pesquisa possui limitações cuja presença deve ser ponderada tanto na interpretação dos resultados aqui expostos e discutidos, como na elaboração de pesquisas futuras sobre o tema da tomada de decisão no CCL e em outros grupos de doenças neuropsiquiátricas.

O tamanho amostral é um aspecto importante em pesquisa, pois um número grande de sujeitos significa que os resultados observados não ocorreram ao acaso ou por erro amostral. Em outras palavras, o teste estatístico é capaz de prover maior poder às diferenças e igualdades constatadas entre os grupos e, portanto, às conclusões que delas derivam.

Neste contexto, salienta-se que uma das dificuldades encontradas ao longo da realização do presente estudo foi a obtenção de sujeitos para a composição da amostra. Tal obstáculo foi decorrente tanto da falta de disponibilidade dos pacientes para participar da pesquisa quanto do fato de haver apenas uma pessoa disponível para a coleta de dados. Deste modo, recomenda-se que pesquisas futuras sejam realizadas por uma equipe de profissionais ou, ainda, de maneira multicêntrica, de forma a garantir um tamanho amostral total grande o suficiente para prover níveis ótimos de poder estatístico.

Outro ponto a se levantar é a bateria neuropsicológica aplicada. Como exposto anteriormente, a tomada de decisão é uma função complexa, que sofre influência de outros domínios cognitivos. Assim, para que haja um maior aprofundamento em sua análise, recomenda-se a inclusão de outras tarefas na bateria de testes, além das utilizadas no presente estudo, com destaque para aquelas voltadas a outras funções executivas e ao cálculo do QI.

No entanto, é válido lembrar que testes experimentais de tomada de decisão, por avaliarem uma função complexa, costumam ter um tempo de aplicação longo, ocupando 
uma grande porção da sessão de avaliação. Em pesquisas envolvendo sujeitos idosos, que se cansam mais facilmente que participantes mais jovens, sugere-se a aplicação de sessões mais breves de forma a promover maior prontidão do idoso para a execução do teste. Logo, para que se tenham dados mais aprofundados, a coleta pode se dar em mais de uma sessão de avaliação. Tal procedimento se torna mais viável com a presença de uma equipe, ao invés de apenas um pesquisador, como foi o caso do presente estudo.

Além da inclusão de testes de função executiva e para o cálculo de QI, recomendase a aplicação de instrumentos e procedimentos para a avaliação emocional, como questionários ou entrevistas semi-estruturadas. Isso porque a tomada de decisão sob risco, além de depender da cognição, também possui copiosas relações com sistemas neurais dedicados ao processamento emocional. 


\section{Conclusões}

O mundo atual passa por diversas e significativas mudanças, tanto tecnológicas como sociais. O crescimento no número de idosos impõe necessidades as quais a sociedade, o governo e a comunidade médica e científica devem suprir. Neste contexto, o presente trabalho se propôs a dar subsídios para que medidas sistemáticas e embasadas cientificamente possam ser propostas e executadas, de modo a responder a esse desafio.

A tomada de decisão é tão complexa quanto fundamental para uma interação adequada do ser humano com seu ambiente físico e social. Trata-se de uma função que depende da coordenação apropriada de todo o aparato neurocognitivo e emocional. Sua integridade é ainda mais fudamental para o idoso nos dias atuais, pois sua autonomia está cada vez maior, incluindo não só atividades básicas de vida diária, mas também ocupando frequentemente postos de trabalho. Desse modo, ele deve manejar diversas exigências com as questões típicas do envelhecimento, como o cuidado com a saúde e as limitações características deste período.

A despeito das limitações acima apontadas, a pesquisa aqui descrita trouxe importantes contribuições para a área. Por exemplo, um aspecto central observado no presente estudo é o papel que o parâmetro de aversão ao atraso do CGT pode ter no futuro das pesquisas e do tratamento para o CCL e para a demência. Tal variável é uma medida que traduz o controle da impulsividade do indivíduo, habilidade esta que está incluída nas funções executivas. Considerando-se que a literatura mostra que alterações em funções executivas podem ser importantes marcadores para o risco de conversão do CCL para a demência, entendse-se que este parâmetro do CGT poderá, no futuro, compor mais uma medida de risco, fundamental para o melhor direcionamento do tratamento precoce para a demência.

Os resultados obtidos também fornecem informações valiosas para o manejo clínico do paciente com CCL. Pôde-se observar que os pacientes com CCL tiveram uma postura 
mais retraída em suas apostas, possivelmente determinada pela percepção do paciente sobre suas limitações no controle da impulsividade e pelo viés negativo de seu autoconceito decorrente do diagnóstico. Frente a isso, sugere-se que o clínico que acompanha o paciente tenha especial atenção ao modo como o idoso lida com a situação de seu diagnóstico, isto é, se ele se retrai de suas atividades ou se mantém aberto a elas. Isso se deve ao fato de que o modo como essa reação se dará pode retroagir na própria evolução clínica desse indivíduo.

Vale lembrar, todavia, que o estudo aqui descrito representa apenas um enfoque particular nesse tema tão amplo. O modelo neurocognitivo faz parte de um rol de outras modalidades de estudo sobre como o ser humano elabora suas estratégias de tomada de decisão. Estudos naturalísticos sobre tomada de decisão, com a análise direta de situações reais, podem prover insights provavelmente não abarcados pela situação experimental e por instrumentos clínicos. Logo, a presente pesquisa também propõe ser um estímulo para que estudos futuros investiguem também a postura do idoso diretamente em seu ambiente natural, com situações e pessoas significativas de seu cotidiano. 


\section{Referências Bibliográficas}

Abraham, R., Moskvina, V., Sims, R., Hollingworth, P., Morgan, A., Georgieva, L. et al. (2008). A genome-wide association study for late-onset Alzheimer's disease using DNA pooling. BMC medical genomics, 1(1), 1-44.

Adlard, P. A., Perreau, V. M., Pop, V., \& Cotman, C. W. (2005). Voluntary exercise decreases amyloid load in a transgenic model of Alzheimer's disease. The Journal of Neuroscience, 25(17), 4217-4221.

Ahlskog, J. E., Geda, Y. E., Graff-Radford, N. R., \& Petersen, R. C. (2011). Physical exercise as a preventive or disease-modifying treatment of dementia and brain aging. Mayo Clinic Proceedings 86(9), 876-884.

Albert, M. S., DeKosky, S. T., Dickson, D., Dubois, B., Feldman, H. H., Fox, N. C. et al. (2011). The diagnosis of mild cognitive impairment due to Alzheimer's disease: Recommendations from the National Institute on Aging-Alzheimer's Association workgroups on diagnostic guidelines for Alzheimer's disease. Alzheimer's \& Dementia, 7(3), 270-279.

Alves, J. E. D. (2008). A transição demográfica e a janela de oportunidade.Braudel Papers, 1, 1-13.

American Psychiatric Association. (2013). The Diagnostic and Statistical Manual of Mental Disorders: DSM 5. Arlington: American Psychiatric Association.

Angevaren, M., Aufdemkampe, G., Verhaar, H. J., Aleman, A., \& Vanhees, L. (2008). Physical activity and enhanced fitness to improve cognitive function in older people without known cognitive impairment. The Cochrane database of systematic reviews, (2), CD005381.

Apostolova, L. G., \& Cummings, J. L. (2007). Neuropsychiatric manifestations in mild cognitive impairment: a systematic review of the literature. Dementia and geriatric cognitive disorders, 25(2), 115-126. 
Aprahamian, I., Martinelli, J., \& Yassuda, M. (2009). Doença de Alzheimer: revisão da epidemiologia e diagnóstico. Revista Brasileira de Clínica Médica, 27-35.

Aretouli, E., Okonkwo, O. C., Samek, J., \& Brandt, J. (2010). The fate of the $0.5 \mathrm{~s}$ : predictors of 2-year outcome in mild cognitive impairment. Journal of the International Neuropsychological Society, 17(2), 277.

Aretouli, E., Tsilidis, K. K., \& Brandt, J. (2013). Four-year outcome of mild cognitive impairment: The contribution of executive dysfunction. Neuropsychology, 27(1), 95.

Artero, S., Ancelin, M. L., Portet, F., Dupuy, A., Berr, C., Dartigues, J. F. et al. (2008). Risk profiles for mild cognitive impairment and progression to dementia are gender specific. Journal of Neurology, Neurosurgery \& Psychiatry, 79(9), 979-984.

Artola, A., Von Frijtag, J. C., Fermont, P. C., Gispen, W. H., Schrama, L. H., Kamal, A., \& Spruijt, B. M. (2006). Long-lasting modulation of the induction of LTD and LTP in rat hippocampal CA1 by behavioural stress and environmental enrichment. European Journal of Neuroscience, 23(1), 261-272.

Atti, A. R., Forlani, C., De Ronchi, D., Palmer, K., Casadio, P., Dalmonte, E., \& Fratiglioni, L. (2010). Cognitive Impairment after Age 60: Clinical and Social Correlates in the" Faenza Project". Journal of Alzheimer's Disease, 21(4), 1325-1334.

Azad, N. A., Al Bugami, M., \& Loy-English, I. (2007). Gender differences in dementia risk factors. Gender medicine, 4(2), 120-129.

Baker, L. D., Frank, L. L., Foster-Schubert, K., Green, P. S., Wilkinson, C. W., McTiernan, A. et al. (2010). Effects of aerobic exercise on mild cognitive impairment: a controlled trial. Archives of neurology, 67(1), 71-79.

Baldivia, B., Andrade, V. M., \& Bueno, O. F. A. (2008). Contribution of education, occupation and cognitively stimulating activities to the formation of cognitive reserve. Dementia \& Neuropsychologia, 2(3), 173-182.

Barnes, D. E., \& Yaffe, K. (2011). The projected effect of risk factor reduction on Alzheimer's disease prevalence. The Lancet Neurology, 10(9), 819-828. 
Barnes, D. E., Alexopoulos, G. S., Lopez, O. L., Williamson, J. D., \& Yaffe, K. (2006). Depressive symptoms, vascular disease, and mild cognitive impairment: findings from the Cardiovascular Health Study. Archives of general psychiatry, 63(3), 273-279.

Bayard, S., Raffard, S., \& Gely-Nargeot, M. C. (2011). Do facets of self-reported impulsivity predict decision-making under ambiguity and risk? Evidence from a community sample. Psychiatry research, 190(2), 322-326.

Bear, M. F., Connors, B. W. \& Paradiso, M. A. (2008). Neurociências: desvendando o sistema nervosa. Porto Alegre: Artmed.

Bechara, A. (2007). lowa Gambling Task Professional Manual. Lutz: Psychological Assessment Resources.

Bechara, A., \& Damasio, A. R. (2005). The somatic marker hypothesis: A neural theory of economic decision. Games and economic behavior, 52(2), 336-372.

Bechara, A. (2011). The somatic marker framework and the neurological basis of decisionmaking. In R. P. Ebstein, S. Shamay-Tsoory, \& S. H. Chew (Eds.), From DNA to Social Cognition (pp. 159-183). Hoboken, New Jersey: Wiley-Blackwell.

Bechara, A., Damasio, A. R., Damasio, H., \& Anderson, S. W. (1994). Insensitivity to future consequences following damage to human prefrontal cortex. Cognition, 50, 7-15. doi:10.1016/0010-0277(94)90018-3.

Bechara, A., Tranel, D., \& Damasio, H. (2000). Characterization of the decision-making deficit of patients with ventromedial prefrontal cortex lesions. Brain, 123, 2189-2202. doi:10.1093/brain/123.11.2189

Bechara, A., Damasio, H., Tranel, D., \& Damasio, A. R. (1997). Deciding advantageously before knowing the advantageous strategy. Science, 275, 1293-1295. doi:10.1126/science.275.5304.1293.

Boyle, P. A., Buchman, A. S., Wilson, R. S., Leurgans, S. E., \& Bennett, D. A. (2010). Physical Frailty Is Associated with Incident Mild Cognitive Impairment in Community-Based Older Persons. Journal of the American Geriatrics Society, 58(2), 248-255. 
Brand, M. (2008). Does the feedback from previous trials influence current decisions? A study on the role of feedback processing in making decisions under explicit risk conditions. Journal of Neuropsychology, 2, 431-443. doi:10.1348/174866407X220607.

Brandt, J., Aretouli, E., Neijstrom, E., Samek, J., Manning, K., Albert, M. S., \& BandeenRoche, K. (2009). Selectivity of executive function deficits in mild cognitive impairment. Neuropsychology, 23(5), 607.

Brand, M., \& Altstötter-Gleich, C. (2008). Personality and decision-making in laboratory gambling tasks-Evidence for a relationship between deciding advantageously under risk conditions and perfectionism. Personality and Individual Differences, 45(3), 226231.

Brand, M., Fujiwara, E., Borsutzky, S., Kalbe, E., Kessler, J., \& Markowitsch, H. J. (2005). Decision-making deficits of Korsakoff patients in a new gambling task with explicit rules: Associations with executive functions. Neuropsychology, 19, 267-277. doi:10.1037/0894-4105.19.3.267.

Brand, M., Kalbe, E., Kracht, L. W., Riebel, U., Münch, J., Kessler, J., \& Markowitsch, H. J. (2004). Organic and psychogenic factors leading to executive dysfunctions in a patient suffering from surgery of a colloid cyst of the Foramen of Monro. Neurocase, 10(6), 420-425.

Brand, M., Labudda, K., Kalbe, E., Hilker, R., Emmans, D., Fuchs, G. et al. (2004). Decision-making impairments in patients with Parkinson's disease. Behavioural neurology, 15(3-4), 77-85.

Brand, M., Labudda, K., \& Markowitsch, H. J. (2006). Neuropsychological correlates of decision-making in ambiguous and risky situations. Neural Networks, 19, 1266-1276. doi:10.1016/j.neunet.2006.03.001.

Brand, M., Laier, C., Pawlikowski, M., \& Markowitsch, H. J. (2009). Decision making with and without feedback: The role of intelligence, strategies, executive functions, and 
cognitive styles. Journal of Clinical and Experimental Neuropsychology, 31(8), 984998.

Brand, M., Pawlikowski, M., Labudda, K., Laier, C., Rothkirch, N., Von Rothkirch, N. (2009). Do amnesic patients with Korsakoff's syndrome use feedback when making decisions under risky conditions? An experimental investigation with the Game of Dice Task with and without feedback. Brain and Cognition, 69, 279-290. doi:10.1016/j.bandc.2008.08.003.

Brand, M., Recknor, E. C., Grabenhorst, F., \& Bechara, A. (2007). Decisions under ambiguity and decisions under risk: Correlations with executive functions and comparisons of two different gambling tasks with implicit and explicit rules. Journal of Clinical and Experimental Neuropsychology, 29, 86-99. doi:10.1080/13803390500507196.

Brand, M., \& Schiebener, J. (2013). Interactions of age and cognitive functions in predicting decision making under risky conditions over the life span. Journal of clinical and experimental neuropsychology, 35(1), 9-23..

Brucki S. M. D., Nitrini R., Caramelli P., Bertolucci P. H. F. \& Okamoto, I. H. (2003). Sugestões para o uso do mini-exame do estado mental no Brasil. Arquivos de NeuroPsiquiatria, 61(3): 777-781.

Busemeyer, J. R., \& Stout, J. C. (2002). A contribution of cognitive decision models to clinical assessment: decomposing performance on the Bechara gambling task. Psychological assessment, 14(3), 253.

Caixeta, L. \& Pinto, P. H. (2014). Reserva cerebral, plasticidade e o cérebro do idoso. In: L. Caixeta \& A. L. Teixeira, Neuropsicologia Geriátrica: neuropsiquiatria cognitiva em idosos. Porto Alegre: Artmed.

Cambridge Cognition (2005). CANTABeclipse. Test Administration Guide / Manual version 3.0.0. Cambridge: Cambridge Cognition Limited. 
Caracciolo, B., Gatz, M., Xu, W., Pedersen, N. L., \& Fratiglioni, L. (2012). Differential distribution of subjective and objective cognitive impairment in the population: a nation-wide twin-study. Journal of Alzheimer's Disease, 29(2), 393-403.

Caracciolo, B., Gatz, M., Xu, W., Marengoni, A., Pedersen, N. L., \& Fratiglioni, L. (2013). Relationship of subjective cognitive impairment and cognitive impairment no dementia to chronic disease and multimorbidity in a nation-wide twin study. Journal of Alzheimer's Disease, 36(2), 275-284.

Carrasquillo, M. M., Zou, F., Pankratz, V. S., Wilcox, S. L., Ma, L., Walker, L. P. et al. (2009). Genetic variation in PCDH11X is associated with susceptibility to late-onset Alzheimer's disease. Nature genetics, 41(2), 192-198.

Carter, S., \& Pasqualini, M. S. (2004). Stronger autonomic response accompanies better learning: A test of Damasio's somatic marker hypothesis. Cognition and Emotion, 18, 901-911. doi:10.1080/02699930341000338.

Casserly, I., \& Topol, E. J. (2004). Convergence of atherosclerosis and Alzheimer's disease: inflammation, cholesterol, and misfolded proteins. The Lancet, 363(9415), 1139-1146.

Chen, J. H., Lin, K. P., \& Chen, Y. C. (2009). Risk factors for dementia.Journal of the Formosan Medical Association, 108(10), 754-764.

Chu, C., \& Tranel, D. (1997). The autonomic-related cortex: pathology in Alzheimer's disease. Cerebral Cortex, 7(1), 86-95. doi:10.1093/cercor/7.1.86.

Clark, L., Bechara, A., Damasio, H., Aitken, M. R. F., Sahakian, B. J., \& Robbins, T. W. (2008). Differential effects of insular and ventromedial prefrontal cortex lesions on risky decision-making. Brain, 131, 1311-1322. doi:10.1093/brain/awn066.

Clark, L. R., Schiehser, D. M., Weissberger, G. H., Salmon, D. P., Delis, D. C., \& Bondi, M. W. (2012). Specific measures of executive function predict cognitive decline in older adults. Journal of the International Neuropsychological Society, 18(01), 118-127.

Cohen, J. (2013). Statistical power analysis for the behavioral sciences. New Jersey: Routledge Academic. 
Crone, E. A., Somsen, R. J. M., Van Beek, B., \& Van der Molen, M. W. (2004).Heart rate and skin conductance analysis of antecendents and consequences of decision making. Psychophysiology, 41, 531-540. doi:10.1111/j.1469-8986.2004.00197.x

Damasio, A. R. (1994). Descartes' Error: Emotion, Reason, and the Human Brain. New York: Grosset/Putnam.

Damasio, A. R., Tranel, D., \& Damasio, H. (1991). Somatic markers and the guidance of behavior: Theory and preliminary testing. In H. S. Levin, H. M. Eisenberg, \& A. L. Benton (Eds.), Frontal Lobe Function and Dysfunction(pp. 217-228). New York: Oxford University Press.

Daviglus, M. L., Plassman, B. L., Pirzada, A., Bell, C. C., Bowen, P. E., Burke, J. R. et al. (2011). Risk factors and preventive interventions for Alzheimer disease: state of the science. Archives of neurology, 68(9), 1185-1190.

Deakin, J., Aitken, M., Robbins, T., \& Sahakian, B. J. (2004). Risk taking during decisionmaking in normal volunteers changes with age. Journal of the International Neuropsychological Society, 10(04), 590-598.

Denburg, N. L., Cole, C. A., Hernandez, M., Yamada, T. H., Tranel, D., Bechara, A., \& Wallace, R. B. (2007). The Orbitofrontal Cortex, Real-World Decision Making, and Normal Aging. Annals of the New York Academy of Sciences, 1121(1), 480-498.

Del Duca, G. F., Silva, M. C. D., \& Hallal, P. C. (2009). Incapacidade funcional para atividades básicas e instrumentais da vida diária em idosos. Revista Saúde Pública, 43(5), 796-805.

Delazer, M., Sinz, H., Zamarian, L., \& Benke, T. (2007). Decision-making with explicit and stable rules in mild Alzheimer's disease. Neuropsychologia, 45(8), 1632-1641. doi:10.1016/j.neuropsychologia.2007.01.006.

Drobetz, R., Maercker, A., \& Forstmeier, S. (2012). Delay of gratification in old age: assessment, age-related effects, and clinical implications. Aging clinical and experimental research, 24(1), 6-14. 
Dror, I. E., Katona, M., \& Mungur, K. (1998). Age differences in decision-making: To take a risk or not? Gerontology, 44(2), 67-71.

Edwards, W. (1954). The theory of decision-making. Psychological Bulletin, 51, 380417.doi: $10.1037 / \mathrm{h} 0053870$

Epstein, L. G., \& Wang, T. (1994). Intertemporal asset pricing under knightian uncertainty. Econometrica, 62, 283-322.

Fabrigoule, C., Letenneur, L., Dartigues, J. F., Zarrouk, M., Commenges, D., \& BarbergerGateu, P. (1995). Social and leisure activities and risk of dementia: a prospective longitudinal study. Journal of the American Geriatric Society, 43(5), 485-490.

Farina, N., Isaac, M. G., Clark, A. R., Rusted, J., \& Tabet, N. (2012). Vitamin E for Alzheimer's dementia and mild cognitive impairment. Cochrane Database Syst Rev, 11.

Farrer, L. A., Cupples, L. A., Haines, J. L., Hyman, B., Kukull, W. A., Mayeux, R. et al. (1997). Effects of age, sex, and ethnicity on the association between apolipoprotein $E$ genotype and Alzheimer disease: a meta-analysis. Jama, 278(16), 1349-1356.

Folstein M. F., Folstein S. E. \& McHugh P. R. (1975). "Mini-Mental State". A practical method for gradin the state of patients for the clinician. Journal of Psychiatric Research, 12, 189-198.

Fratiglioni, L., Wang, H. X., Ericsson, K., Maytan, M., \& Winblad, B. (2000). Influence of social network on occurrence of dementia: a community-based longitudinal study. The lancet, 355(9212), 1315-1319.

Ganguli, M., Dodge, H. H., Chen, P., Belle, S., \& DeKosky, S. T. (2000). Ten-year incidence of dementia in a rural elderly US community population The MoVIES Project. Neurology, 54(5), 1109-1116.

Gates, N. J., Sachdev, P. S., Singh, M. A. F., \& Valenzuela, M. (2011). Cognitive and memory training in adults at risk of dementia: a systematic review. BMC geriatrics, 11(1), 55. 
Geda, Y. E., Knopman, D. S., Mrazek, D. A., Jicha, G. A., Smith, G. E., Negash, S. et al. (2006). Depression, apolipoprotein E genotype, and the incidence of mild cognitive impairment: a prospective cohort study. Archives of Neurology, 63(3), 435-440.

Giacomin, K. C., Moraes, G. V. O., \& Teixeira, A. L. (2014). Entrevista clínica e relação profissional com o paciente geriátrico. In: L. Caixeta \& A. L. Teixeira, Neuropsicologia Geriátrica: neuropsiquiatria cognitiva em idosos. Porto Alegre: Artmed.

Godinho, C., Gorczevski, I., \& Heisler, A. (2010). Clinical and demographic characteristics of elderly patients with dementia assisted at an outpatient clinic in Southern Brazil. Dementia \& Neuropsychologia, 4(1), 42-46.

Green, L., Fry, A. F., \& Myerson, J. (1994). Discounting of delayed rewards: A life-span comparison. Psychological Science, 5(1), 33-36.

Griffith, H. R., Okonkwo, O. C., den Hollander, J. A., Belue, K., Copeland, J., Harrell, L. E. et al. (2010). Brain metabolic correlates of decision making in amnestic mild cognitive impairment. Aging, Neuropsychology, and Cognition, 17(4), 492-504.

Gupta, R., Koscik, T. R., Bechara, A., \& Tranel, D. (2011). The amygdala and decisionmaking. Neuropsychologia, $\quad$ 49(4), 760-766. doi:10.1016/j.neuropsychologia.2010.09.029.

Haaland, V. Ø., Landrø, N. I., Kano, M., Ito, M., \& Fukudo, S. (2007). Decision making as measured with the lowa Gambling Task in patients with borderline personality disorder. Journal of the International Neuropsychological Society, 13, 699-703. doi:10.1017/S1355617707070890.

Haier, R., Siegel, B., McLachlan, A., Soderling, E., Lottenberg, S., \& Buchsbaum, M. (1992). Regional glucose metabolic changes after learning a complex visuospatial/motor task: a PET study. Brain Research Bulletin, 570, 134-143.

Inouye, K., Pedrazzani, E. S., \& Pavarini, S. C. I. (2008). Octogenários e cuidadores: perfil sócio-demográfico e correlação da variável qualidade de vida. Texto \& Contexto Enfermagem, 17(2), 350-357. 
Johns, E. K., Phillips, N. A., Belleville, S., Goupil, D., Babins, L., Kelner, N., ... \& Chertkow, H. (2012). The profile of executive functioning in amnestic mild cognitive impairment: disproportionate deficits in inhibitory control.Journal of the International Neuropsychological Society, 18(03), 541-555.

Kandel, E. R., Schwartz, J. H., \& Jessell, T. M. (2012). Principles of neural science. New York: McGraw-Hill.

Karsch, U. M. (2003). Idosos dependentes: famílias e cuidadores. Caderno de Saúde Pública, 19(3), 861-866.

Katzman, R., Terry, R., DeTeresa, R., Brown, T., Davies, P., Fuld, P. \& Peck, A. (1988). Clinical, pathological, and neurochemical changes in dementia: a subgroup with preserved mental status and numerous neocortical plaques. Annals of neurology, 23(2), 138-144.

Kim, S., \& Lee, D. (2011). Prefrontal cortex and impulsive decision-making. Biological psychiatry, 69(12), 1140-6. doi:10.1016/j.biopsych.2010.07.005.

Knapp, M., \& Prince, M. (2007). Dementia UK: report to the Alzheimer's Society. Kings College London and London School of Economics and Political Science.

Knight, F. H. (1921).Risk, Uncertainty, and Profit. Boston, MA: Hart, Schaffner \& Marx; Houghton Mifflin Co.

Kukull, W. A., Higdon, R., Bowen, J. D., McCormick, W. C., Teri, L., Schellenberg, G. D. et al. (2002). Dementia and Alzheimer disease incidence: a prospective cohort study. Archives of Neurology,59(11), 1737-1746.

Lamar, M., \& Resnick, S. M. (2004). Aging and prefrontal functions: dissociating orbitofrontal and dorsolateral abilities. Neurobiology of aging, 25(4), 553-558.

Launer, L. J., Andersen, K., Dewey, M., Letenneur, L., Ott, A., Amaducci, L. A. et al. (1999). Rates and risk factors for dementia and Alzheimer's disease Results from EURODEM pooled analyses. Neurology, 52(1), 78-78. 
Lautenschlager, N. T., Cox, K., \& Kurz, A. F. (2010). Physical activity and mild cognitive impairment and Alzheimer's disease. Current neurology and neuroscience reports, $10(5)$, 352-358.

Leber, A. B., Turk-Browne, N. B., \& Chun, M. M. (2008). Neural predictors of moment-tomoment fluctuations in cognitive flexibility. Proceedings of the National Academy of Sciences, 105(36), 13592-13597.

Lebrão, M. L. (2007). O envelhecimento no Brasil: aspectos da transição demográfica e epidemiológica. Saúde Coletiva, 4(17), 135-40.

LeDoux, J. (2007). The amygdala. Current Biology, 17(20), R868-R874.

Li, H., Li, J., Li, N., Li, B., Wang, P., \& Zhou, T. (2011). Cognitive intervention for persons with mild cognitive impairment: A meta-analysis. Ageing research reviews, 10(2), 285296.

Li, G. E., Shen, Y. C., Chen, C. H., Zhau, Y. W., Li, S. R., \& Lu, M. (1991). A three-year follow-up study of age-related dementia in an urban area of Beijing. Acta Psychiatrica Scandinavica, 83(2), 99-104.

Lloret, A., Badía, M. C., Mora, N. J., Pallardó, F. V., Alonso, M. D., \& Viña, J. (2009). Vitamin E paradox in Alzheimer's disease: it does not prevent loss of cognition and may even be detrimental. Journal of Alzheimer's Disease, 17(1), 143-149.

Löckenhoff, C. E., O'Donoghue, T., \& Dunning, D. (2011). Age differences in temporal discounting: the role of dispositional affect and anticipated emotions. Psychology and aging, 26(2), 274.

Lopez, O. L., Jagust, W. J., Dulberg, C., Becker, J. T., DeKosky, S. T., Fitzpatrick, A. et al. (2003). Risk factors for mild cognitive impairment in the Cardiovascular Health Study Cognition Study: part 2.Archives of neurology, 60(10), 1394-1399.

López-Pousa, S., Vilalta-Franch, J., Llinàs-Regla, J., Garre-Olmo, J., \& Román, G. C. (2004). Incidence of dementia in a rural community in Spain: the Girona cohort study. Neuroepidemiology, 23(4), 170-177. 
Luchsinger, J. A., Reitz, C., Honig, L. S., Tang, M. X., Shea, S., \& Mayeux, R. (2005). Aggregation of vascular risk factors and risk of incident Alzheimer disease. Neurology, 65(4), 545-551.

Luck, T., Luppa, M., Briel, S., \& Riedel-Heller, S. G. (2010). Incidence of mild cognitive impairment: a systematic review. Dementia and geriatric cognitive disorders, 29(2), 164-175.

Mandell, A. M. \& Green, R. C. (2011). Alzheimer's Disease. In: A. Budson \& N. Kowall (Eds.), The Handbook of Alzheimer's Disease and other dementias. Oxford: WileyBlackwell.

Márquez, A. M., \& Bailén, J. R. A. (2012). Demencia tipo Alzheimer y toma de decisiones. Alzheimer: Realidades e investigación en demencia, 52, 12-20. doi:10.5538/11371242.2012.52.12.

de Melo, M. C., Souza, A. L., Leandro, E. L., de Arruda Mauricio, H., Silva, I. D., \& de Oliveira, J. M. O. (2009). A educação em saúde como agente promotor de qualidade de vida para o idoso. Ciência \& saúde coletiva, 14(5), 1579-1586.

MacPherson, S. E., Phillips, L. H., \& Della Sala, S. (2002). Age, executive function and social decision making: A dorsolateral prefrontal theory of cognitive aging. Psychology and aging, 17(4), 598.

Miller, D. I., Taler, V., Davidson, P. S., \& Messier, C. (2012). Measuring the impact of exercise on cognitive aging: methodological issues. Neurobiology of aging, 33(3), 622-629.

Mohammed, A. H., Zhu, S. W., Darmopil, S., Hjerling-Leffler, J., Ernfors, P., Winblad, B. et al. (2002). Environmental enrichment and the brain. Progress in brain research, 138, 109-133.

Monastero, R., Mangialasche, F., Camarda, C., Ercolani, S., \& Camarda, R. (2009). A systematic review of neuropsychiatric symptoms in mild cognitive impairment. Journal of Alzheimer's disease, 18(1), 11-30. 
Motta, L. B. D., \& Aguiar, A. C. D. (2007). Novas competências profissionais em saúde eo envelhecimento populacional brasileiro: integralidade, interdisciplinaridade e intersetorialidade. Ciência \& Saúde Coletiva, 12(2), 363-372.

Must, A., Szabó, Z., Bódi, N., Szász, A., Janka, Z., \& Kéri, S. (2006). Sensitivity to reward and punishment and the prefrontal cortex in major depression. Journal of Affective Disorders, 90, 209-215. doi:10.1016/j.jad.2005.12.005.

Nascimento, E. (2004). WAIS-III: Escala de Inteligência Wechsler para Adultos:Manual. São Paulo: Casa do Psicólogo.

Nitrini, R., Caramelli, P., Herrera Jr, E., Bahia, V. S., Caixeta, L. F., Radanovic, M. et al. (2004). Incidence of dementia in a community-dwelling Brazilian population. Alzheimer Disease \& Associated Disorders, 18(4), 241-246.

Paiva, P. D. T. A., \& Wajnman, S. (2005). Das causas às consequências econômicas da transição demográfica no Brasil. Revista brasileira de estudos populacionais, 22(2), 13-15.

Petersen, R. C., Caracciolo, B., Brayne, C., Gauthier, S., Jelic, V., \& Fratiglioni, L. (2014). Mild cognitive impairment: a concept in evolution. Journal of internal medicine, 275(3), 214-228.

Petersen, R. C., Smith, G. E., Waring, S. C., Ivnik, R. J., Tangalos, E. G., \& Kokmen, E. (1999). Mild cognitive impairment: clinical characterization and outcome. Archives of neurology, 56(3), 303-308.

Petersen, R. C., Thomas, R. G., Grundman, M., Bennett, D., Doody, R., Ferris, S. et al. (2005). Vitamin E and donepezil for the treatment of mild cognitive impairment. New England Journal of Medicine, 352(23), 2379-2388.

Prakash, R. S., Voss, M. W., Erickson, K. I., \& Kramer, A. F. (2014). Physical Activity and Cognitive Vitality. Annual review of psychology. Recuperado em 12 de setembro, 2014, de http://www.annualreviews.org/doi/abs/10.1146/annurev-psych-010814015249?journalCode=psych. 
Prince, M., \& Jackson, J. (2009). World Alzheimer's report. London, Alzheimer's Disease International.

Prince, M., Bryce, R., Albanese, E., Wimo, A., Ribeiro, W., \& Ferri, C. P. (2013). The global prevalence of dementia: a systematic review and metaanalysis. Alzheimer's \& Dementia, 9(1), 63-75.

Queiroz, V. S., \& de Brito Ramalho, H. M. (2009). A escolha ocupacional dos idosos no mercado de trabalho: evidencias para o Brasil. Revista Economia, 10(4), 817-848.

Rahman, S., Robbins, T. W., Hodges, J. R., Mehta, M. A., Nestor, P. J., Clark, L., \& Sahakian, B. J. (2005). Methylphenidate ('Ritalin') can ameliorate abnormal risktaking behavior in the frontal variant of frontotemporal dementia. Neuropsychopharmacology, 31(3), 651-658.

Rahman, S., Sahakian, B. J., Hodges, J. R., Rogers, R. D., \& Robbins, T. W. (1999). Specific cognitive deficits in mild frontal variant frontotemporal dementia. Brain, 122(8), 1469-1493.

Ratnavalli, E., Brayne, C., Dawson, K., \& Hodges, J. R. (2002). The prevalence of frontotemporal dementia. Neurology, 58(11), 1615-1621.

Read, D., \& Read, N. L. (2004). Time discounting over the lifespan. Organizational behavior and human decision processes, 94(1), 22-32.

Reisberg, B., Ferris, S. H., de Leon, M. J., \& Crook, T. (1982). The Global Deterioration Scale for assessment of primary degenerative dementia. The American journal of psychiatry, 139(9), 1136-1139.

Reisberg, B., Ferris, S. H., de Leon, M. J., Franssen, E. S. E., Kluger, A., Mir, P. et al. (1988). Stage-specific behavioral, cognitive, and in vivo changes in community residing subjects with age-associated memory impairment and primary degenerative dementia of the Alzheimer type. Drug Development Research, 15(2-3), 101-114.

Reitz, C., Brayne, C., \& Mayeux, R. (2011). Epidemiology of Alzheimer disease. Nature reviews Neurology, 7(3), 137-152. doi:10.1038/nrneurol.2011.2. 
Roberts, R. O., Geda, Y. E., Knopman, D. S., Christianson, T. J., Pankratz, V. S., Boeve, B. F. et al. (2008). Association of duration and severity of diabetes mellitus with mild cognitive impairment. Archives of neurology, 65(8), 1066-1073.

Ruitenberg, A., Ott, A., van Swieten, J. C., Hofman, A., \& Breteler, M. (2001). Incidence of dementia: does gender make a difference?. Neurobiology of aging, 22(4), 575-580.

Russ, T. C., \& Morling, J. R. (2012). Cholinesterase inhibitors for mild cognitive impairment. The Cochrane database of systematic reviews, 9, CD009132-CD009132.

Salzman, C. D., \& Fusi, S. (2010). Emotion, cognition, and mental state representation in amygdala and prefrontal cortex. Annual review of neuroscience, 33, 173.

Schiebener, J., Zamarian, L., Delazer, M., \& Brand, M. (2011). Executive functions, categorization of probabilities, and learning from feedback: What does really matter for decision making under explicit risk conditions? Journal of clinical and experimental neuropsychology, 33(9), 1025-1039.

Shiv, B., Loewenstein, G., \& Bechara, A. (2005). The dark side of emotion in decisionmaking: When individuals with decreased emotional reactions make more advantageous decisions. Cognitive Brain Research, 23(1), 85-92.

Simon, S. S., Yokomizo, J. E., \& Bottino, C. (2012). Cognitive intervention in amnestic Mild Cognitive Impairment: A systematic review. Neuroscience \& Biobehavioral Reviews, 36(4), 1163-1178.

Sinz, H., Zamarian, L., Benke, T., Wenning, G. K., \& Delazer, M. (2008). Impact of ambiguity and risk on decision making in mild Alzheimer's disease. Neuropsychologia, 46(7), 2043-55. doi:10.1016/j.neuropsychologia.2008.02.002.

Smoski, M. J., Lynch, T. R., Rosenthal, M. Z., Cheavens, J. S., Chapman, A. L., \& Krishnan, R. R. (2008). Decision-making and risk aversion among depressive adults. Journal of Behavior Therapy and Experimental Psychiatry, 39, 567-76. doi:10.1016/j.jbtep.2008.01.004. 
Soares, V. L. D., Soares, C. D. \& Caixeta, L. (2012). Métodos de avaliação neuropsicológica no diagnóstico da Doença de Alzheimer. In: L. Caixeta et al., Doença de Alzheimer. Porto Alegre: Artmed.

Solfrizzi, V., Panza, F., Colacicco, A. M., D'introno, A., Capurso, C., Torres, F. et al. (2004). Vascular risk factors, incidence of $\mathrm{MCl}$, and rates of progression to dementia. Neurology, 63(10), 1882-1891.

Sofroniew, M. V., Howe, C. L., \& Mobley, W. C. (2001). Nerve growth factor signaling, neuroprotection, and neural repair. Annual review of neuroscience, 24(1), 1217-1281.

Sosa-Ortiz, A. L., Acosta-Castillo, I., \& Prince, M. J. (2012). Epidemiology of dementias and Alzheimer's disease. Archives of medical research, 43(8), 600-608.

Sporns, O. (2011). Networks of the Brain. Cambridge: The MIT Press.

Stella, F. (2012). Comprometimento Cognitivo Leve. In: L. Caixeta \& A. L. Teixeira, Neuropsicologia Geriátrica: neuropsiquiatria cognitiva em idosos. Porto Alegre: Artmed.

Stephan, B. C., Brayne, C., Savva, G. M., \& Matthews, F. E. (2011). Occurrence of medical co-morbidity in mild cognitive impairment: implications for generalisation of $\mathrm{MCl}$ research. Age and ageing, 40(4), 501-507.

Stephan, B. C. M., Hunter, S., Harris, D., Llewellyn, D. J., Siervo, M., Matthews, F. E., \& Brayne, C. (2011). The neuropathological profile of mild cognitive impairment (MCl): a systematic review. Molecular psychiatry, 17(11), 1056-1076.

Stepaniuk, J., Ritchie, L. J., \& Tuokko, H. (2008). Neuropsychiatric impairments as predictors of mild cognitive impairment, dementia, and Alzheimer's disease. American journal of Alzheimer's disease and other dementias, 23(4), 326-333.

Stern, Y. (2002). What is cognitive reserve? Theory and research application of the reserve concept. Journal of the International Neuropsychological Society, 8(03), 448-460.

Stern, Y. (2009). Cognitive reserve. Neuropsychologia, 47(10), 2015-2028.

Stern, Y. (2012). Cognitive reserve in ageing and Alzheimer's disease. The Lancet Neurology, 11(11), 1006-1012. 
Suh, G. H., \& Shah, A. (2001). A review of the epidemiological transition in dementiacross-national comparisons of the indices related to Alzheimer's disease and vascular dementia. Acta Psychiatrica Scandinavica, 104(1), 4-11.

Summers, M. J., \& Saunders, N. L. (2012). Neuropsychological measures predict decline to Alzheimer's dementia from mild cognitive impairment.Neuropsychology, 26(4), 498.

Suzuki, A., Hirota, A., Takasawa, N., \& Shigemasu, K. (2003). Application of the somatic marker hypothesis to individual differences in decision-making. Biological Psychology, 65, 81-88. doi:10.1016/S0301-0511(03)00093-0.

Tabert, M. H., Manly, J. J., Liu, X., Pelton, G. H., Rosenblum, S., Jacobs, M., ... \& Devanand, D. P. (2006). Neuropsychological prediction of conversion to Alzheimer disease in patients with mild cognitive impairment. Archives of General Psychiatry, 63(8), 916-924.

Tang, Y. P., Wang, H., Feng, R., Kyin, M., \& Tsien, J. Z. (2001). Differential effects of enrichment on learning and memory function in NR2B transgenic mice. Neuropharmacology, 41(6), 779-790.

Tervo, S., Kivipelto, M., Hänninen, T., Vanhanen, M., Hallikainen, M., Mannermaa, A., \& Soininen, H. (2004). Incidence and risk factors for mild cognitive impairment: a population-based three-year follow-up study of cognitively healthy elderly subjects. Dementia and geriatric cognitive disorders, 17(3), 196-203.

Valenzuela, M. J. (2008). Brain reserve and the prevention of dementia.Current opinion in psychiatry, 21(3), 296-302.

Valenzuela, M. J., \& Sachdev, P. (2006). Brain reserve and dementia: a systematic review. Psychological medicine, 36(04), 441-454.

Valenzuela, M. J., Breakspear, M., \& Sachdev, P. (2007). Complex mental activity and the aging brain: molecular, cellular and cortical network mechanisms. Brain Research Reviews, 56(1), 198-213. 
Valenzuela, M. J., Matthews, F. E., Brayne, C., Ince, P., Halliday, G., Kril, J. J. et al. (2012). Multiple biological pathways link cognitive lifestyle to protection from dementia. Biological psychiatry, 71(9), 783-791.

Vandenbos, Gary R. (Org.) Dicionário de Psicologia da APA. Porto Alegre: Artmed, 2010.

Verdejo-García, A., Pérez-García, M., \& Bechara, A. (2006). Emotion, decision-making and substance dependence: a somatic-marker model of addiction. Current neuropharmacology, 4(1), 17.

Xu, W., Caracciolo, B., Wang, H. X., Winblad, B., Bäckman, L., Qiu, C., \& Fratiglioni, L. (2010). Accelerated progression from mild cognitive impairment to dementia in people with diabetes. Diabetes, 59(11), 2928-2935.

Yip, A. G., Brayne, C., \& Matthews, F. E. (2006). Risk factors for incident dementia in England and Wales: The Medical Research Council Cognitive Function and Ageing Study. A population-based nested case-control study.Age and ageing, 35(2), 154160.

Wajnman, S., Oliveira, A. M. H. C., \& Oliveira, E. D. (2004). Os idosos no mercado de trabalho: tendências e conseqüências. In: A. A. Camarano, Os novos idosos brasileiros: muito além dos 60? Rio de Janeiro: Ipea.

Wang, H. X., Xu, W., \& Pei, J. J. (2012). Leisure activities, cognition and dementia. Biochimica et Biophysica Acta (BBA)-Molecular Basis of Disease, 1822(3), 482-491.

Whitmer, R. A., Sidney, S., Selby, J., Johnston, S. C., \& Yaffe, K. (2005). Midlife cardiovascular risk factors and risk of dementia in late life. Neurology, 64(2), 277-281.

Winblad, B., Palmer, K., Kivipelto, M., Jelic, V., Fratiglioni, L., Wahlund, L. O. et al. (2004). Mild cognitive impairment-beyond controversies, towards a consensus: report of the International Working Group on Mild Cognitive Impairment. Journal of internal medicine, 256(3), 240-246. 
Wood, S., Busemeyer, J., Koling, A., Cox, C. R., \& Davis, H. (2005). Older adults as adaptive decision makers: evidence from the lowa Gambling Task. Psychology and aging, 20(2), 220.

World Health Organization (2011). Global health and aging. Recuperado em 14 de setembro de 2012, de http://www.who.int/ageing/publications/global_health.pdf

World Health Organization (2012). Dementia: a public health priority. Recuperado em 14 de setembro, 2012 , de http://whqlibdoc.who.int/publications/2012/9789241564459_eng.pdf.

Zamarian, L., Sinz, H., Bonatti, E., Gamboz, N., \& Delazer, M. (2008). Normal aging affects decisions under ambiguity, but not decisions under risk. Neuropsychology, 22, 645657. doi:10.1037/0894-4105.22.5.645.

Zamarian, L., Weiss, E. M., \& Delazer, M. (2010). The impact of mild cognitive impairment on decision making in two gambling tasks. The Journals of Gerontology Series B: Psychological Sciences and Social Sciences, gbq067.

Zheng, D., Sun, H., Dong, X., Liu, B., Xu, Y., Chen, S., ... \& Wang, X. (2014). Executive dysfunction and gray matter atrophy in amnestic mild cognitive impairment. Neurobiology of aging, 35(3), 548-555.

Ziegler-Graham, K., Brookmeyer, R., Johnson, E., \& Arrighi, H. M. (2008). Worldwide variation in the doubling time of Alzheimer's disease incidence rates. Alzheimer's \& Dementia, 4(5), 316-323. 


\title{
Apêndices
}

\section{APÊNDICE A - Termo de Consentimento Livre e Esclarecido}

\author{
TERMO DE CONSENTIMENTO LIVRE E ESCLARECIDO \\ Avaliação neuropsicológica da tomada de decisão no Comprometimento Cognitivo Leve \\ Pesquisadores: Rodolfo Santos Flaborea \\ Prof. Dr. Marcelo Fernandes da Costa.
}

Você está convidado(a) a participar de um estudo sobre os aspectos neuropsicológicos da tomada de decisão em pacientes com Comprometimento Cognitivo Leve.

Serão utilizados vários instrumentos padronizados para exame de atenção, memória, linguagem, funções visuo-espaciais, raciocínio e tomada de decisão. São testes que compõem uma bateria de avaliação neuropsicológica, que demanda, aproximadamente, 40 minutos para a aplicação em cada sessão. Os testes não são invasivos e não oferecem riscos.

Após a conclusão da pesquisa, os dados coletados serão armazenados em meio impresso e eletrônico no Instituto de Psicologia da USP, Bloco D, sala 202.

Os resultados serão sigilosos o seu nome não será divulgado. Apenas os dados dos resultados da avaliação poderão ser divulgados em publicações científicas.

Como voluntário(a) para este estudo:

- Você pode esclarecer quaisquer dúvidas sobre este estudo.

- A sua participação é totalmente voluntária. Você pode recusar-se a participar da pesquisa ou retirar seu consentimento durante o desenvolvimento da mesma, sem qualquer penalização ou prejuízo.

- Você terá conhecimento dos resultados obtidos mediante entrega de relatório de avaliação neuropsicológica e entrevista devolutiva, caso desejar.

- Caso seja detectada qualquer alteração grave, será fornecida orientação quanto à necessidade de encaminhamento.

"Após ter lido as informações acima (ou alguém ter lido), estou ciente de que o estudo será útil para o conhecimento sobre os aspectos neuropsicológicos da tomada de decisão no Comprometimento Cognitivo Leve. Autorizo a utilização dos resultados divulgação em publicações científicas".

Este documento possui duas vias, sendo uma retida pelo participante da pesquisa ou por seu representante legal e uma arquivada pelo pesquisador.

Comitê de Ética em Pesquisa com Seres Humanos do IPUSP

Endereço: Av Prof. Mello Moraes, 1721, Bloco G, sala 27 - Cidade Universitária

CEP: 05508-030 São Paulo - SP - Telefones: (11) 3091-4182

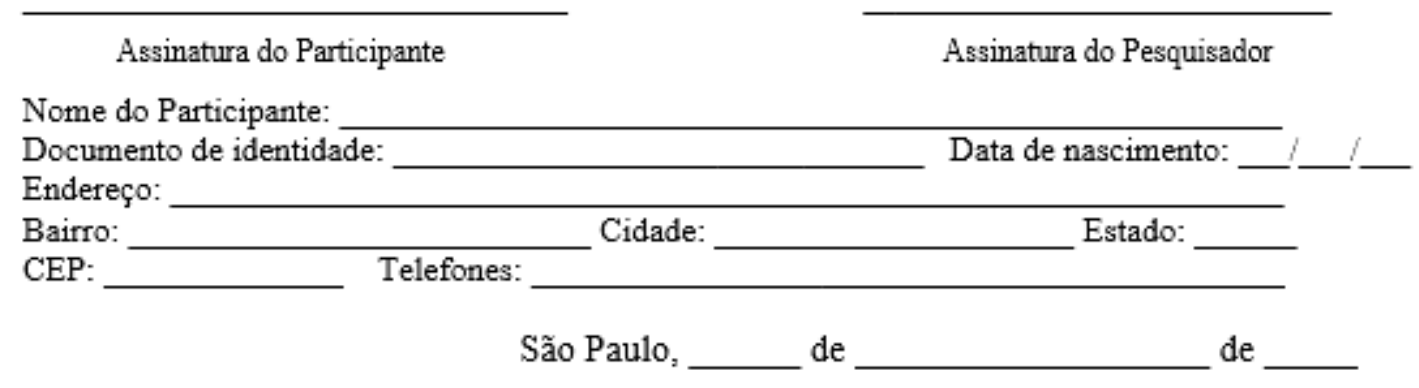


APÊNDICE B - Boxplots referente à idade e à escolaridade
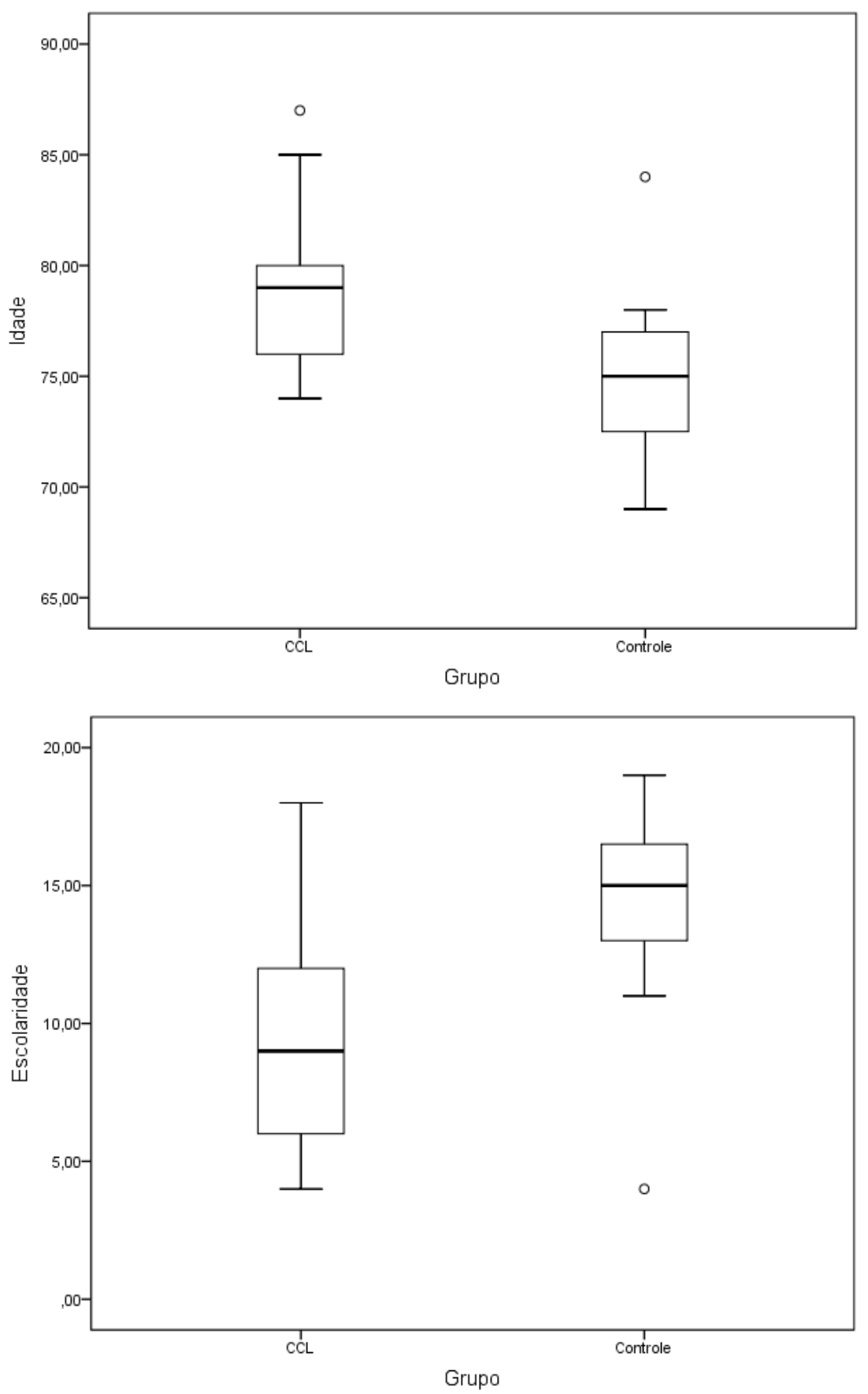
APÊNDICE C - Boxplot referente ao escore do MEEM.

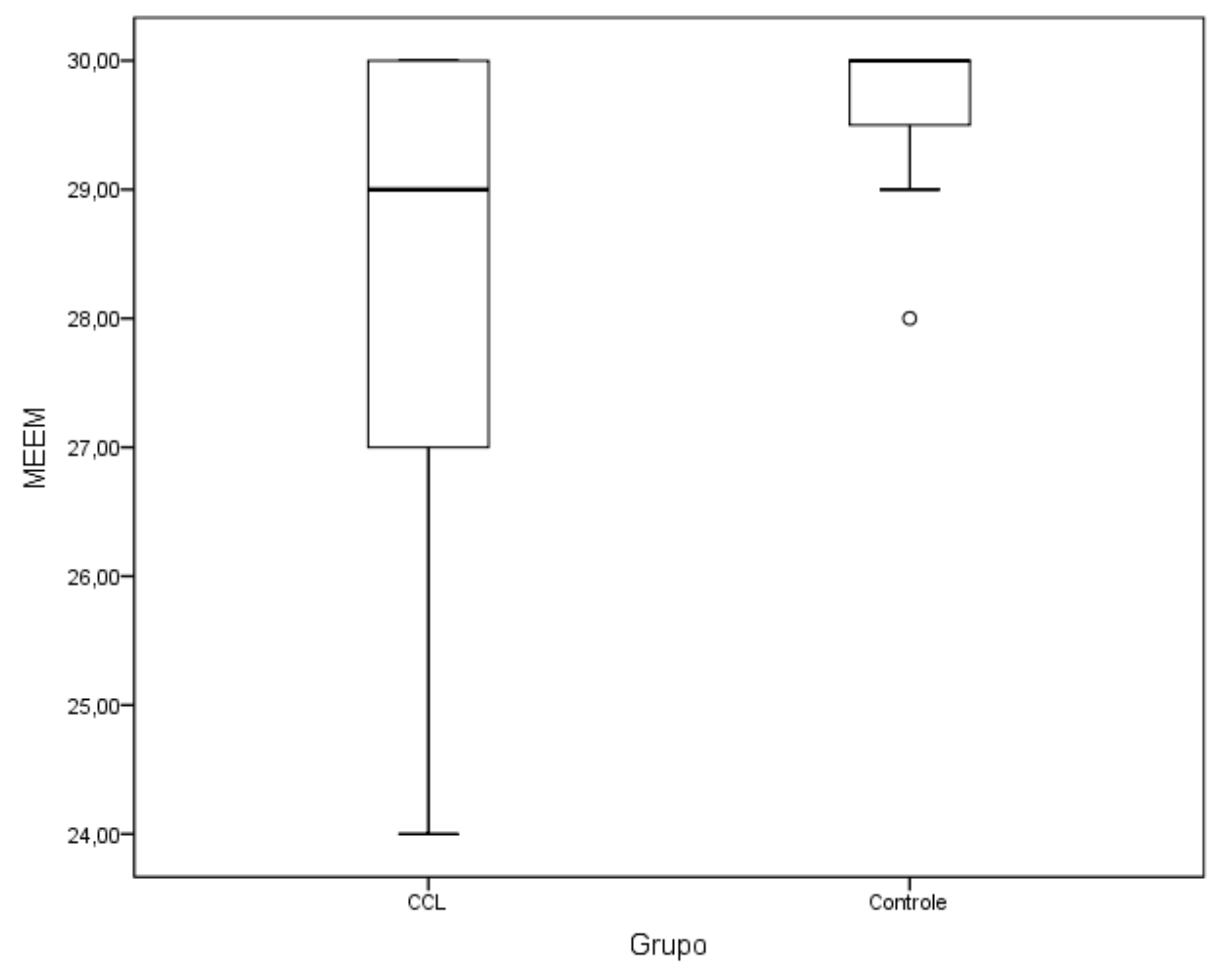


APÊNDICE D - Boxplots referentes ao intervalo de deliberação, qualidade de tomada de decisão e ajuste de risco.
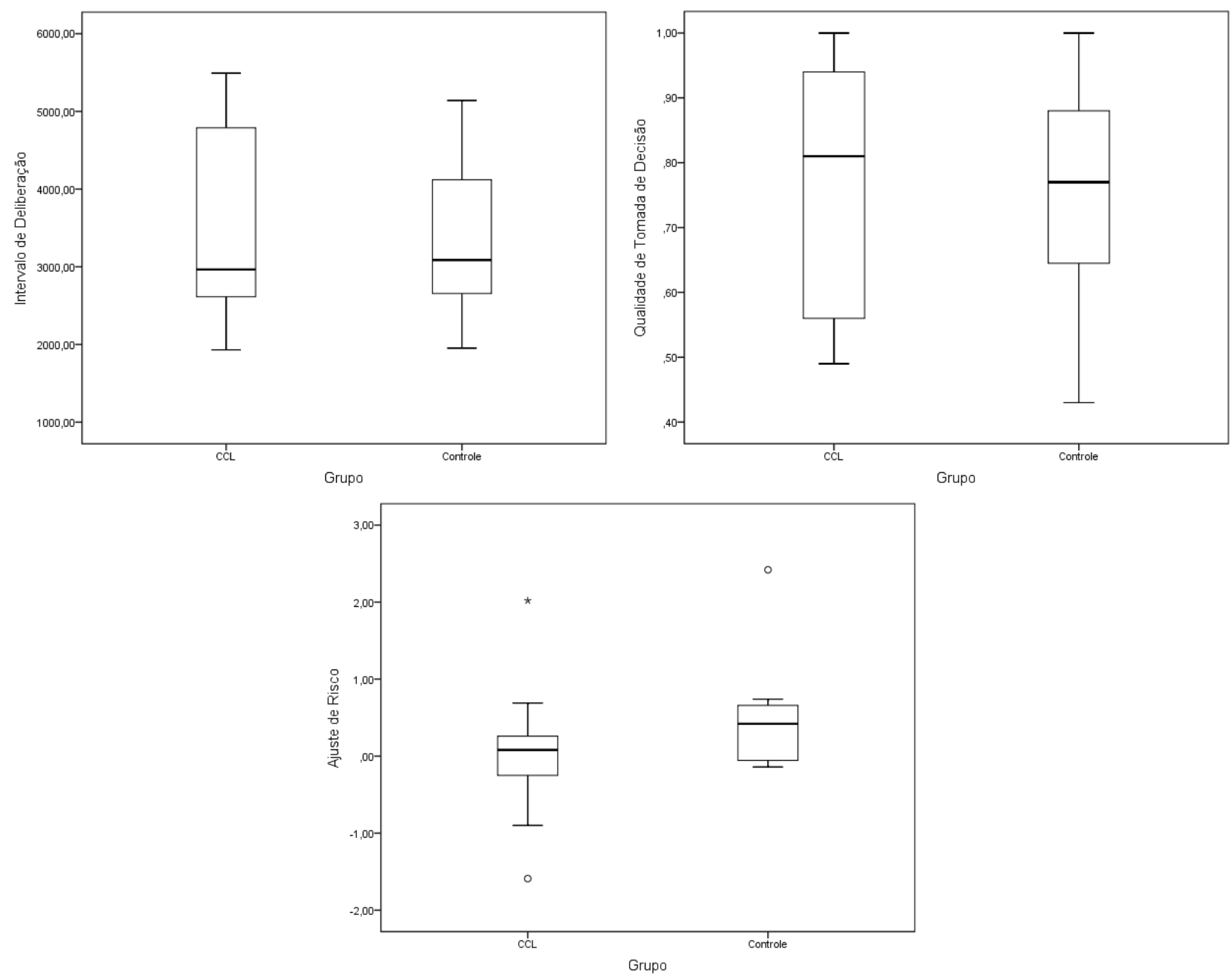
APÊNDICE E - Intervalo de confiança referente ao escore do MEEM.

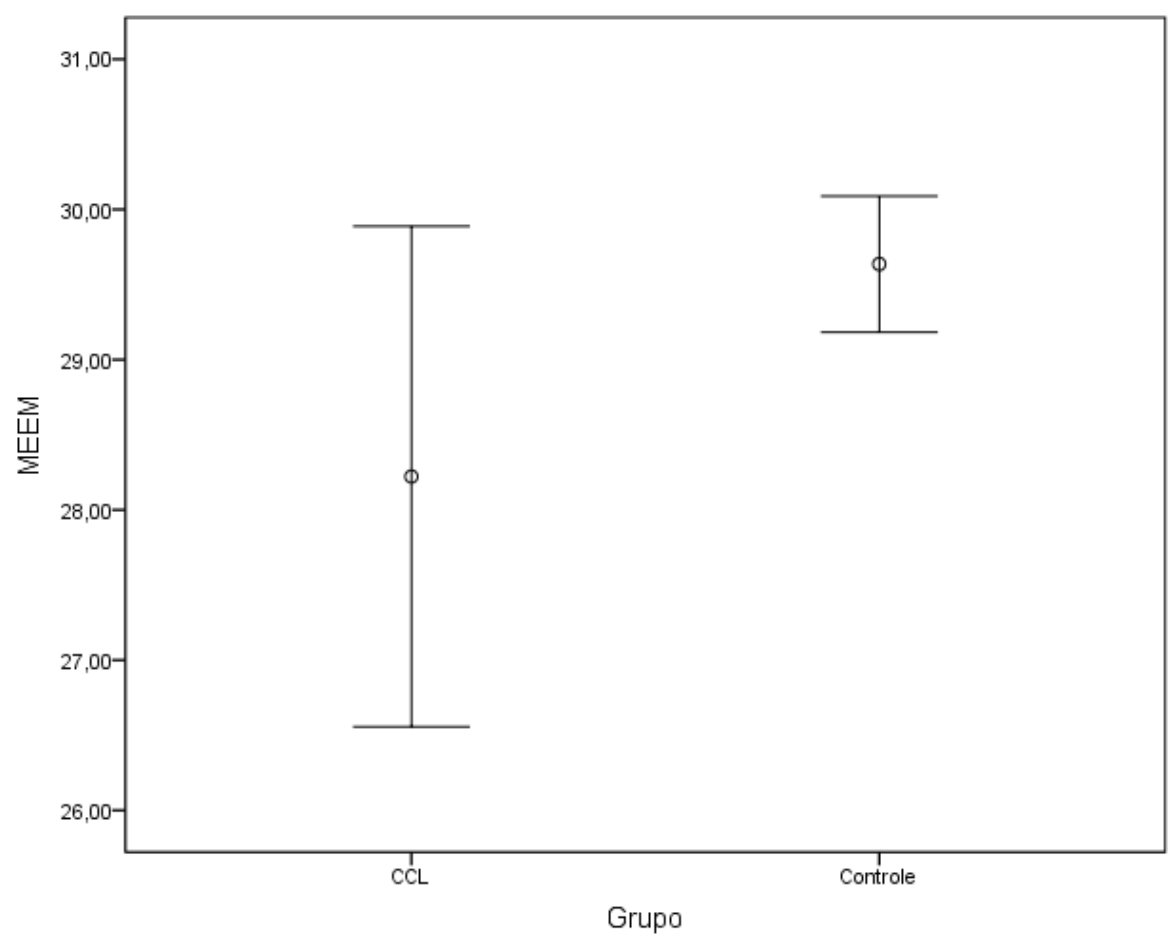


APÊNDICE F - Intervalos de confiança referentes aos parâmetros do CGT.
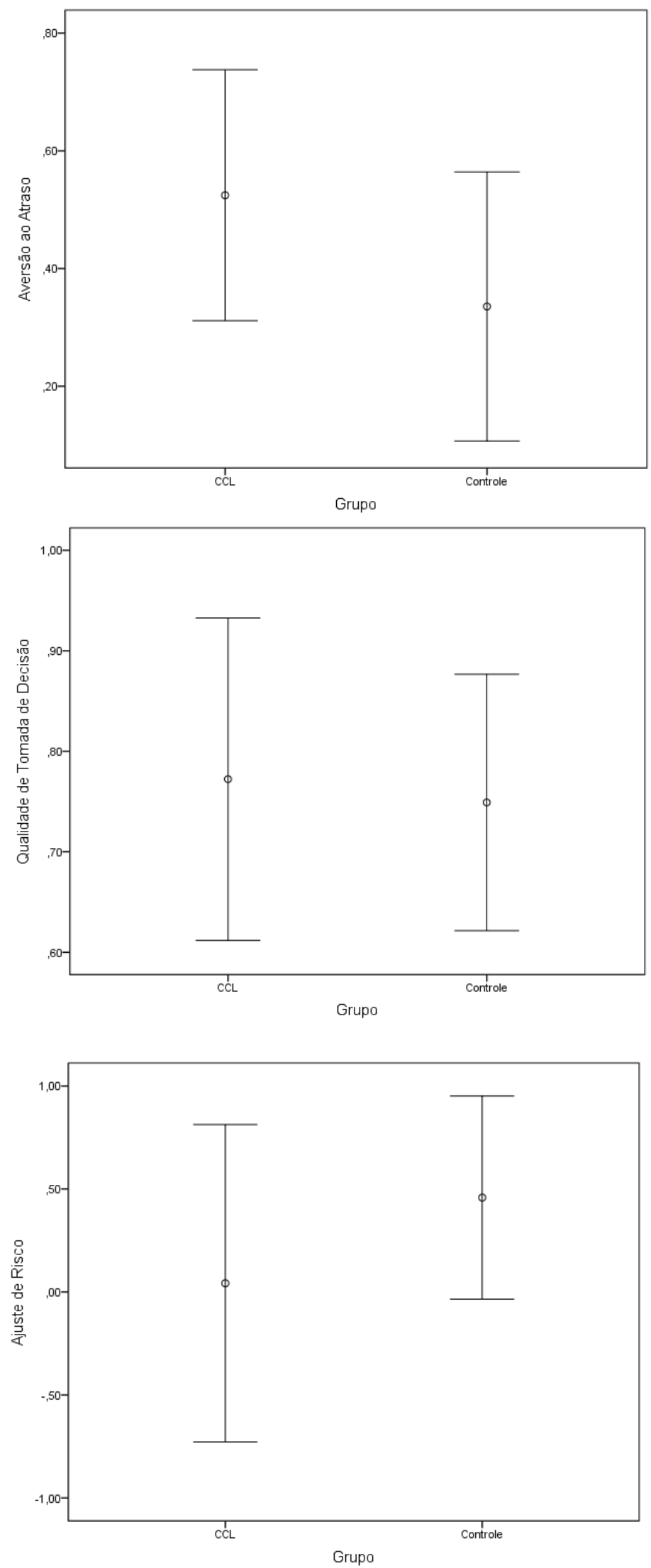

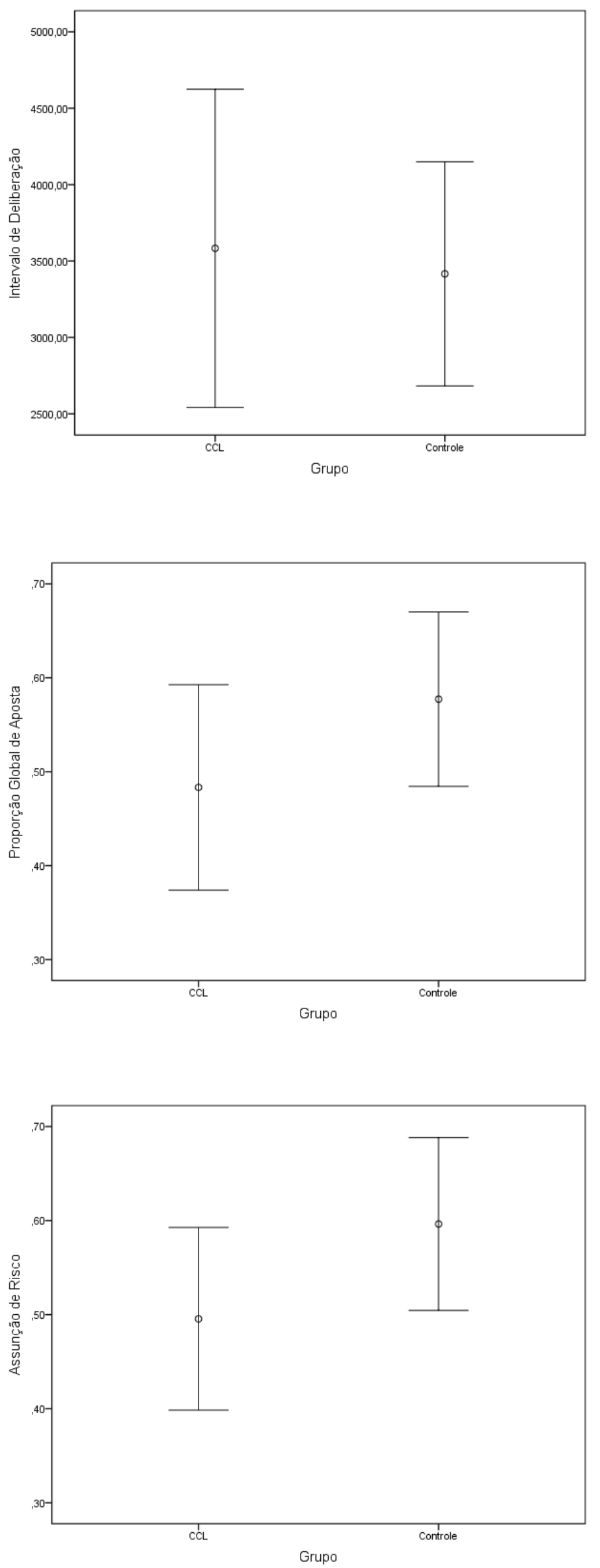